\title{
MORPHOLOGY OF THE FEMALE
} REPRODUCTIVE ORGANS OF

\section{THE AFRICAN LION}

(Panthera leo)

by
Dr. Marthinus J. Hartman BVSc (Hons)

Submitted in partial fulfilment of the requirements for the degree

MMedVet (Chir)(Small Animals)

in the

Faculty of Veterinary Science

University of Pretoria

January 2012 
Research conducted in the Section of Anatomy Department of Anatomy and Physiology

Faculty of Veterinary Science University of Pretoria

\section{Promoter:}

Professor Robert M Kirberger BVSc MMedVet(Rad) Dip ECVDI

Section of Diagnostic Imaging

Department of Companion Animal Clinical Studies

Faculty of Veterinary Science

University of Pretoria

\section{Co Promoter:}

Professor Hermanus B Groenewald BVSc PhD

Section of Anatomy

Department of Anatomy and Physiology

Faculty of Veterinary Science

University of Pretoria 
To my lovely wife Suenette for her love and support and to my dear children M.J., Erik and Niel for their unconditional love and contributions to the cause of their father's career.

Quote

Every great success begins with a dream. Always remember you have within you the strength, the passion and the ability to reach for the stars and to change your destiny.

Modified: Harriet Tubman 


\section{Acknowledgements}

My sincere appreciation to the following people for their contributions in empowering me to complete this dissertation:

My parents Thinus and Elna for providing me with education and supplying me with the basic life skills and principles that lead to success.

To my wife Suenette for encouraging me at times when I doubted certain decisions I made.

Our sons M.J., Erik and Niel for trusting me to guide their lives and our destiny as a family.

Professor Robert Kirberger for teaching me most things I know about research and to pay attention to detail. For investing your valuable time and efforts into my career. Every time I perform research during my career I will be grateful for the mentorship you have provided.

Professor Herman Groenewald for allowing me to conduct this research in your department and for your valuable guidance during this study.

Wilma Olivier for your kind assistance with the logistical challenges.

Charmaine Vermeulen for being so patient and precise while performing the photography.

Adam Flink and Mishack Mothemane for your help and assistance with the lions in the Anatomy halls.

To my saviour Jesus for blessing my research. 


\section{List of Contents}

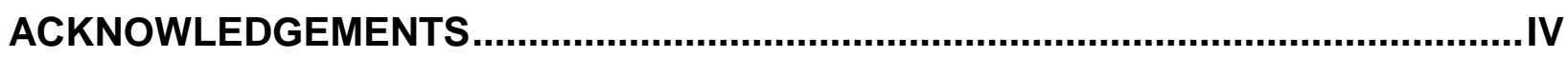

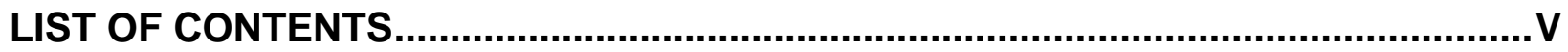

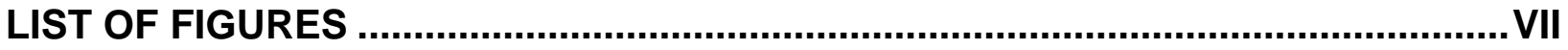

LIST OF TABLES

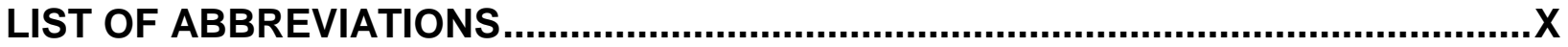

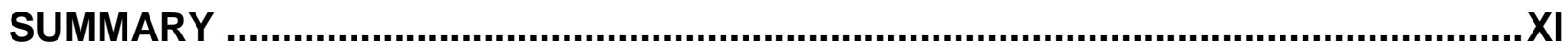

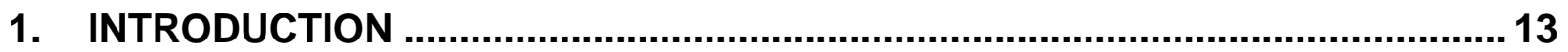

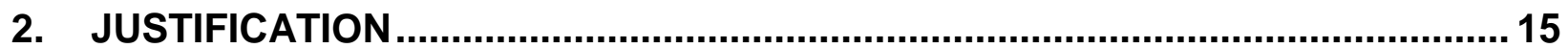

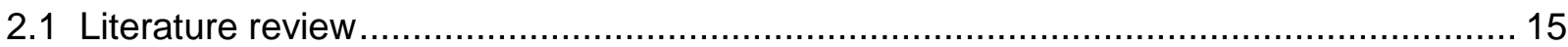

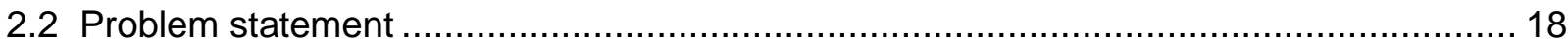

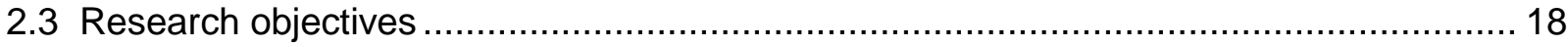

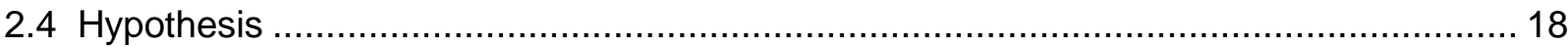

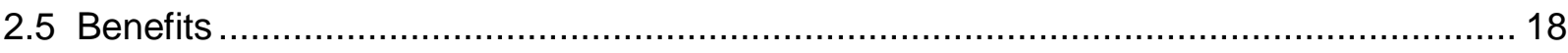

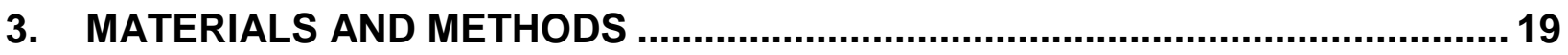

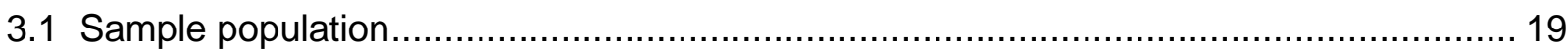

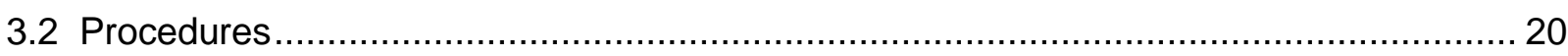

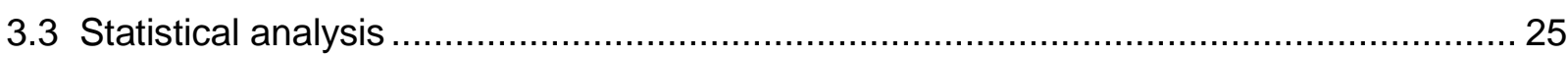

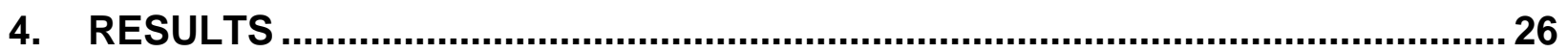

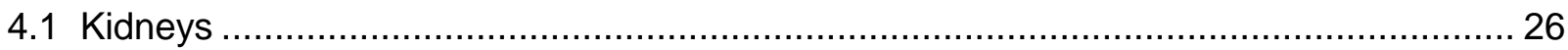

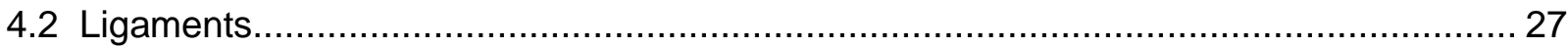

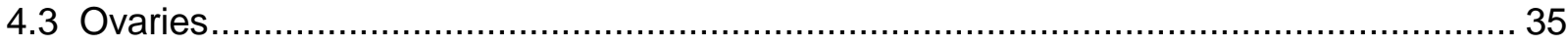

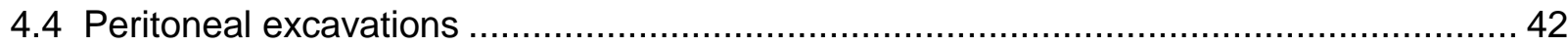

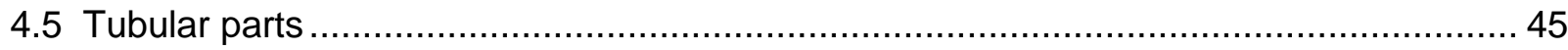

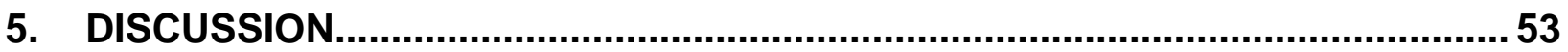

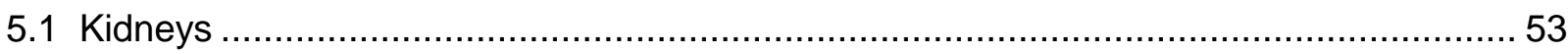

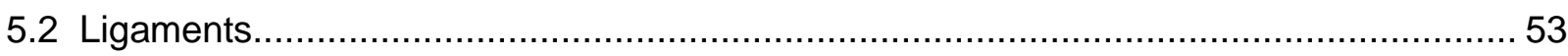

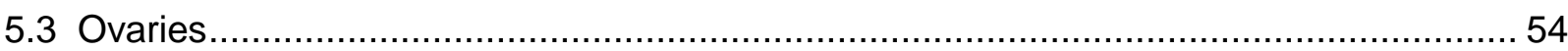




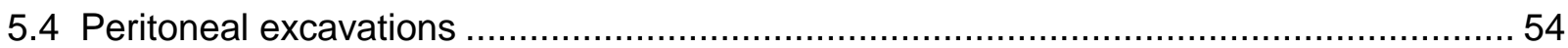

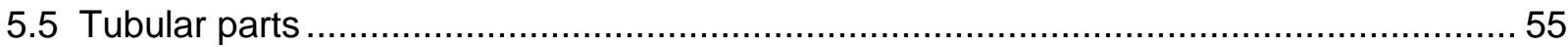

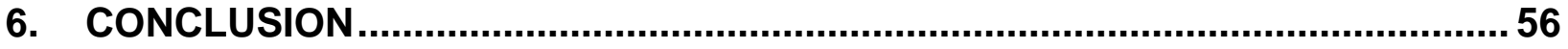

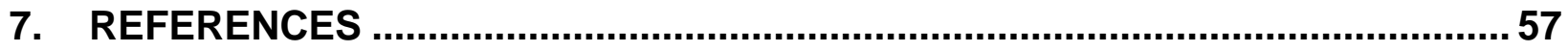

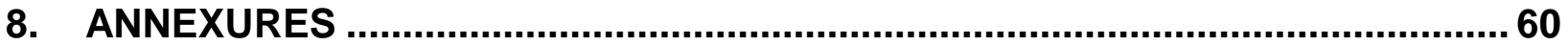

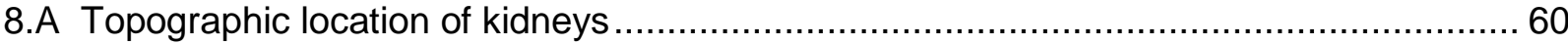

8.B Topographic location of ovaries situated caudal in relation to the caudal pole of the

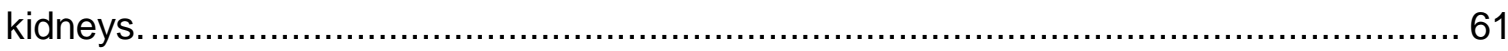

8.C Topographic location of anatomical landmarks of female reproductive organs situated caudal in relation to the origin of the ipsilateral phernico-abdominal artery.

8.D Topographic location of anatomical landmarks of female reproductive organs situated cranial in relation to the origin of the ipsilateral deep circumflex iliac artery

8.E Topographic location of the lines of peritoneal reflection in relation to the pecten ossis pubis recorded in centimetres.

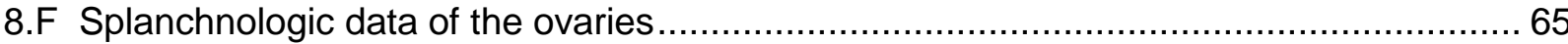

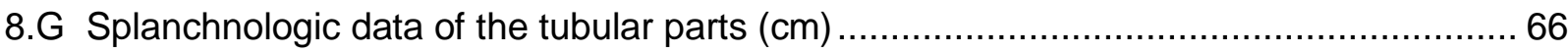




\section{List of Figures}

Figure 1 Lioness 1 in a hanging position in the Anatomy hall.

Figure 2 Lioness 1 in a natural hanging position against a white sheeted background........ 20

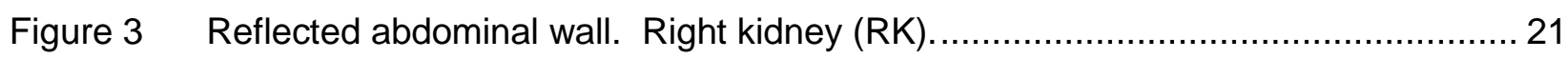

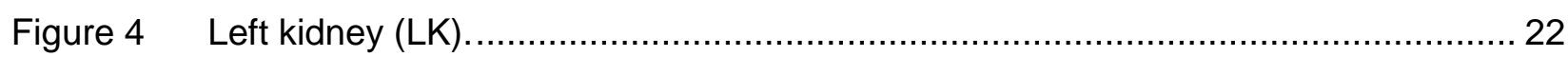

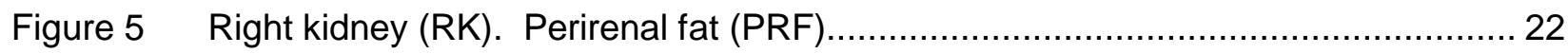

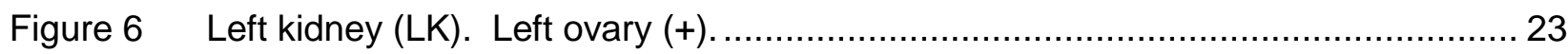

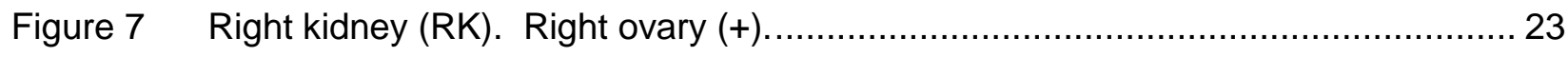

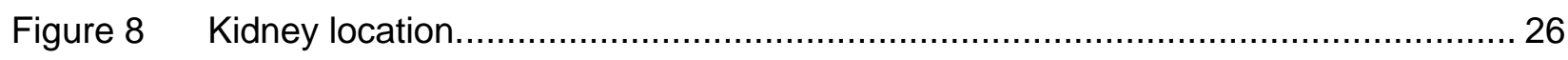

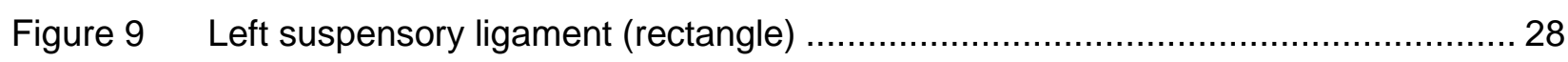

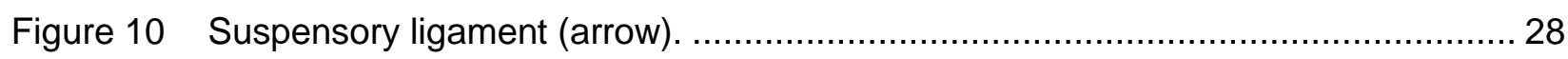

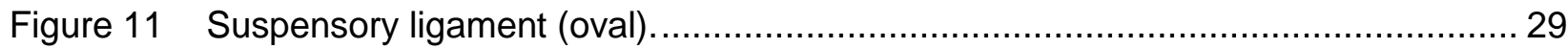

Figure 12 Suspensory ligament (oval) and right kidney (RK) ......................................... 29

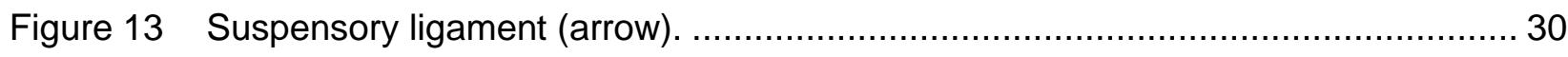

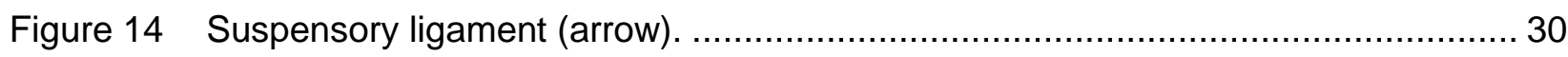

Figure 15 Right suspensory ligament dissected out. ................................................... 31

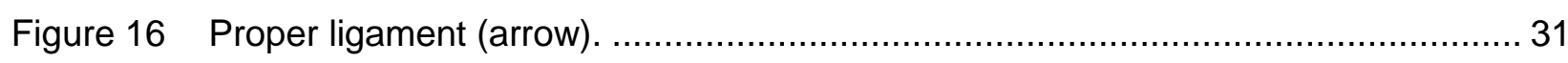

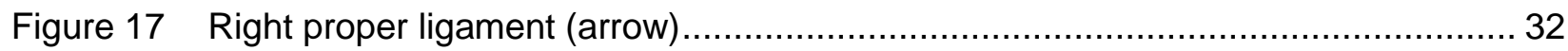

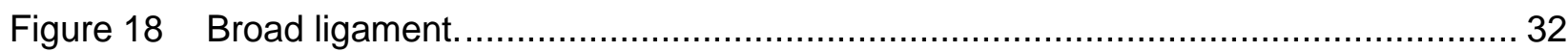

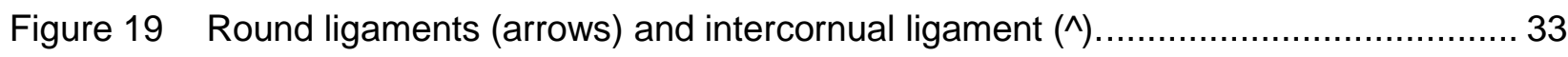

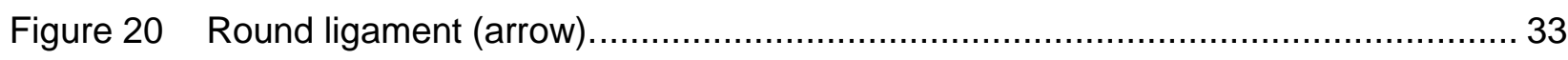

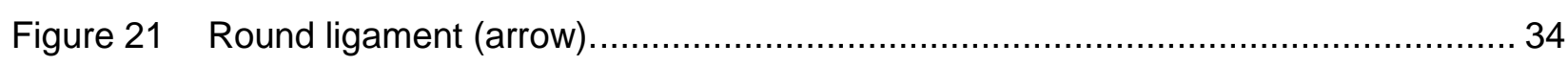

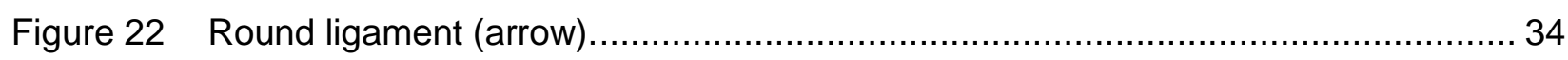

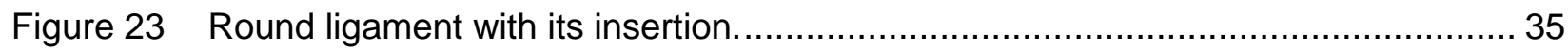

Figure 24 Intercornual ligament (arrow) situated dorsal to the bladder. ................................ 35

Figure 25 Phrenicoabdominal arteries (arrows) ............................................................ 37

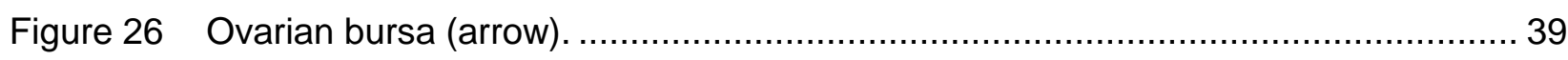

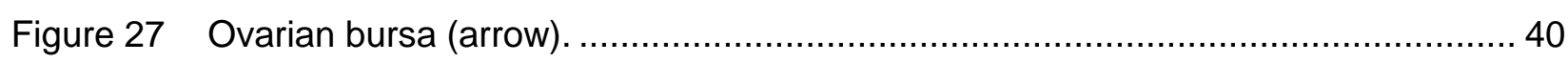

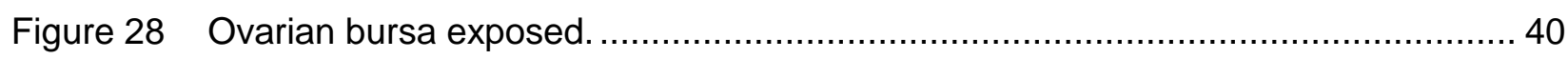

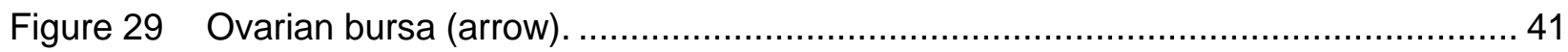

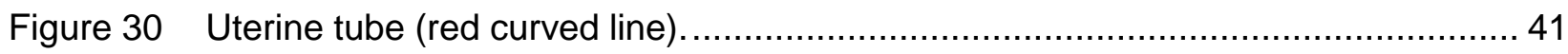

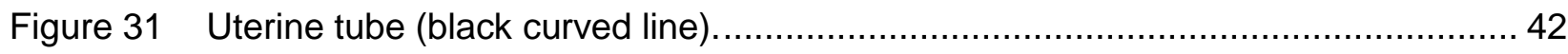

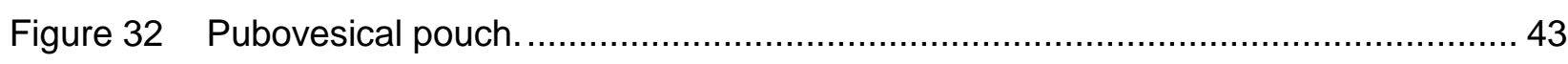

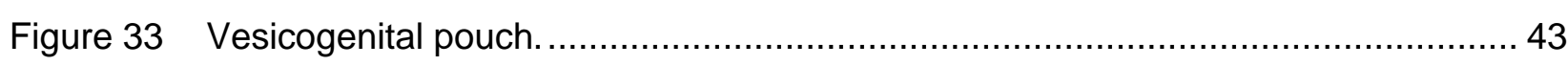




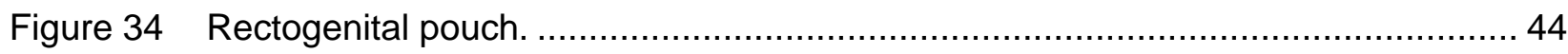

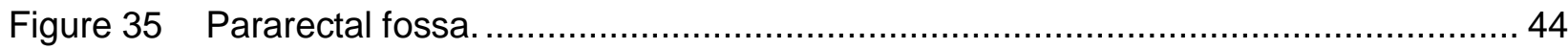

Figure 36 Peritoneal reflection on the dorsal aspect of the vagina (arrow) . ........................ 45

Figure 37 Opening to the clitoral fossa (oval) .......................................................... 46

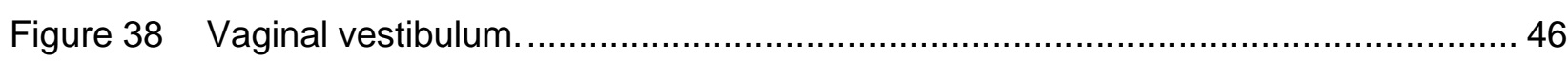

Figure 39 Vaginal folds on the inside of an exposed vagina............................................. 47

Figure 40 Cervix (circle) and vaginal fornix (arrows).................................................... 48

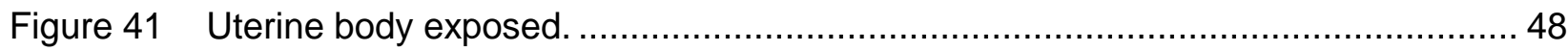

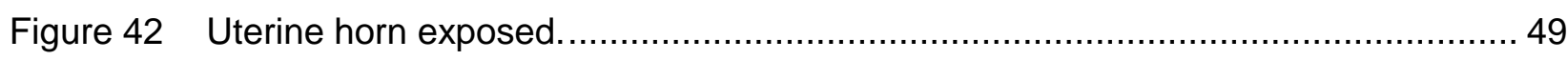

Figure 43 Opening of uterine tube (oval) and uterine tube (line) .................................... 50

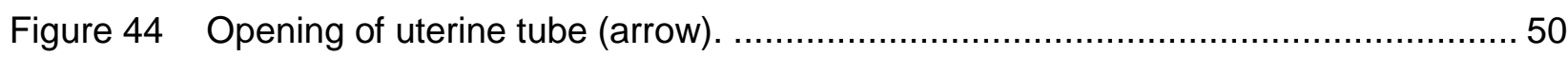

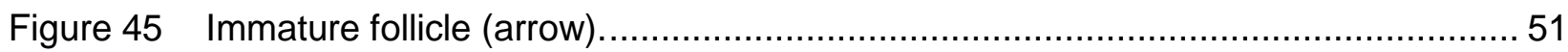

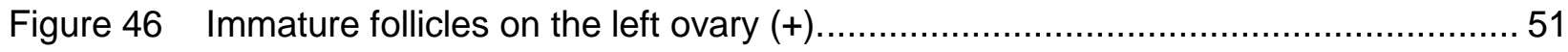

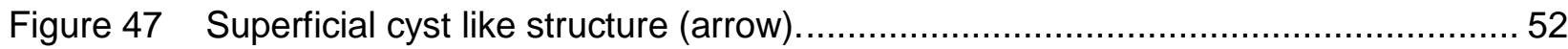

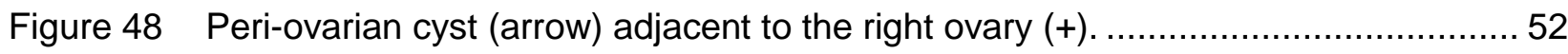




\section{List of Tables}

Table 1 Topographic location of kidneys in three lionesses.

Table 2 Topographic location of ovaries.

Table 3 Topographic location of anatomical landmarks of female reproductive organs situated caudal in relation to the origin of the ipsilateral phrenicoabdominal arteries.

Table 4 Topographic location of anatomical landmarks of female reproductive organs situated cranial in relation to the origin of the ipsilateral deep circumflex iliac arteries.

Table 5 Splanchnologic data of the ovaries

Table 6 Topographic location of lines of peritoneal reflection described in relation to the cranial border of the pubis. Negative figures indicate a location cranial to the cranial border of the pubis.

Table 7 Splanchnologic data of tubular parts. 


\section{List of Abbreviations}

T12 Twelfth thoracic vertebra

R13 Thirteenth rib

$\mathrm{T} \quad$ Thoracic vertebra

L Lumbar vertebra 


\section{Summary}

\section{Morphology of the female reproductive organs of the African lion (Panthera leo).} Marthinus J. Hartman marthinus.hartman@up.ac.za

The objectivie of this study was to describe the splanchnology and topography of the female reproductive organs of the African lion.

The reproductive organs of three embalmed cadavers from three-year-old known aged nulliparous lionesses weighing between $120 \mathrm{~kg}$ and $140 \mathrm{~kg}$ were studied. Two fresh carcasses from another study were used for some of the topographical photos since these rendered better quality images. The project was approved by the Animal Use and Care Committee and Research Committee of the University of Pretoria (protocol number V038-09).

The topography and splanchnology of the reproductive organs were studied and described in situ and after removal.

The kidneys were located far caudally in relation to the thirteenth ribs with the left kidney further caudal. The suspensory ligament was very well developed. It originated in a fan-like manner from the dorso-lateral abdominal wall lateral to the kidney extending up to a few centimetres cranial to the kidney. The proper ligament of the ovary was well developed and consisted of several clearly distinguishable bands. The broad ligament resembled that of the cat with the exeption of the cranial part of the mesovarium being very well developed. The round ligament was well developed and inserted on the medial femoral fascia. It therefore did not extend to the vulva as in other canine and feline species. The left ovary was longer, wider and heavier than its right counterpart and the ovaries were relatively small in relation to body weight. The ovarian bursa had a short mesosalpinx that did not cover any part of the ovary and the fimbriae extended the entire length of the ovary. The urethral tuberculum as well as the urethral crest was very well developed. The left uterine horn was longer than the right and the tip of the uterine horn was located dorsal to the proper ligament. The uterine tube was prominently convoluted, situated entirely on the lateral aspect of the ovary and was found to open directly into the tip of the uterine horn and not onto a papilla.

The female reproductive organs of the African lion resemble that of the domestic cat and dog with some major differences especially to the size and development of certain structures. The 
clinical relevance of these differences has to be debated and some thoughts might include the following:

1) does the suspensory and proper ligaments of the gravid uterus contract to suspend the entire uterus closer to the body wall during hunting since the lioness is the primary hunter in the pride?

2) does the lioness have to roll on her back and extend her back legs after mating to facilitate sperm entering the dorsally located tip of the uterine horn while the round ligament stabilises the terminal part of the uterine horn, and does this have a bearing on the fact that multiple copulations are required over a prolonged period for conception by lions?

3) do more ovulations take place from the bigger left ovary and?

4) are more conceptusses borne by the longer left uterine horn?

The anatomical information obtained during this study was subsequently applied in a surgical study on sixteen lionesses using laparoscopy to perform laparoscopic ovariectomy and salpingectomy. The availability of these two laparoscopic procedures subsequently led to a wider interest to its application in population control of lions in the smaller national parks of South Africa.

\section{Key terms}

African lion, Panthera leo, morphology, splanchnology, topography, reproductive organs, kidneys, ligaments, ovaries, peritoneal excavations, tubular parts. 


\section{Introduction}

In 2008 there were an estimated four to five thousand African lions incorporated in breeding programmes on commercial farms in South Africa. ${ }^{1}$ These lions formed part of the hunting industry, which came under fire from various environmental and animal rights groups as well from government. Recent international media attention to so-called "canned lion hunting" has placed the spotlight on this hunting industry, and forced the Department of Environmental Affairs and Tourism (DEAT) to take a closer look at this sector. ${ }^{2}$

Amended legislation regulating hunting of large carnivores subsequently became much stricter and created a slow-down in the successful marketing of lions for hunting purposes. ${ }^{2}$ This in turn created a situation where the lion population outgrowed the commercial demand, and lion numbers became excessive on these farms. Given the protein demands of lion prides and the financial strain this posed to farmers, culling became an unfortunate reality to the livelihood of these carnivores.

The South African Predator Breeder Association is of the opinion that this industry is regulated appropriately and that it is a legitimate member of this huge industry in Southern Africa, providing jobs and creating foreign currency for South Africa. ${ }^{1}$ Somehow there needed to be a compromise between authority and industry. Population control in the prides of African lions on commercial farms might provide a means to achieve this and also prevent possible culling or neglect of these magnificent animals.

Male castration results in loss of the mane which is not desirable as this destroys any value to the hunting or tourism industry. Male vasectomy results in mating without pregnancy. This may encourage lionesses to seek other "fertile" males or become solitary individuals. This may create problems of its own regarding the highly specialised social structure of these prides. It therefore seems that surgical female sterilization is an option of contraception to be investigated.

Various surgical sterilisation techniques including conventional celiotomy as well as laparoscopy exist for female animal patients. Current sterilisation options in human medicine include ovariohysterectomy, ovariectomy and salpingectomy of which the latter needs to be investigated further in animal patients. In the smaller national parks of South Africa the growing lion population pose a serious risk to free ranging game numbers since there are not enough 
seperate lion prides, bachelor males or other predators to create natural competition. A need for the control in lion population growth therefore exists and laparoscopic ovariectomy and salpingectomy as well as unilateral ovariectomy, ovariohysterectomy and salpingectomy may offer viable options. The effects of female contraception on the social behaviour and pride structure of the African lion has yet to be determined.

This masters project was undertaken to have a better knowledge of the femaly lion reproductive tract and to equip the author for future surgical studies on this organ system. 


\section{Justification}

\subsection{Literature review}

Currently few comprehensive anatomical studies exist in wild carnivores. In particular, no reports on the reproductive organs in these species have been published. Due to this lack of reproductive information, the literature was searched for applicable anatomical studies of other species and the dog and cat were used as reference species for this study.

The reproductive anatomy of the bitch is well described. ${ }^{3}$ Included in the reproductive organs are five different ligaments namely the suspensory, proper, broad, round and intercornual ligament. The ovaries, uterine tube, uterine horns and uterus are attached to the dorsolateral walls of the abdominal cavity and to the lateral walls of the pelvic cavity by paired double folds of peritoneum called the broad ligament. Cranially, it is attached by means of the suspensory ligament of the ovary to the junction of the middle and distal thirds of the last rib. The ligament is reflected off the vagina onto the rectum dorsally and ventrally onto the urethra and bladder. The ligament is broadest at the level of the ovary, tapering cranially and caudally. In a $12 \mathrm{~kg}$ dog the distance spanned by the broad ligament at the ovarian level varies from 6 to $9 \mathrm{~cm}$. A peritoneal fold arises from the lateral surface of the broad ligament and extends from the ovary through the inguinal canal. It contains the round ligament of the uterus in its free border and extends into the subcutaneous region of the vulva and may even extend to the labia. Morphologically, the broad ligament is divided into three regions: mesovarium, mesosalpinx and mesometrium. The suspensory ligament of the ovary is attached cranially to the middle and ventral thirds of the last one or two ribs. Caudally, it attaches to the ventral aspect of the ovary and mesosalpinx, lying between the opening or the ovarian bursa and the ascending uterine tube. It is continued caudally as the proper ligament of the ovary. This in turn attaches to the cranial end of the uterine horn. There it is continuous with the round ligament of the uterus. Both the proper and the suspensory ovarian ligament are composed of connective tissue mixed with smooth muscle fibres. The intercornual ligament is situated at the bifurcation between the two uterine horns. ${ }^{3}$

The ovary with its associated bursa and mesosalpinx as well as its location in relation to the kidney has been well described. The ovaries lie caudal to the kidneys and in a $12 \mathrm{~kg}$ dog averages $1.5 \mathrm{~cm}$ in length, $0.7 \mathrm{~cm}$ in width, $0.5 \mathrm{~cm}$ in thickness and $0.3 \mathrm{gm}$ in weight. In a sexually mature bitch the left ovary is located approximately $12 \mathrm{~cm}$ caudal to the middle of the 
thirteenth rib (R13) and 1-3 cm caudal to the corresponding kidney. The right ovary is located approximately $10 \mathrm{~cm}$ caudal to the last rib of the right side. ${ }^{3}$

The tubular parts consist of the vagina and its contained structures, the cervix with its two openings, the uterine body and two horns and the uterine tubes with their various divisions. ${ }^{3 ; 4}$ The vagina extends from the uterus to the vulva. Cranially the vaginal fornix extends ventral to the cervix. The cervix lies obliquely and may extend $0.5-1 \mathrm{~cm}$ into the vagina, and is $0.8 \mathrm{~cm}$ in diameter. In a $12 \mathrm{~kg}$ dog the vagina averages $12 \mathrm{~cm}$ long and $1.5 \mathrm{~cm}$ in diameter. The longitudinal folds (rugae) of the vaginal mucosa are high, allowing for great expansion in diameter. Smaller transverse folds connecting the longitudinal folds permit craniocaudal stretching of the vagina. ${ }^{3}$ The vaginal vestibule is the space connecting the vagina with the external opening. In a mature nonpregnant $12 \mathrm{~kg}$ dog the vestibule is approximately $3 \mathrm{~cm}$ long. The urethral tubercle is a ridgelike projection on the ventral floor of the vestibule, near the vaginovestibular junction. It contains the external urethral orifice. ${ }^{3}$

The anatomy and histology of the uterotubal junction of various mammalian species has been investigated and compared. ${ }^{3 ; 5}$ From the abdominal ostium the uterine tube at first runs cranioventrally. Approximately halfway between the caudal extremity of the ovary and the cranial tip of the uterine horn, the uterine tube bends sharply cranially and runs along the free edge of the suspensory ligament of the ovary. It then swings onto the dorsal aspect of the suspensory ligament and runs in a tortuous manner caudomesially toward the ovary. At the middle of the ovary the uterine tube curves caudolaterally toward the apex of the uterine horn, where the uterine tube terminates. The uterotubal junction or uterine ostium is an important physiologic sphincter for the passage of sperm up the tube as well as the passage of blastocysts down the tube. ${ }^{5}$

The peritoneal excavations of the dog have also been described. ${ }^{6}$ They consist of the pubovesical pouch which is situated within the first $2 \mathrm{~cm}$ after entering the pelvic cavity, the rectovesical pouch, the vesicogenital pouch and the rectogenital pouch. ${ }^{3}$

A textbook published in 1969 covers the various components of the urinary ${ }^{7}$ and reproductive tracts of the domestic cat. ${ }^{8}$ The latter consists of the ovaries, oviducts, uterus, vagina, vestibule (uroreproductive sinus) and vulva. ${ }^{9}$ Size and location of the ovaries, the mesovarium, oviduct, mesosalpinx, proper ligament of the ovary, mesometrium, round ligament, suspensory ligament, right and left horns as well as body and location of the uterus, cervix, location of the vagina, the vestibule, urethral tubercle, vestibular glands and their openings, clitoris and its fossa, vulva and labia as well as the relevant arteries and veins were described. ${ }^{9}$ The gravid uterus, its placenta 
and blood supply have also been described. ${ }^{10}$ In another feline anatomy textbook ${ }^{4}$ reference is made to several unobtainable older publications including a dissertation in 1911 by E. De Bryunde Ouboter on the juvenile and gravid uterus of the domestic cat; a description of the reproductive organs of the cat in 1933 by E. Seiferle; and a dissertation in 1935 by St Bede on the reproductive organs of the domestic cat.

Some general anatomical descriptions for the lion exist. These include: Morphology of the adrenal gland: ${ }^{11}$ gross anatomical description of the renal venous system; ${ }^{12}$ arterial segmentation of the spleen; ${ }^{13}$ papillae distribution on the tongue $;^{14}$ gross anatomy of the tongue $;^{15}$ and gross morphology of the liver. ${ }^{16}$ Radiological anatomy of the normal appendicular skeleton; $;^{17 ; 18}$ histological appraisal of sterilization ${ }^{19}$ and hyoid apparatus and pharynx have also been described. ${ }^{20}$ Body dimensions have also been compiled. ${ }^{21}$ The splanchnology and topography of female reproductive organs differ between nulliparous and parous individuals, and age is thus of importance. Captive bred lions usually have accurate birth records and the age of free ranging lions can be determined. ${ }^{22}$ Female African lions reach sexual maturity between 43 and 66 months of age (mean = 48 months) and all lionesses over 5.5 years of age will have ovulated. $^{23}$

Various male reproductive organ anatomical studies have been described. These include seminiferous tubules and testicular morphometry of adult African lions $;{ }^{24}$ sertoli cell index and spermatic reserves in adult captive African lions $;{ }^{25}$ cryptorchidism in the lion ${ }^{26}$ and spermogram of African lions. ${ }^{27}$ The effect of genetic diversity on testicular morphology in free-ranging lions has also been published. ${ }^{28}$

Some studies on the anatomy of endangered wild carnivores have been published: The ultrasonographic anatomy of the liver, spleen and urinary tract of the cheetah (Acinonyx jubatus), ${ }^{29}$ a two part study on the radiologic anatomy of the appendicular skeleton of the lion ${ }^{17 ; 18}$ and the skeletal muscle fibre type and metabolic characteristics of the lion (Panthera leo) and the caracal (Caracal caracal). ${ }^{30}$ The ultrasonographic and laparoscopic characteristics of the reproductive tract of the lioness (Panthera leo) has also been described. ${ }^{31}$

Various terms for anatomical structures are available both in Latin and English. Some authors use Latin terminology and other prefer English depending on the audience involved. For purposes of this article English terminology will be used unless only the Latin version exists. For instance the uterine tube has synonyms like fallopian tube, oviduct, Tubae uterina and Salpinx. . $; 4 ; 8 ; 9 ; 32$ 


\subsection{Problem statement}

There is no description of the female reproductive organs of the African lion available.

To perform laparoscopic sterilization of the lioness a sound knowledge of the splanchnology, topography and arterial supply of the female reproductive tract is required.

\subsection{Research objectives}

The purpose of this study was to accurately measure and describe the splanchnology and topography of the female reproductive organs in the African lion.

\subsection{Hypothesis}

The female reproductive organs of the African lion will resemble that of the domestic cat, with a few possible differences especially with regard to size.

\subsection{Benefits}

A complete description of the splanchnology and topography of the female reproductive organs of the African lion will provide background knowledge for future reference during laparoscopic procedures performed on the described organs. 


\section{Materials and Methods}

\subsection{Sample population}

Three captive bred nulliparous lionesses aged approximately 3 years were obtained from a farm in the North West Province of South Africa. The lionesses were lured with bait and distress calls and subsequently darted with a combination of zolazepam and tiletamine (Zoletil ${ }^{\circledR}$, Virbac) at a dose of $3,3 \mathrm{mg} / \mathrm{kg}$ administered intramuscularly. The common carotid artery was catheterised with a feeding tube, and lions were bled out into a trough until cardiac arrest occurred. Further suction was applied to the intra-arterial catheter to evacuate as much arterial blood as practically possible, and a $4 \%$ formalin solution was run in by gravity. Cotton wool plugs were placed in the nostrils, pharynx, rectum and vagina to prevent seepage from the orifices. Approximately forty litres of formalin was needed to embalm each lioness. The cadavers were transported to the Department of Anatomy and Physiology, Faculty of Veterinary Science, Onderstepoort, South Africa and stored in formalin baths.

The lionesses were rinsed in a water bath for 24 hours prior to the study and each lioness was numbered from one to three, using yellow Aussie ear tags (Milborrow) (Figure 1).

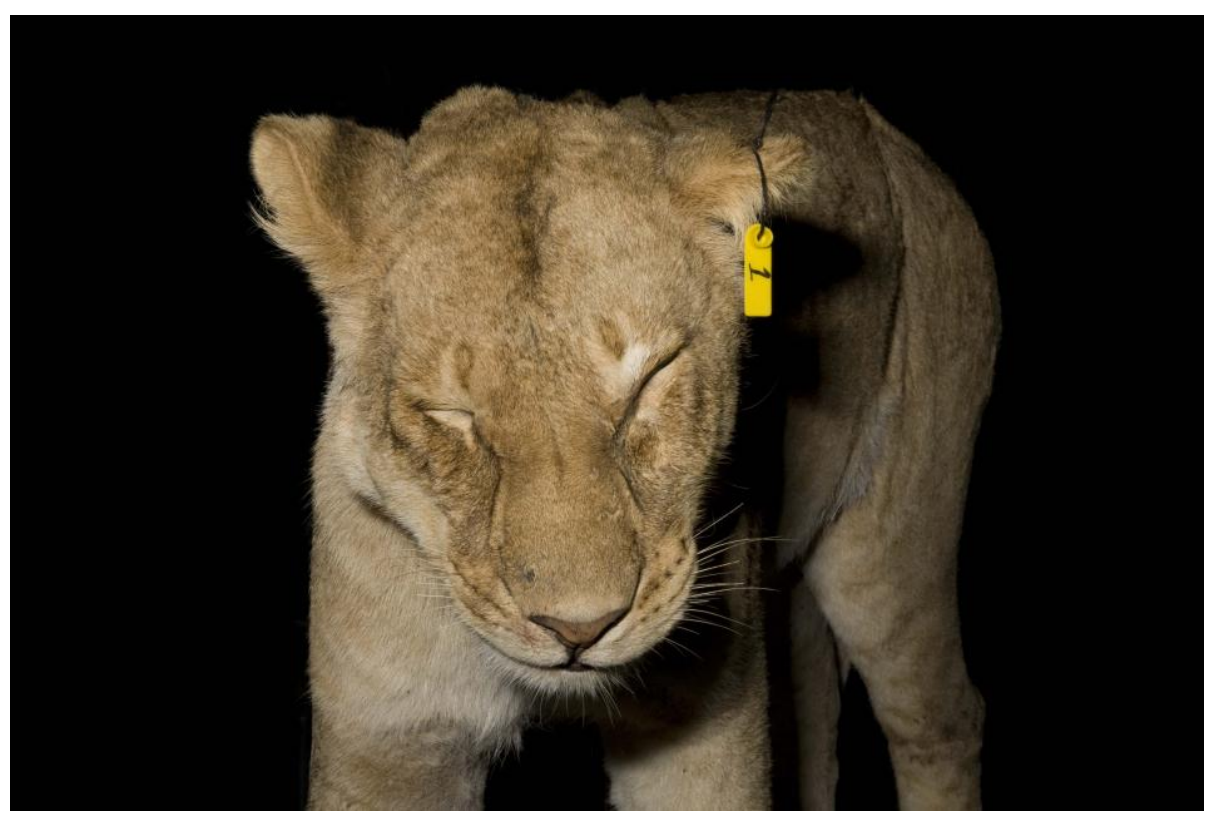

Figure 1 Lioness 1 in a hanging position in the Anatomy hall.

Note the numbered ear tag. 
After weighing the formalin prepared cadavers on an electronic scale, 17 kilograms $(\mathrm{kg})$ was subtracted for formalin present in the carcass, $7 \mathrm{~kg}$ added to compensate for blood loss during exsanguination and $1 \mathrm{~kg}$ was subtracted for metal suspension hooks present on the cadaver. Body weights were 120.5, 138.5 and $140.5 \mathrm{~kg}$. Two fresh carcasses from another study were used for some of the topographical photos since these rendered better quality images.

\subsection{Procedures}

The cadavers were suspended in a natural hanging position by two hooks (Figure 2).

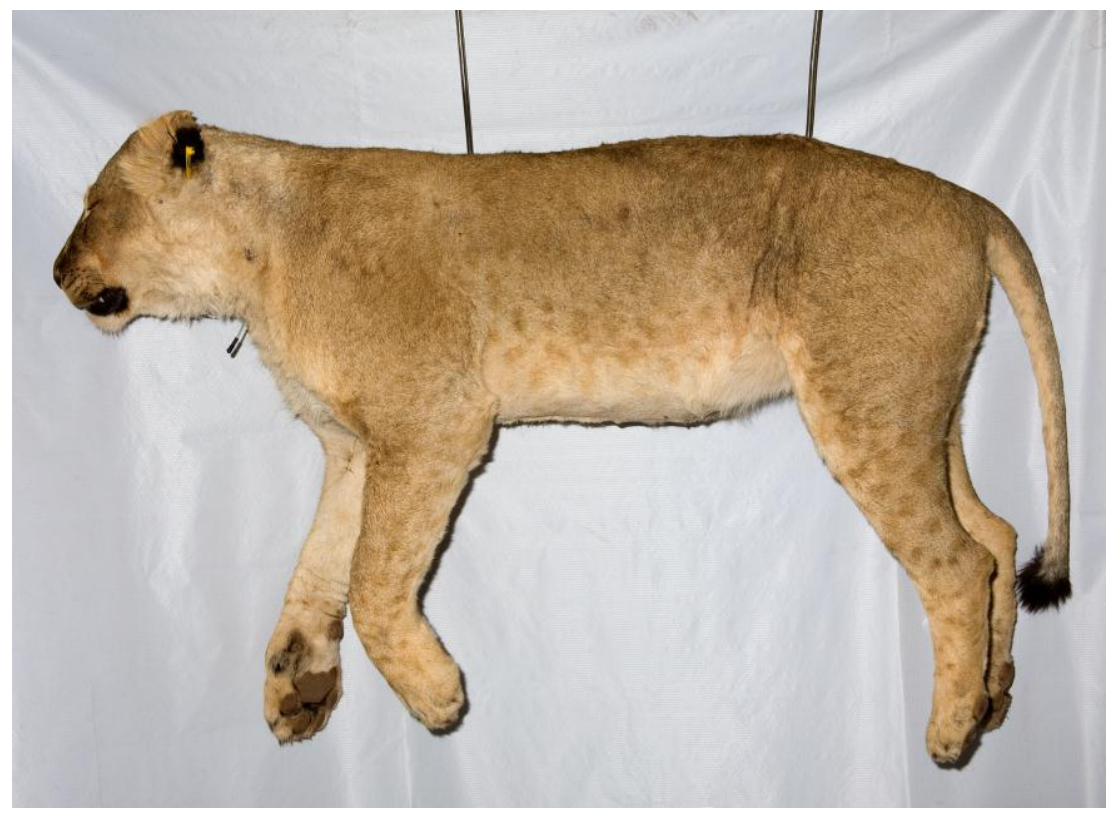

Figure 2 Lioness 1 in a natural hanging position against a white sheeted background.

The skin over the abdominal walls was bilaterally reflected ventrally by means of a saggital incision on the dorsal midline from the twelfth thoracic vertebra (T12) to the level of the iliac crest and dorsoventral incisions from T12 and the level of the iliac crest to the ventral midline. The external abdominal oblique muscles were bilaterally reflected ventrally to the Linea alba by means of longitudinal incisions into the superficial lumbar fascia at the level between the epaxial and abdominal muscles extending from the coxal tuberosity to the twelfth rib. This was followed by dorsoventral incisions at the level of T12 and the coxal tuberosity to the ventral midline. The internal abdominal oblique muscles were bilaterally reflected ventrally to the lateral edge of the rectus abdominus muscles by means of a longitudinal incision into the deep lumbar fascia at the level between the epaxial and abdominal muscles from the coxal tuberosity to the costal 
tuberosity of the thirteenth rib, followed by dorsoventral incisions along the costal arch and from the coxal tuberosity to the ventral midline. The transverse abdominus muscles were bilaterally reflected dorsally by means of a longitudinal incision at the level of the lateral edge of the rectus abdominus muscles followed by ventrodorsal incisions along the costal arch and at the level of the coxal tuberosity (Figure 3).

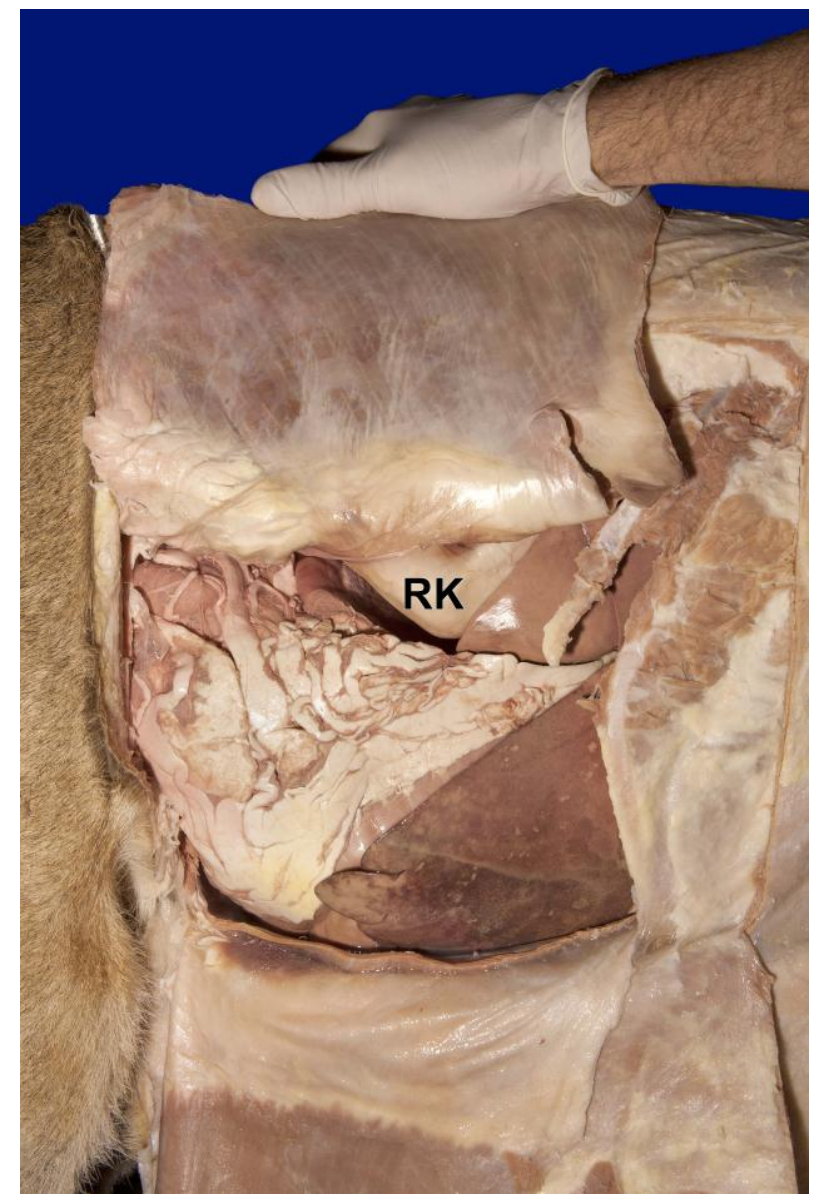

Figure 3 Reflected abdominal wall. Right kidney (RK).

Cranial is to the right of this picture.

Anatomical evaluation of the organs were done and photographed in situ. All photos used in this dissertation were from the formalin embalmed cadavers unless they are stated as being from the fresh carcasses. The topography of the kidneys, suspensory ligaments and ovaries were studied, described and topographic data recorded. All measurements were done in centimetres. The kidney measurements were taken from the tuberculum and also from the most caudal aspect of the caudal arch of R13 and from the iliac crest to the centre of the kidneys (Figures 4 and 5). 


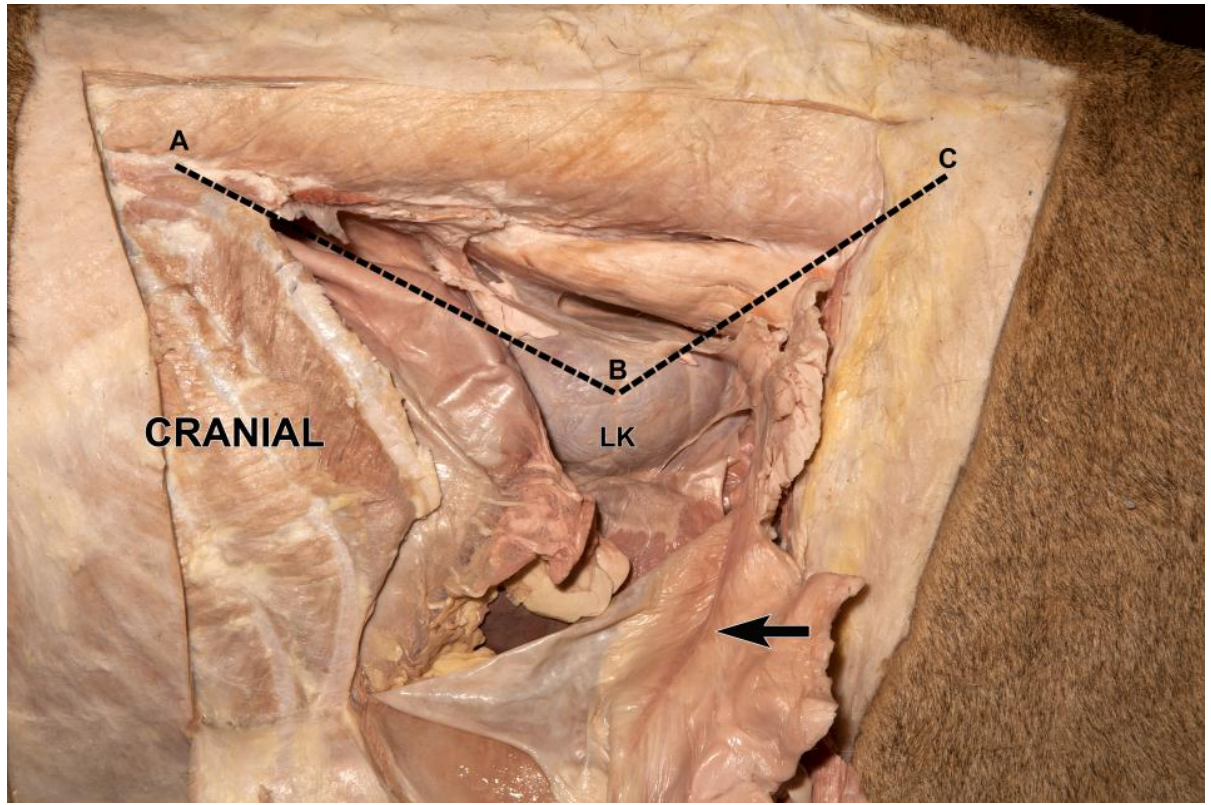

Figure 4 Left kidney (LK).

Measurements were taken from the tuberculum of R13(A) and from the iliac crest (C) to the centre of the kidneys (B).

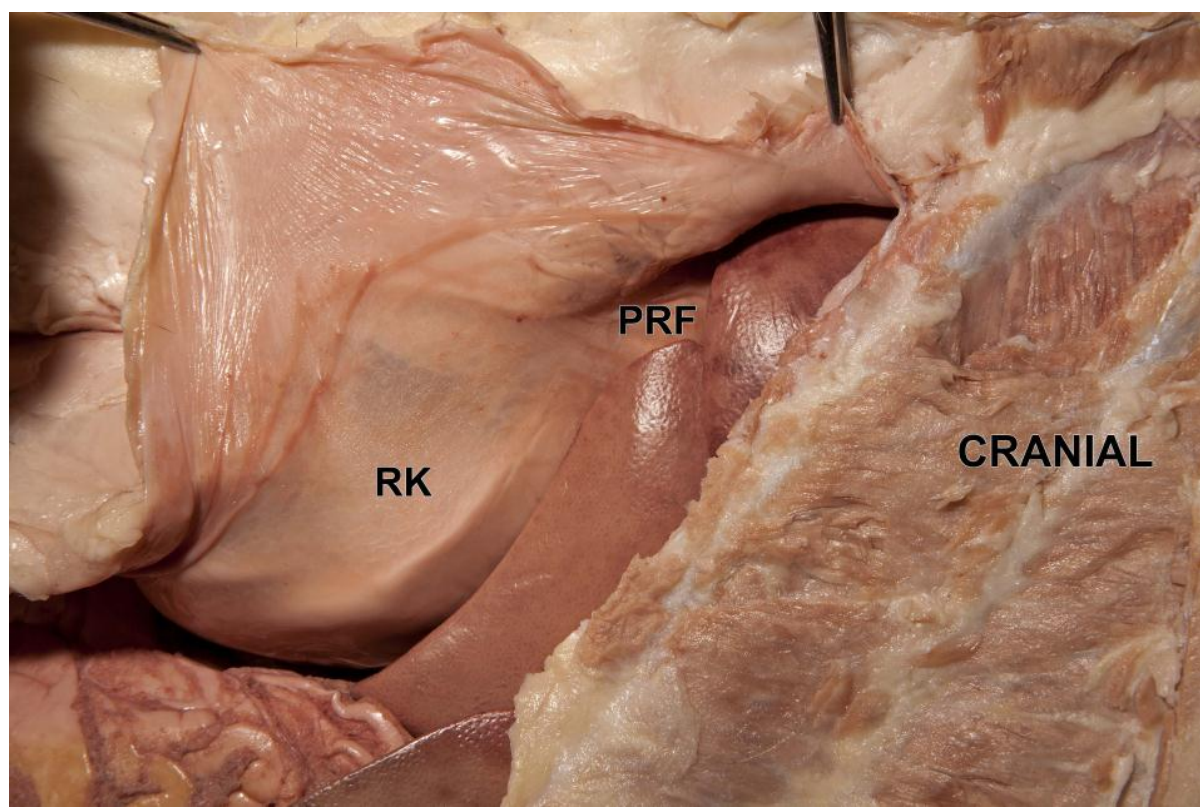

Figure 5 Right kidney (RK). Perirenal fat (PRF).

Ovarian measurements were taken from the caudal pole of the kidney which was visible throught the retroperitoneal fat to the cranial pole of the ovary and from the centre of the ovary to the iliac 
crest. The saggital location of the ovaries in relation to the kidneys was described (Figures 6 and 7).

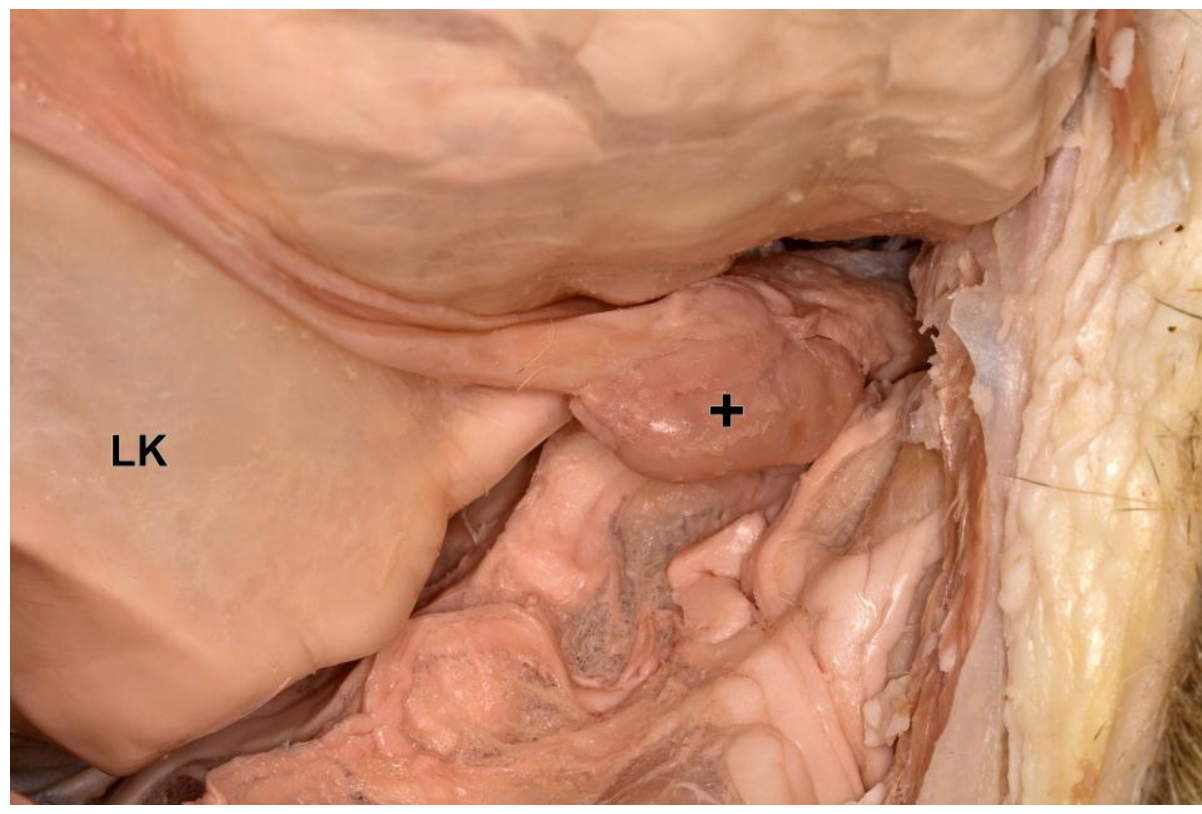

Figure 6 Left kidney (LK). Left ovary (+).

The left ovary was constantly located immediately caudolateral to the caudal pole of the left kidney. This close up view at a craniolateral angle might be deceptive.

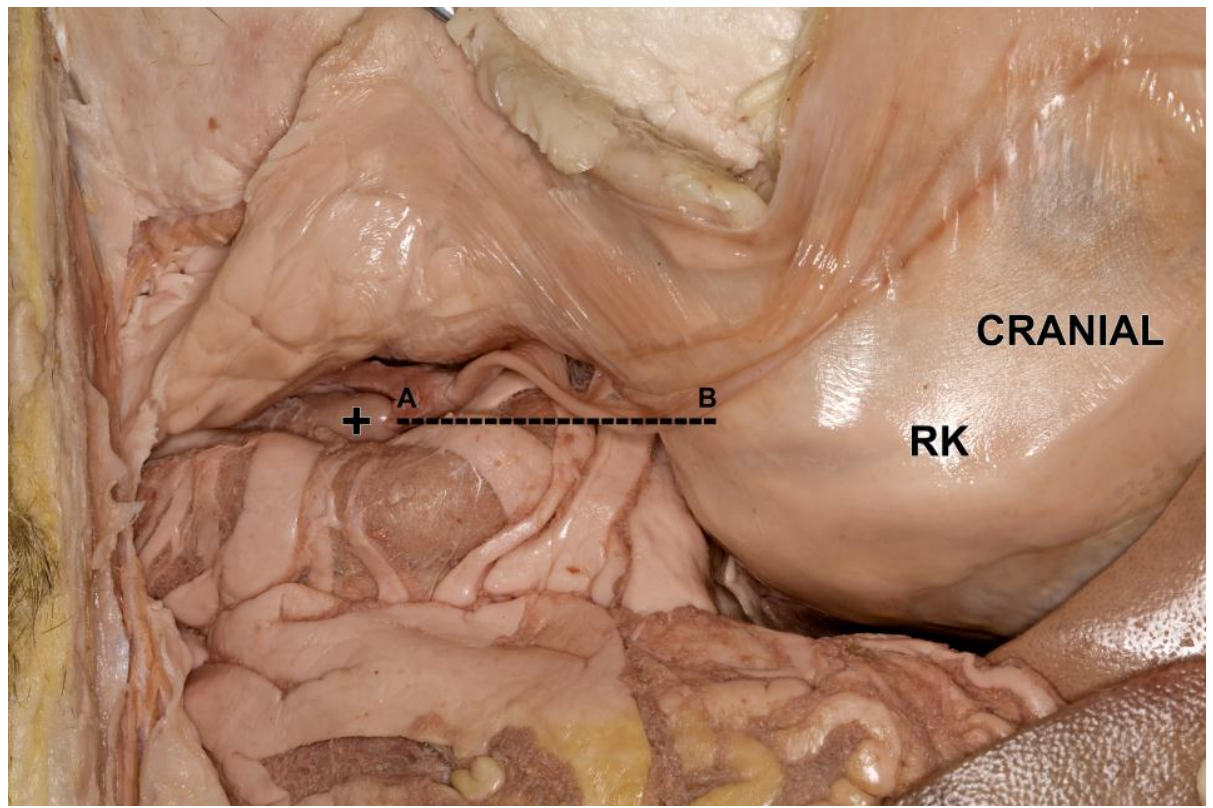

Figure $7 \quad$ Right kidney (RK). Right ovary (+).

The distance between the caudal pole of the kidney and the cranial pole of the ovary was measured from (A) to (B). 
The cadaver was then split into cranial and caudal halves. The bilateral caudal ventrodorsal incisions at the level of the coxal tuberosity were connected ventrally, the distal descending colon was double ligated and transected, the mesocolon, mesoduodenum and duodenocolic ligament were horizontally severed, the spine was sawed through at the cranial aspect of the first lumbar vertebra (L1), the caudal lumbo-diaphragmatic recess was entered and the crura of the diaphragm were transected at the level of $L 1$, the caudal vena cava and aorta were transected and the caudal half of the cadaver was separated with only the urogenital tract and rectum attached to it. The rest of the abdominal viscera were left attached to the cranial half of the cadaver.

The various structures were photographed and topographic data were described with the organs still in situ. The abdominal aorta was dissected to reveal all its branches as well as bifurcation and the relationship of the reproductive organs relative to the phrenicoabdominal and deep circumflex iliac arteries were investigated. The position of the cranial pole of both ovaries, tip of both uterine horns and the origin of both ovarian arteries were measured from the centre of the ipsilateral phrenicoabdominal and deep circumflex iliac arteries. For purposes of future laparoscopic surgery the distance from the parietal peritoneum (abdominal wall) to the centre of the respective ovaries was measured. The maximum distance was measured from the reflexion of the medial aspect of the mesovarium onto the parietal peritoneum up to the mesovarial margin at the centre of the ovary.

The pelvis was then saggitally split with all of the intra pelvic organs positioned in the right hemi pelvis. Redundant left sided intra pelvic muscles and soft tissues were resected. The lines of peritoneal reflection were studied and recorded in order to describe the peritoneal excavations. The following structures were described in relation to the cranial border of the pubis: The pubovesical pouch situated ventrally between the bladder and its lateral ligaments and the pubis; the vesicogenital pouch situated between the genital fold and uterine broad ligament and the bladder and its lateral ligaments; the rectogenital pouch situated dorsally between the roof of the pelvis and the uterine broad ligament and the pararectal fossae extending bilaterally on either side of the rectum.

The reproductive tract including bilateral mesovaria, mesosalpinx's, mesometria (including the intrapelvic part), suspensory ligaments (including the cranial part of the mesovarium), ovaries, proper ligament, tubular structures, vulva and bladder were then removed. 
The specimens were rinsed in clear water for 24 hours and subsequently studied by two observers. Photography of all the above mentioned structures on the individual specimens was done on a blue coloured background. All the ligaments of the reproductive organs were studied including the suspensory ligament, proper ligament, broad ligament, round ligament and the intercornual ligament. The diameter of the cervix and the dimensions of the uterine tubes were done before the organs were incised. The tubular parts were then incised longitudinally along their respective lumina. The lining and inner structure of the uterus, vagina, vulva and vaginal vestibule were grossly examined and measured using a Vernier calliper. The length of the vaginal vestibule was measured from the cranial border of the urethral tubercle to the mucocutaneous junction of the vulva. The length of vagina was measured from the cranial border of the urethral tubercle to the external orifice of the cervix. The length of the cervix was measured from the cranial extent of the vaginal fornix to the external orifice of the cervix. The length of uterine body was measured from the internal orifice of the cervix to the point of convergence of the two uterine horns. The length of the uterine horns was measured. The width of the ovaries was measured from the free margin to the mesovarial margin at the widest point, and the length from the tubular pole to the uterine pole. Both left and right ovaries were separated from the rest of the reproductive organs, weighed and macroscopically examined. The ratio of ovarian weight to body weigth was calculated. Externally visible structures were described.

\subsection{Statistical analysis}

This was a descriptive study and data was presented as upper and lower range. The numbers were inadequate for a more detailed study. 


\section{Results}

\subsection{Kidneys}

Each kidney was located lateral to the abdominal aorta and the caudal vena cava. The left kidney was located further caudally than the right (Figure 8). The centre of the left kidney ranged from 15.4-16.8 cm caudal to the costal tuberculum of the left R13 and the right kidney from 10.0-13.2 cm caudal to the costal tuberculum of the associated R13 (Table 1). The centre of the left kidney also ranged from $7.4-7.6 \mathrm{~cm}$ caudal to the most caudal aspect of the costal arch of the R13 and that of the right kidney $3.1-3.6 \mathrm{~cm}$ caudal to that of R13 (Table 1). The distance from the centre of the left kidney to the ipsilateral iliac crest ranged from $11.2-12.2 \mathrm{~cm}$ and that of the right kindey 12.6-16.2 cm (Table 1). The left kidney was therefore situated caudal to the costal tuberosity of the $\mathrm{R} 13,60 \%$ of the distance from the tuberosity to the iliac crest. The location of the right kidney was $45 \%$ caudal to the costal tuberosity of the R13 in relation to the iliac crest. The cranial pole of the right kidney was embedded in a well developed renal fossa in the caudate process of the caudate liver lobe. A remarkable volume of retroperitoneal perirenal fat was present at the cranial pole of the right kidney (Figures 5 and 8) which fitted snugly into the renal fossa (Figure 5).

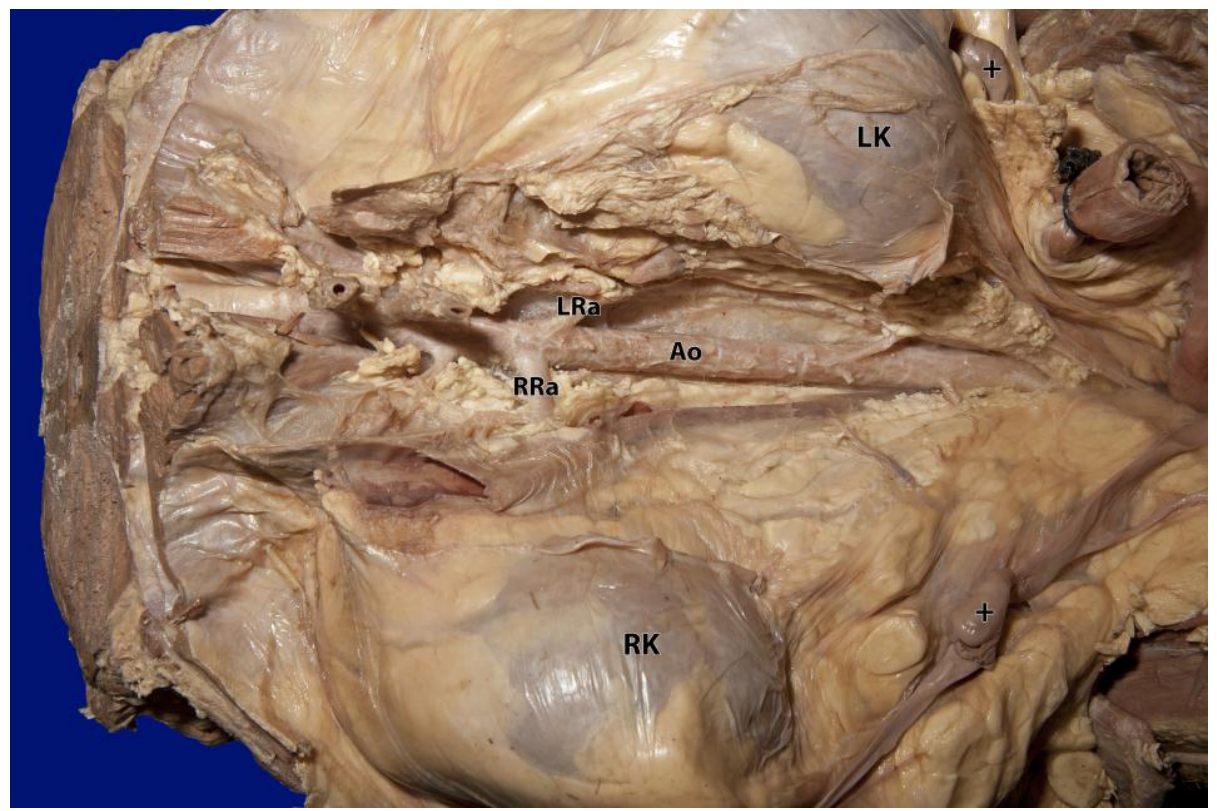

Figure 8 Kidney location.

Left kidney (LK). Right kidney (RK). Ovaries (+). Aorta (Ao). Left renal artery (LRa). Right renal artery $(\mathrm{RRa})$. 
Table $1 \quad$ Topographic location of kidneys in three lionesses.

\begin{tabular}{lcccccc}
\hline Lioness & \multicolumn{2}{c}{$\begin{array}{c}\text { Costal tubercle of rib } \\
\mathbf{1 3} \text { to centre of kidney }\end{array}$} & $\begin{array}{c}\text { Caudal costal arch of rib } \\
\mathbf{1 3} \text { to centre of kidney }\end{array}$ & $\begin{array}{c}\text { Centre of kidney to iliac } \\
\text { crest }\end{array}$ \\
\cline { 2 - 7 } & Left & Right & Left & Right & Left & Right \\
\hline 1 & 16.8 & 12.5 & 7.5 & 3.3 & 12 & 12.6 \\
2 & 16.4 & 13.2 & 7.6 & 3.6 & 11.2 & 14.1 \\
3 & 15.4 & 10 & 7.4 & 3.1 & 12.2 & 16.2 \\
Mean & 16.20 & 11.90 & 7.50 & 3.33 & 11.80 & 14.30 \\
Standard Deviation & 0.72 & 1.68 & 0.10 & 0.25 & 0.53 & 1.81 \\
\hline
\end{tabular}

\subsection{Ligaments}

The suspensory ligament originated in a fanlike manner with several thick separate bands from the dorso-lateral abdominal wall lateral to the kidney extending up to a few centimetres cranial to the kidney (Figures 9-12) and was very well developed (Figures 13-15). The proper ligament was thick with several bands of tissue extending from the caudal pole of the ovary onto the uterine horn and was well developed (Figures 16 and 17). The broad ligament consisted of a cranial part of the mesovarium, the mesovarium, the mesosalpinx and the mesometrium. The cranial part of the mesovarium suspending the suspensory ligament was well developed (Figure 18). The round ligament was a well developed (Figures 19-22) pronounced thickening in the edge of a free peritoneal fold derived from the lateral peritoneal layer of the broad ligament. The ligament originated from the uterine horn, $2-3 \mathrm{~cm}$ caudal to the tip of the horn (Figures 20 and 21) and inserted on the medial femoral fascia (Figure 23). The intercornual ligament was visible but poorly developed (Figure 19 and 24). 


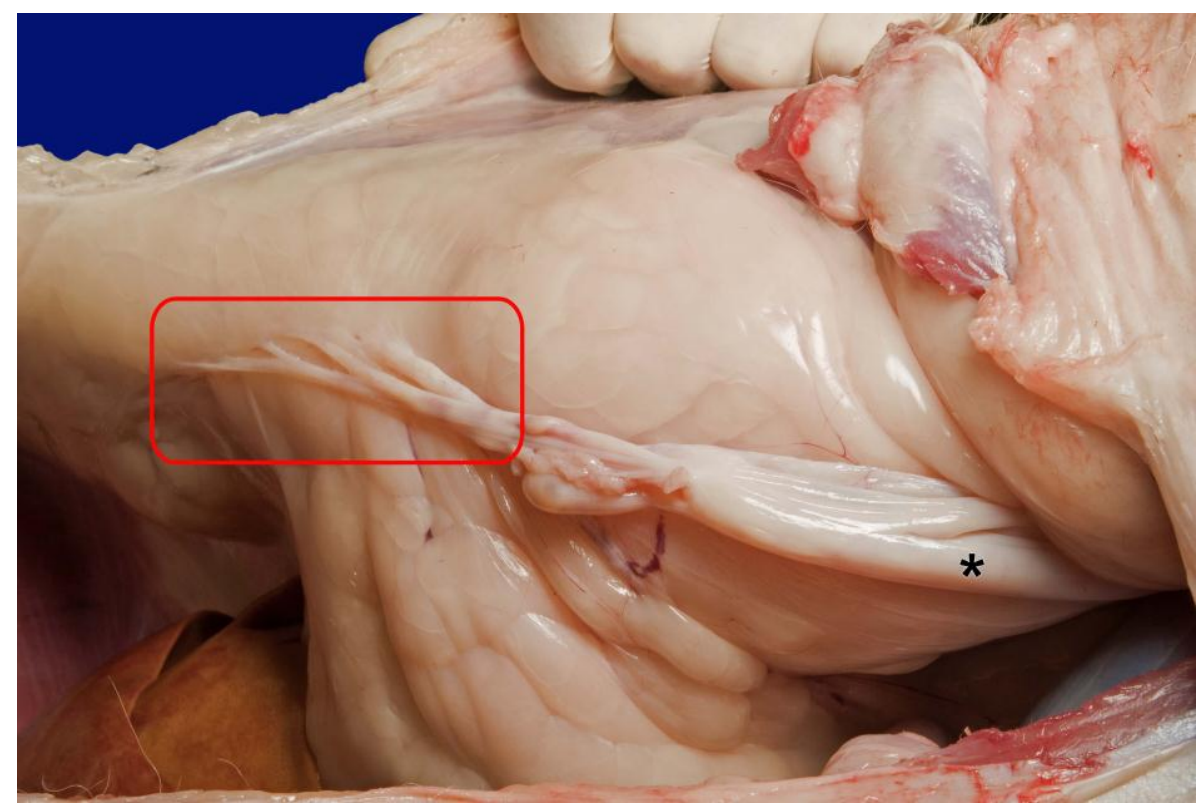

Figure 9 Left suspensory ligament (rectangle) Uterine horn $(*)$. Fresh carcass.

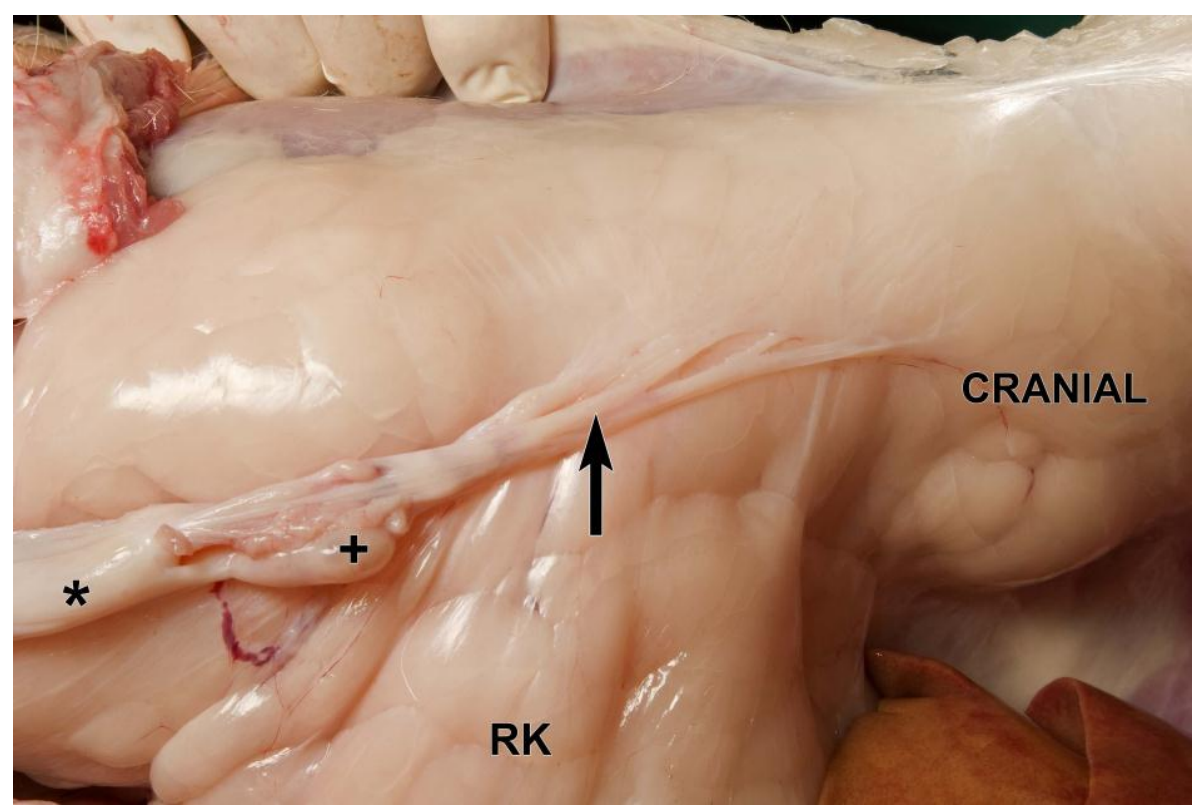

Figure 10 Suspensory ligament (arrow).

Right kidney (RK), uterine horn $(*)$, ovary (+). Fresh carcass. 


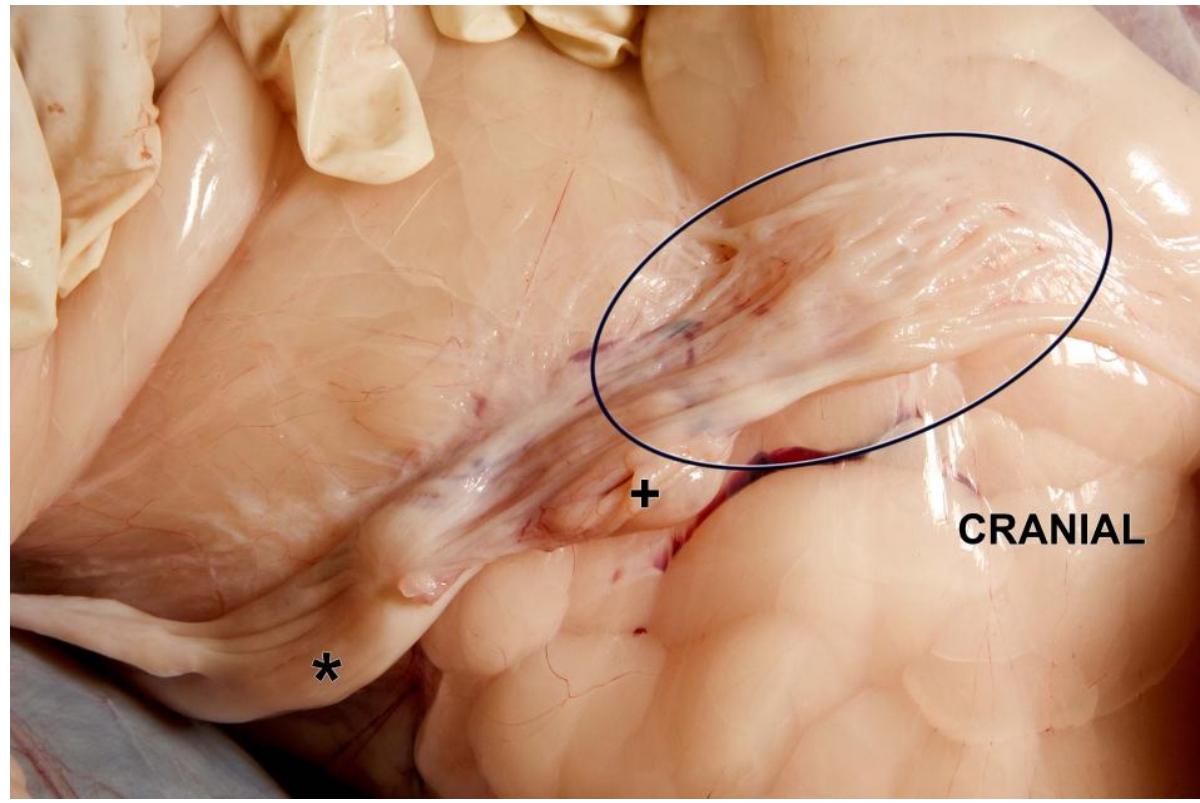

Figure 11 Suspensory ligament (oval).

Right kidney, uterine horn (*), ovary (+). Fresh carcass.

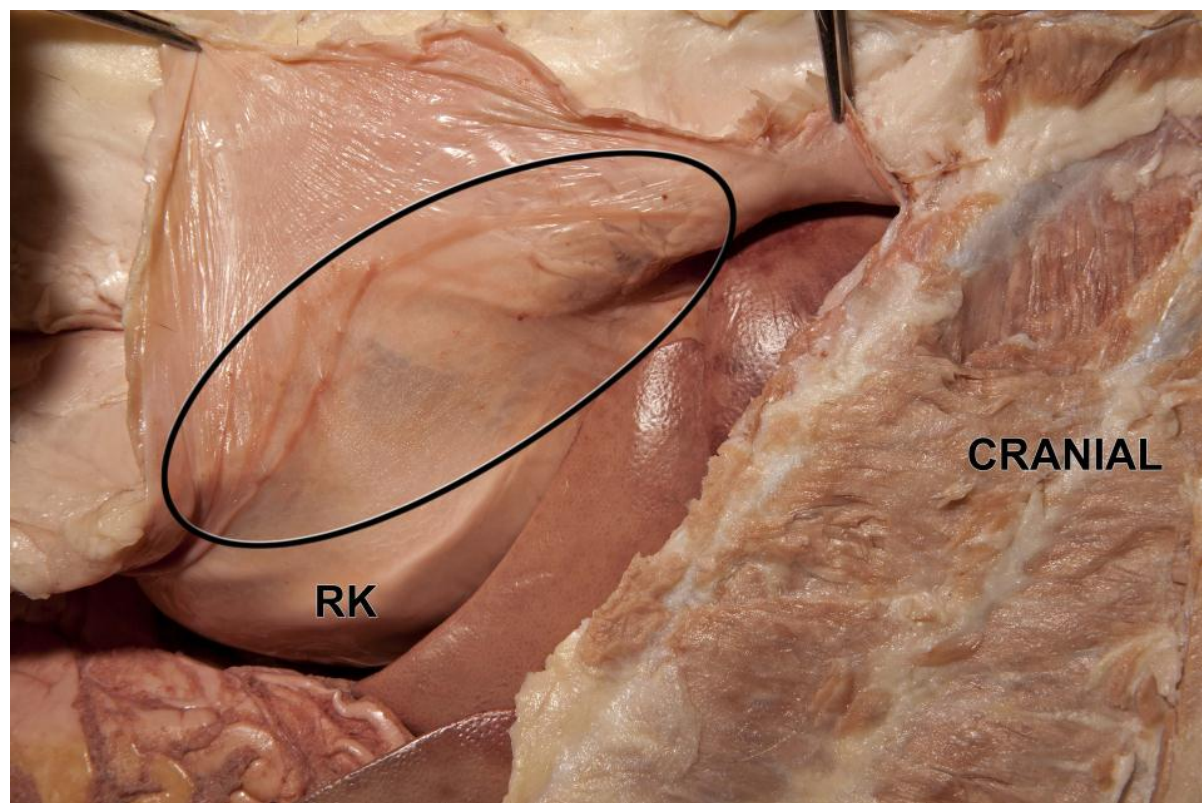

Figure 12 Suspensory ligament (oval) and right kidney (RK). 


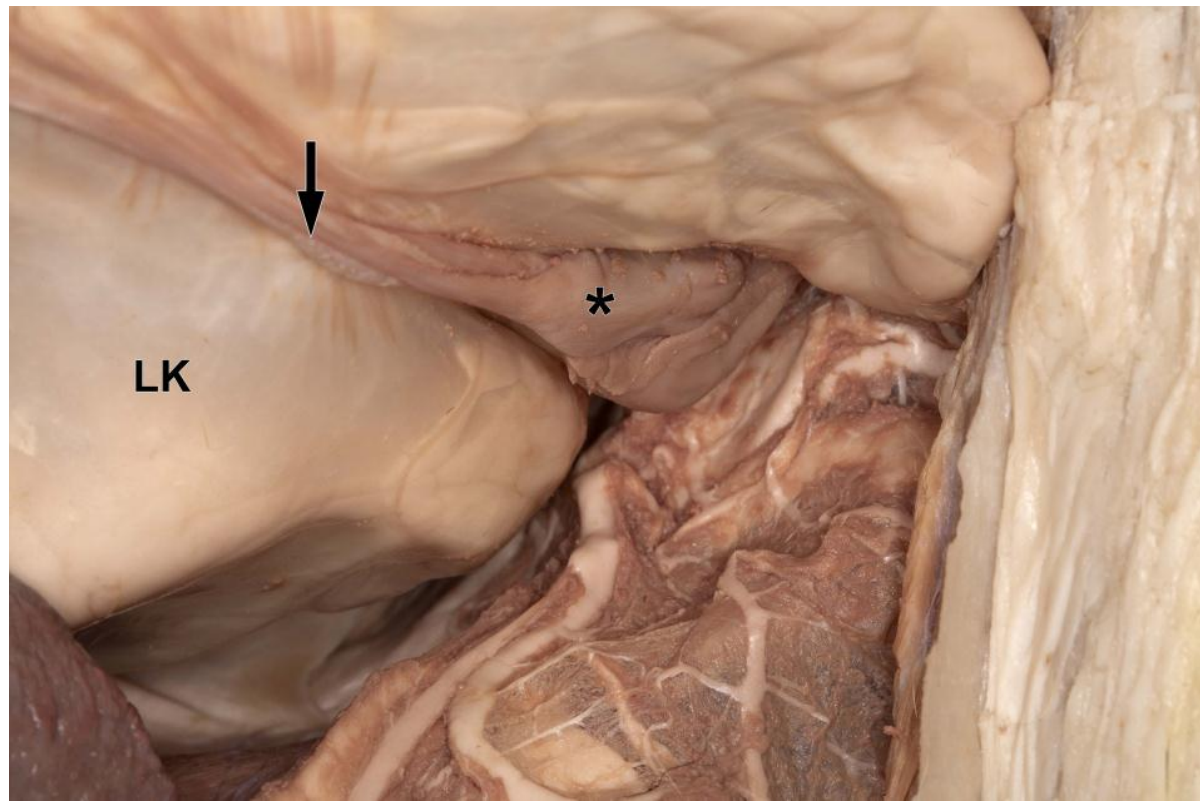

Figure 13 Suspensory ligament (arrow). Left kidney (LK), ovary (*).

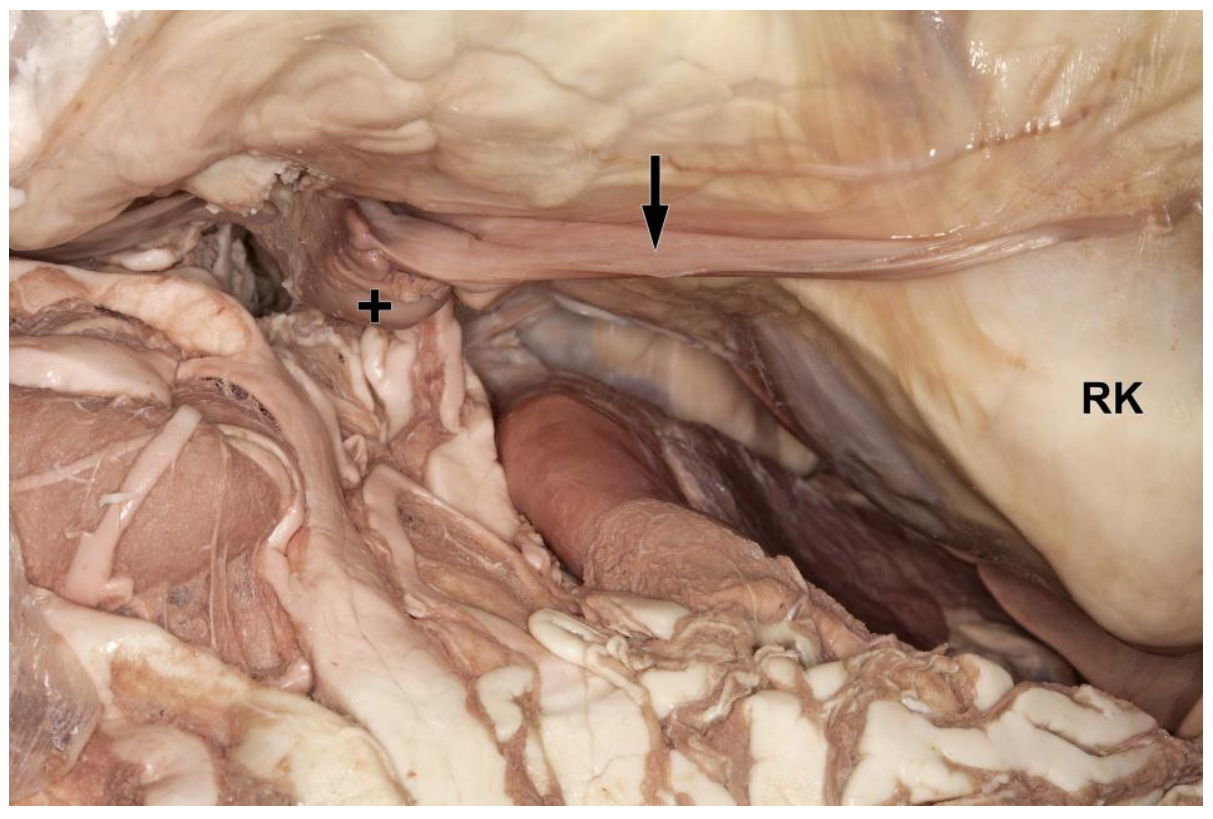

Figure 14 Suspensory ligament (arrow). Right kidney (RK), ovary (+). 


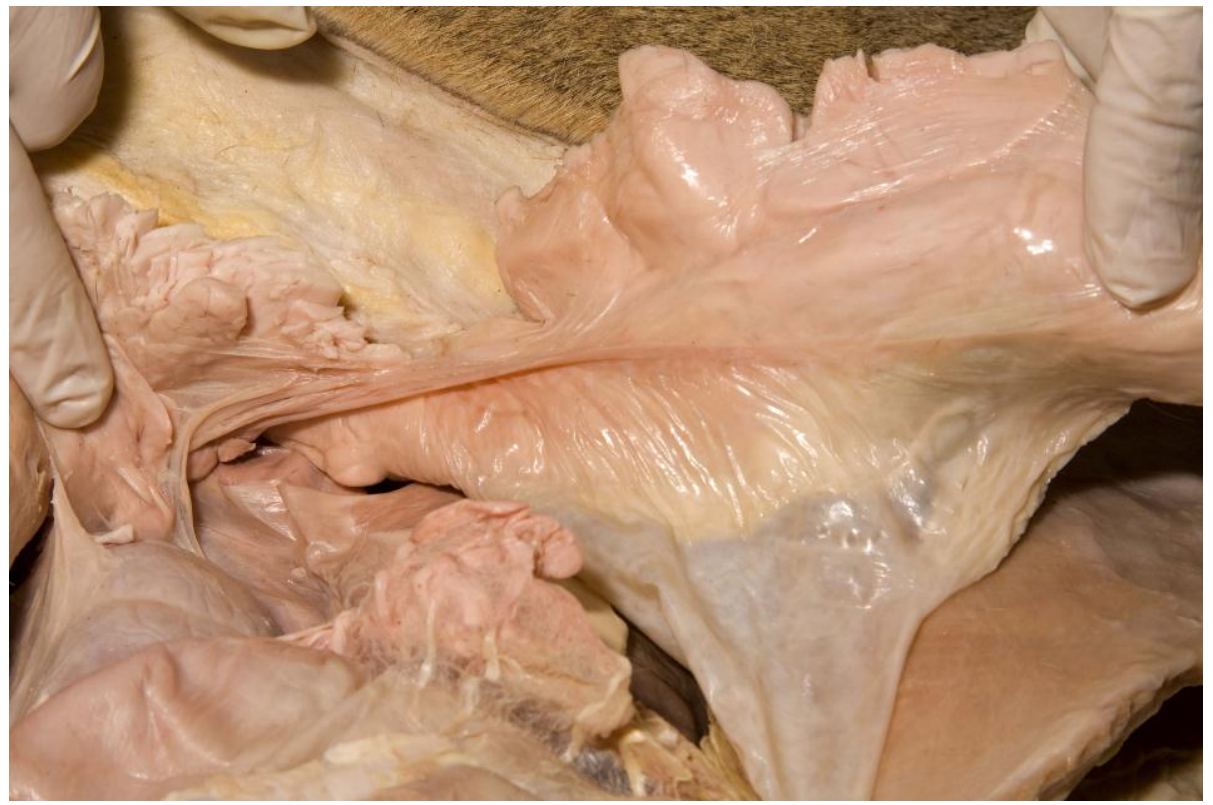

Figure 15 Right suspensory ligament dissected out.

Cranial is to the right of this picture.

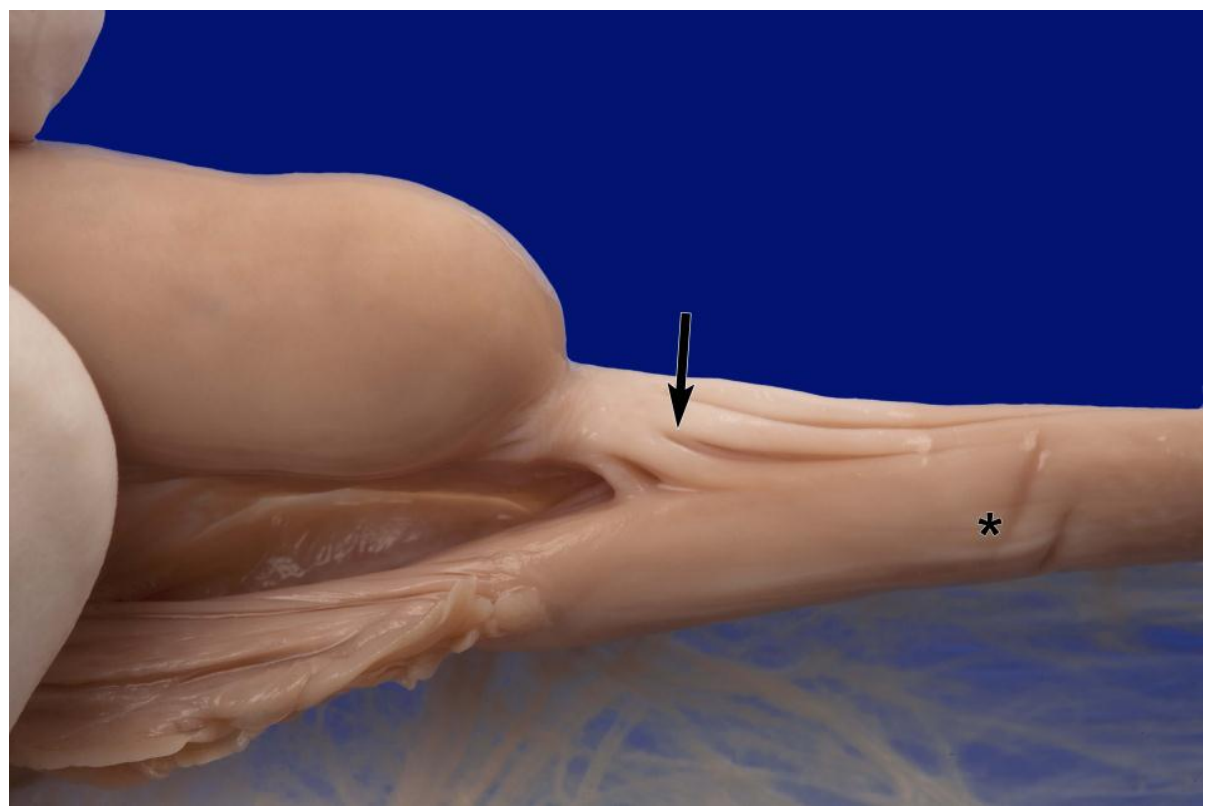

Figure 16 Proper ligament (arrow).

Uterine horn $(*)$. 


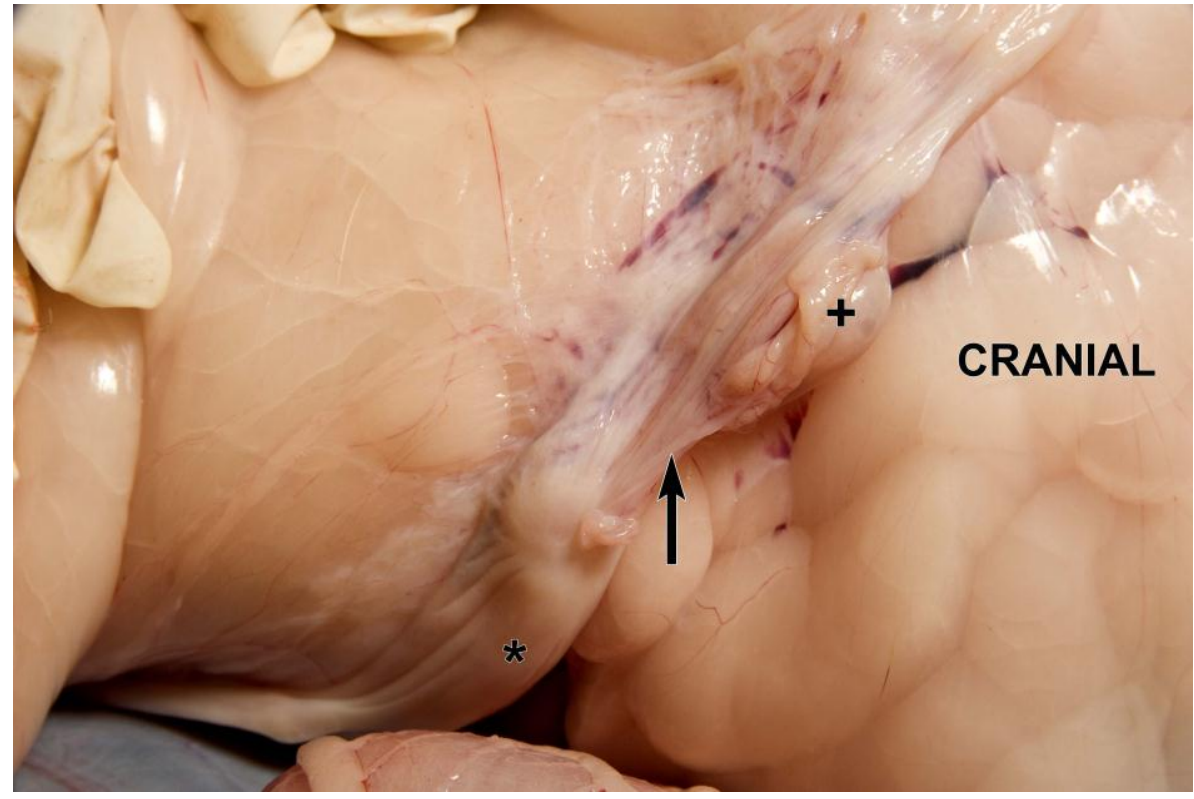

Figure 17 Right proper ligament (arrow) Uterine horn $(*)$ and ovary $(+)$. Fresh carcass.

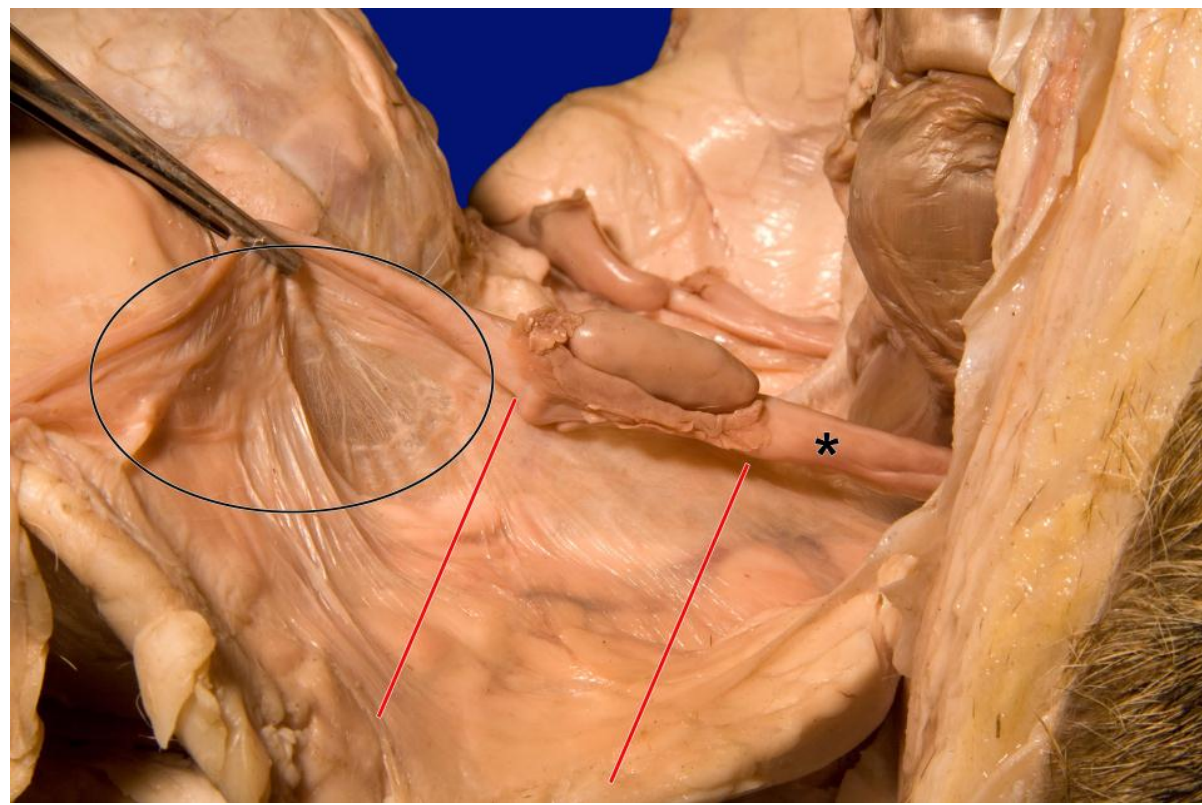

Figure 18 Broad ligament.

Mesovarium (parallel lines). Cranial part of the mesovarium (oval). Right uterine horn (*). Cadaver in dorsal recumbency. 


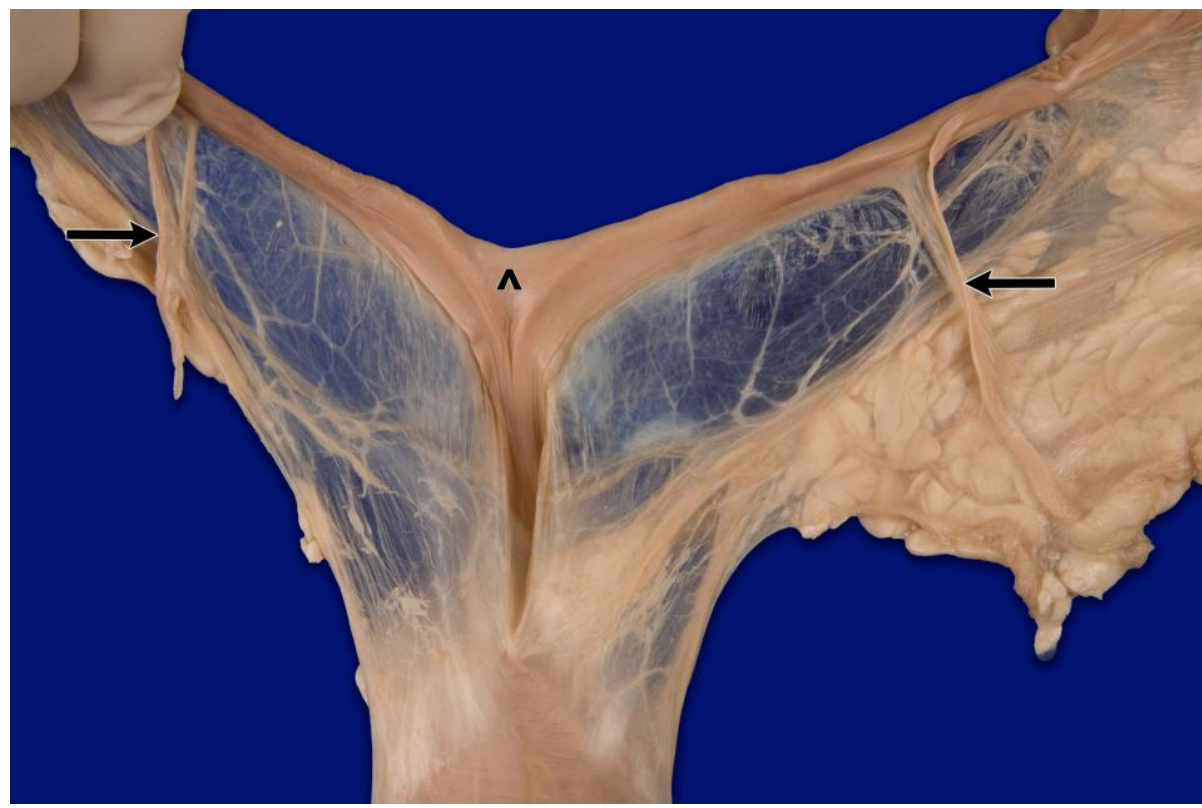

Figure 19 Round ligaments (arrows) and intercornual ligament $\left({ }^{\wedge}\right)$.

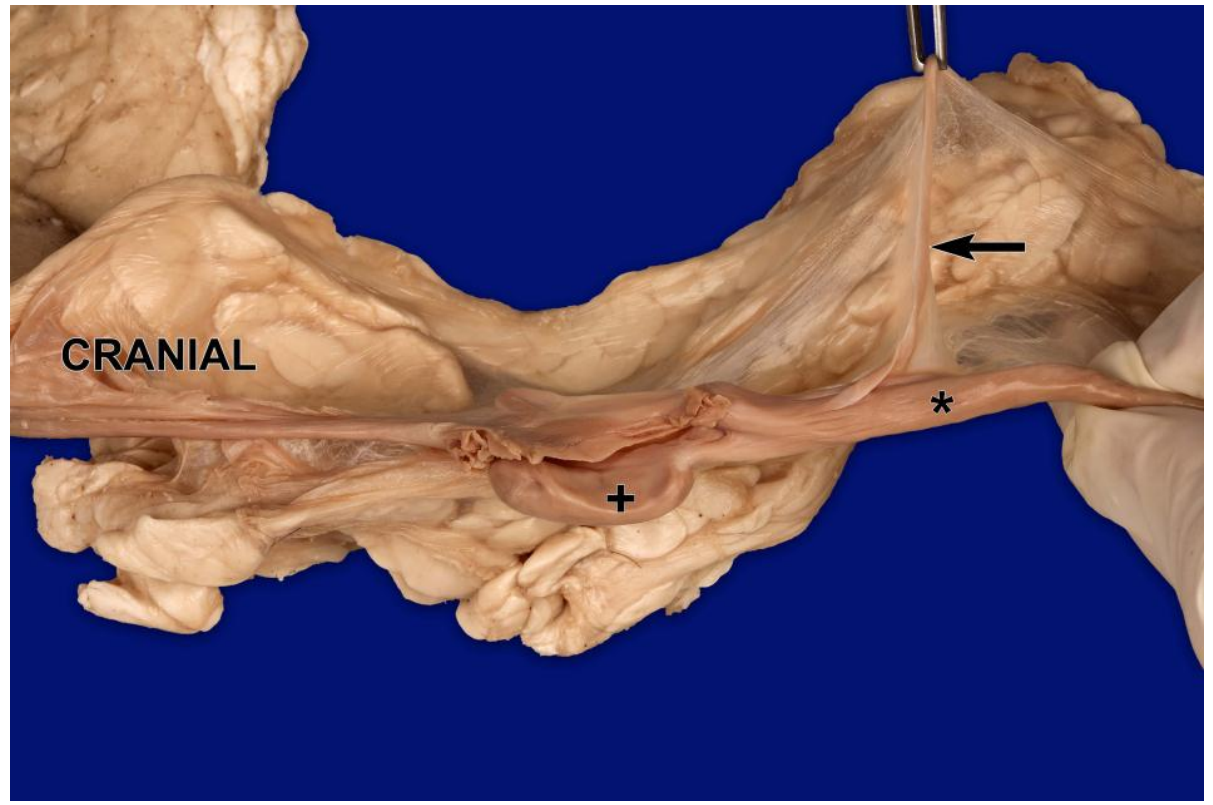

Figure 20 Round ligament (arrow).

Uterine horn $(*)$ and ovary $(+)$. 


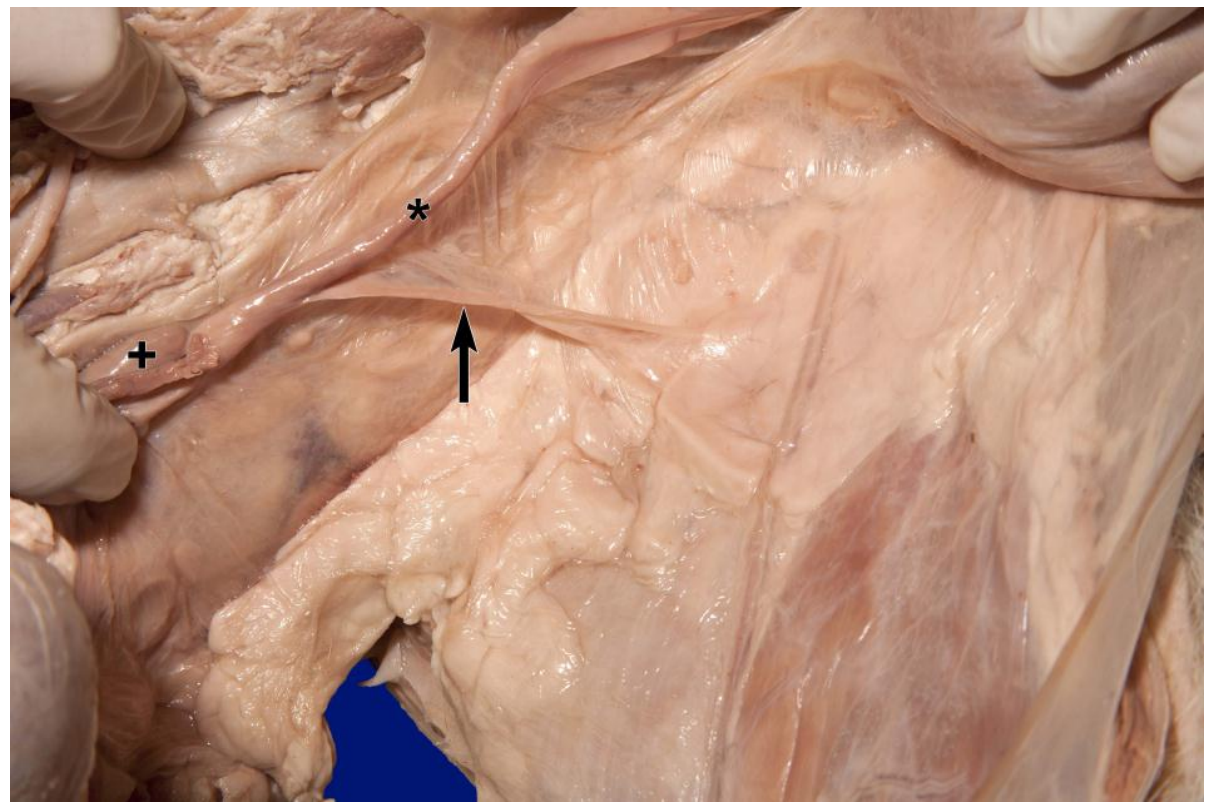

Figure 21 Round ligament (arrow).

Uterine horn $(*)$ and ovary $(+)$ with cadaver in dorsal recumbency.

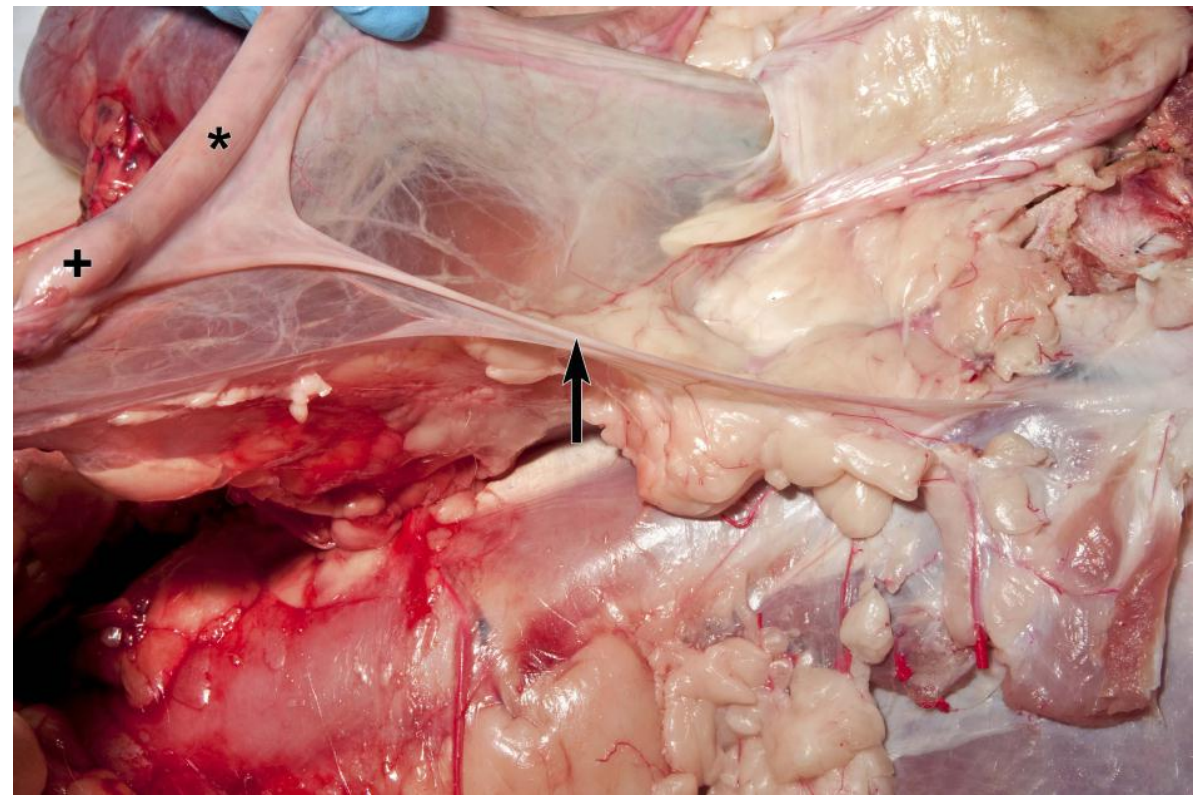

Figure 22 Round ligament (arrow).

Uterine horn $(*)$ and ovary (+). Fresh carcass in dorsal recumbency. 


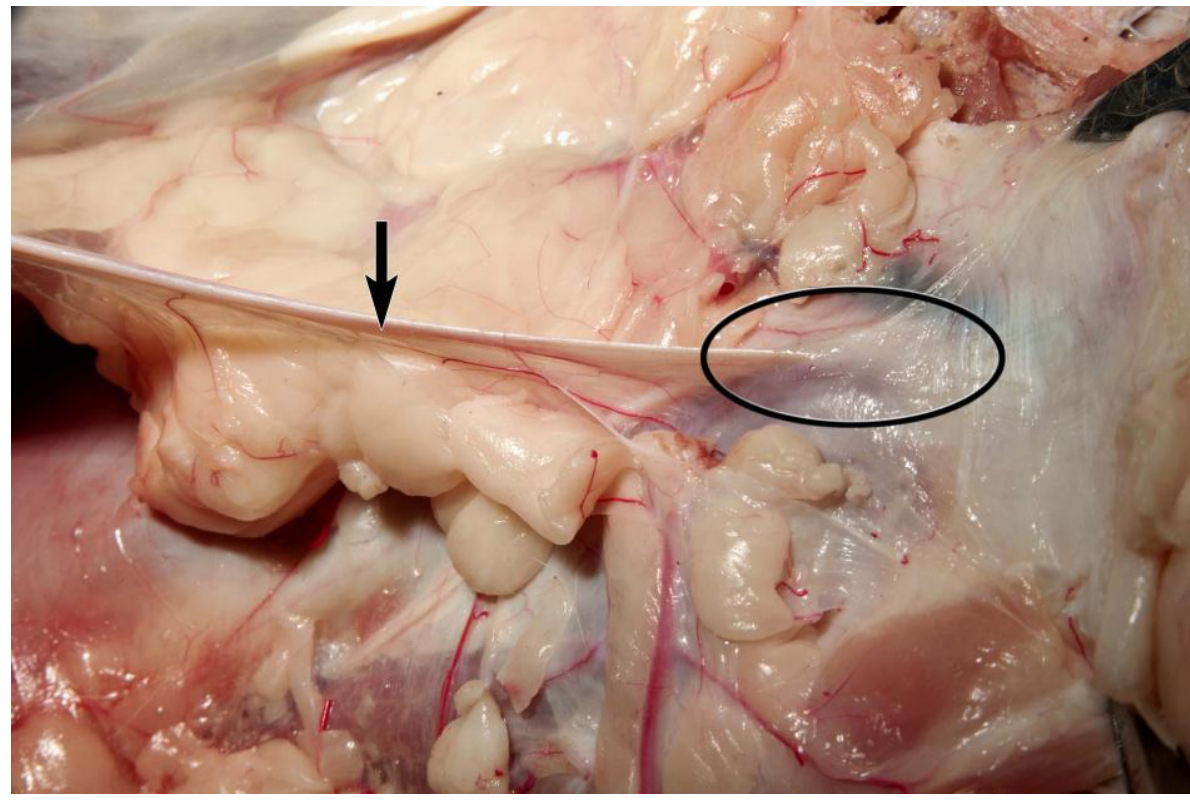

Figure 23 Round ligament with its insertion. Fresh carcass.

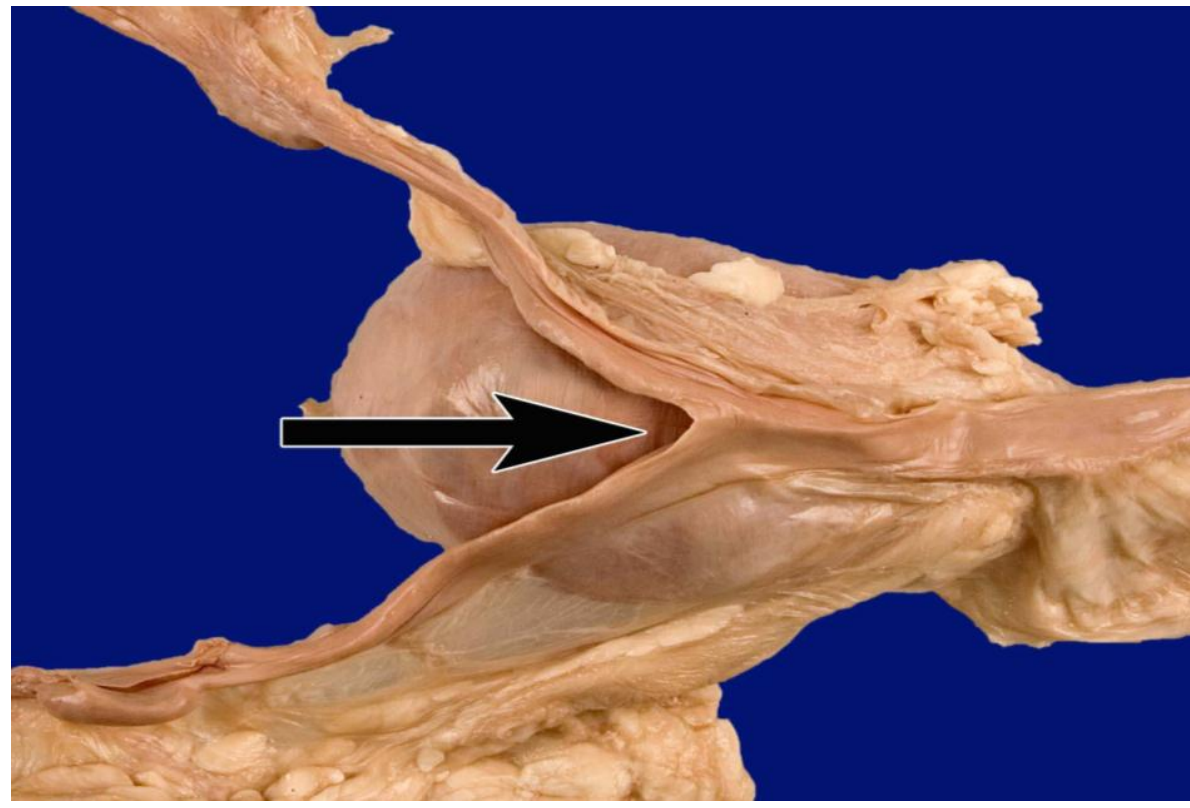

Figure 24 Intercornual ligament (arrow) situated dorsal to the bladder.

\subsection{Ovaries}

The left ovary was consistantly located adjacent to the caudolateral aspect of the caudal pole of the ipsilateral kidney. The position of the cranial pole of the right ovary ranged from $3.8-3.9 \mathrm{~cm}$ 
caudal to the caudal pole of the right kidney (Table 2) in the direct saggital midline of the respective kidney (Figure 8).

Table 2 Topographic location of ovaries.

\begin{tabular}{|c|c|c|c|c|c|c|}
\hline \multirow[t]{2}{*}{ Lioness } & \multicolumn{2}{|c|}{$\begin{array}{c}\text { Distance between } \\
\text { caudal pole of kidney } \\
\text { and cranial pole of } \\
\text { ovary }\end{array}$} & \multicolumn{2}{|c|}{$\begin{array}{l}\text { Medio-lateral topographic } \\
\text { location of ovary }\end{array}$} & \multicolumn{2}{|c|}{$\begin{array}{l}\text { Distance from centre } \\
\text { of ovary to iliac crest }\end{array}$} \\
\hline & Left & Right & Left & Right & Left & Right \\
\hline 1 & 0 & 3.8 & $\begin{array}{l}\text { immediately } \\
\text { caudo-lateral } \\
\text { to caudal } \\
\text { pole }\end{array}$ & $\begin{array}{l}\text { caudal to } \\
\text { and in the } \\
\text { saggital } \\
\text { midline of the } \\
\text { kidney }\end{array}$ & 6.8 & 7.1 \\
\hline 2 & 0 & 3.9 & $\begin{array}{l}\text { immediately } \\
\text { caudo-lateral } \\
\text { to caudal } \\
\text { pole }\end{array}$ & $\begin{array}{l}\text { caudal to } \\
\text { and in the } \\
\text { saggital } \\
\text { midline of the } \\
\text { kidney }\end{array}$ & 7.3 & 7.1 \\
\hline 3 & 0 & 3.9 & $\begin{array}{l}\text { immediately } \\
\text { caudo-lateral } \\
\text { to caudal } \\
\text { pole }\end{array}$ & $\begin{array}{l}\text { caudal to } \\
\text { and in the } \\
\text { saggital } \\
\text { midline of the } \\
\text { kidney }\end{array}$ & 6.1 & 7.2 \\
\hline Mean & 0.00 & 3.87 & - & - & 6.73 & 7.13 \\
\hline Standard Deviation & 0.00 & 0.06 & - & - & 0.60 & 0.06 \\
\hline
\end{tabular}

The phrenicoabdominal arteries were poorly visible and required significant soft tissue dissection to reveal their origin. The deep circumflex arteries were always constantly visible and required much less dissection to reveal their origin.

The two phrenicoabdominal and the two deep circumflex iliac arteries originated opposite to each other from the abdominal aorta (Figure 25). 


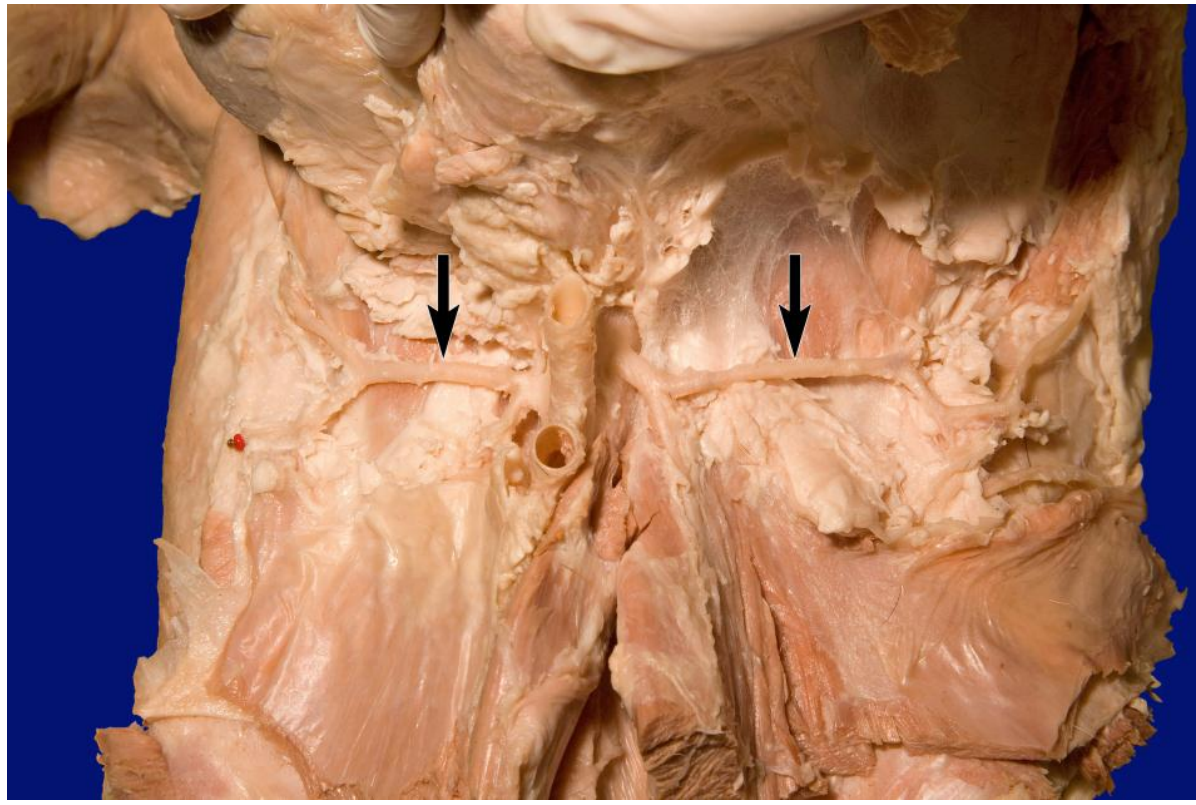

Figure 25 Phrenicoabdominal arteries (arrows).

The left and right ovaries were located $12.1-17.1 \mathrm{~cm}$ and $14.5-15.2 \mathrm{~cm}$ caudal to their respective ipsilateral phrenicoabdominal artery (Table 3).

Table 3 Topographic location of anatomical landmarks of female reproductive organs situated caudal in relation to the origin of the ipsilateral phrenicoabdominal arteries.

\begin{tabular}{lcccccc}
\hline Lioness & LO & RO & TLUH & TRUH & $\begin{array}{c}\text { OL } \\
\text { AO }\end{array}$ & $\begin{array}{c}\text { OR } \\
\text { AO }\end{array}$ \\
\hline 1 & 12.1 & 14.5 & 13.8 & 16.1 & 10 & 11.4 \\
2 & 16.4 & 15.2 & 17.8 & 16.9 & 11.8 & 12.3 \\
3 & 17.1 & 14.5 & 17.9 & 16.3 & 10 & 9.8 \\
Mean & 15.20 & 14.73 & 16.50 & 16.43 & 10.60 & 11.17 \\
Standard Deviation & 2.71 & 0.40 & 2.34 & 0.42 & 1.04 & 1.27 \\
\hline
\end{tabular}

$\mathrm{LO}=$ cranial pole of left ovary; RO = cranial pole of right ovary; TLUH = tip of left uterine horn; TRUH = tip of right uterine horn; OLAO = origin of left ovarian artery; ORAO = origin of right ovarian artery. 
The location of the left ovary in relation to the deep circumflex iliac artery was variable and ranged from 5.9-8.7 cm cranial to the ipsilateral artery (Table 4). The position of the right ovary was more constantly situated $7.8-8.1 \mathrm{~cm}$ cranial to the ipsilateral deep circumflex artery (Table 4).

Table 4 Topographic location of anatomical landmarks of female reproductive organs situated cranial in relation to the origin of the ipsilateral deep circumflex iliac arteries.

\begin{tabular}{lcccccccc}
\hline Lioness & LO & RO & TLUH & TRUH & $\begin{array}{c}\text { OL } \\
\text { AO }\end{array}$ & $\begin{array}{c}\text { OR } \\
\text { AO }\end{array}$ & $\begin{array}{c}\text { PP to } \\
\text { LO }\end{array}$ & $\begin{array}{c}\text { PP to } \\
\text { RO }\end{array}$ \\
\hline 1 & 5.9 & 8.1 & 4.1 & 6.8 & 5.6 & 3.9 & 3.6 & 2.9 \\
2 & 8.2 & 8 & 5.6 & 6.2 & 4.2 & 3.2 & 1.9 & 2.8 \\
3 & 8.7 & 7.8 & 7.5 & 7.3 & 3.9 & 2.7 & 2.8 & 3 \\
Mean & 7.60 & 7.97 & 5.73 & 6.77 & 4.57 & 3.27 & 2.77 & 2.90 \\
Standard Deviation & 1.49 & 0.15 & 1.70 & 0.55 & 0.91 & 0.60 & 0.85 & 0.10 \\
\hline
\end{tabular}

$L O=$ cranial pole of left ovary; $R O=$ cranial pole of right ovary; $T L U H=$ tip of left uterine horn; TRUH = tip of right uterine horn; OLAO = origin of left ovarian artery; OAO = origin of right ovarian artery; PP to $L O=$ distance from parietal peritoneum to centre of left ovary; PP to $\mathrm{RO}=$ distance from parietal peritoneum to centre of right ovary.

The left ovary weighed between 1.4-2.5 grams, with a length of 2.7-3.2 cm and width of 1.1-1.4 $\mathrm{cm}$. The right ovary weighed between 1.1-2.2 grams, with a length of $2.7-3.0 \mathrm{~cm}$ and width of 0.9-1.2 cm (Table 5). The ratio of ovarian weight to bodyweight varied between 0.00001 and 0.000017 (Table 5). The origin of the left ovarian artery was located $10.0-11.8 \mathrm{~cm}$ caudal to the origin of the ipsilateral phrenicoabdominal artery and $3.9-5.6 \mathrm{~cm}$ cranial to that of the deep circumflex iliac artery. Likewise the origin of the right ovarian artery was located $9.8-12.3 \mathrm{~cm}$ caudal to the origin of the phrenicoabdominal artery and $2.7-3.9 \mathrm{~cm}$ cranial to that of the deep circumflex iliac artery (Tables $3 \& 4$ ). 
Table $5 \quad$ Splanchnologic data of the ovaries.

\begin{tabular}{lccccccccc}
\hline Lioness & $\begin{array}{c}\text { Body } \\
\text { mass } \\
(\mathbf{k g})\end{array}$ & \multicolumn{3}{c}{ Left ovary } & \multicolumn{3}{c}{ Right ovary } & Ratio O/B \\
\cline { 3 - 8 } & & $\begin{array}{c}\text { Weight } \\
(\mathbf{g r})\end{array}$ & $\begin{array}{c}\text { Length } \\
(\mathbf{c m})\end{array}$ & $\begin{array}{c}\text { Width } \\
(\mathbf{c m})\end{array}$ & $\begin{array}{c}\text { Weight } \\
(\mathbf{g r})\end{array}$ & $\begin{array}{c}\text { Length } \\
(\mathbf{c m})\end{array}$ & $\begin{array}{c}\text { Width } \\
(\mathbf{c m})\end{array}$ & \\
\hline 1 & 120.5 & 1.4 & 2.7 & 1.2 & 1.1 & 2.7 & 0.9 & 0.00001 \\
2 & 138.5 & 2.5 & 3.2 & 1.4 & 2.2 & 3 & 1.2 & 0.000017 \\
3 & 140.5 & 2.3 & 2.9 & 1.1 & 1.8 & 3 & 0.9 & 0.000015 \\
Mean & 133.17 & 2.07 & 2.93 & 1.23 & 1.70 & 2.90 & 1.00 & 0.000014 \\
Standard Deviation & 11.02 & 0.59 & 0.25 & 0.15 & 0.56 & 0.17 & 0.17 & 0.00 \\
\hline
\end{tabular}

Ratio O/B = Ratio of mean ovarian weight to bodyweight.

The ovarian bursa had a short mesosalpinx that did not cover any part of the ovary (Figures 2629) and extended the entire length of the ovary.

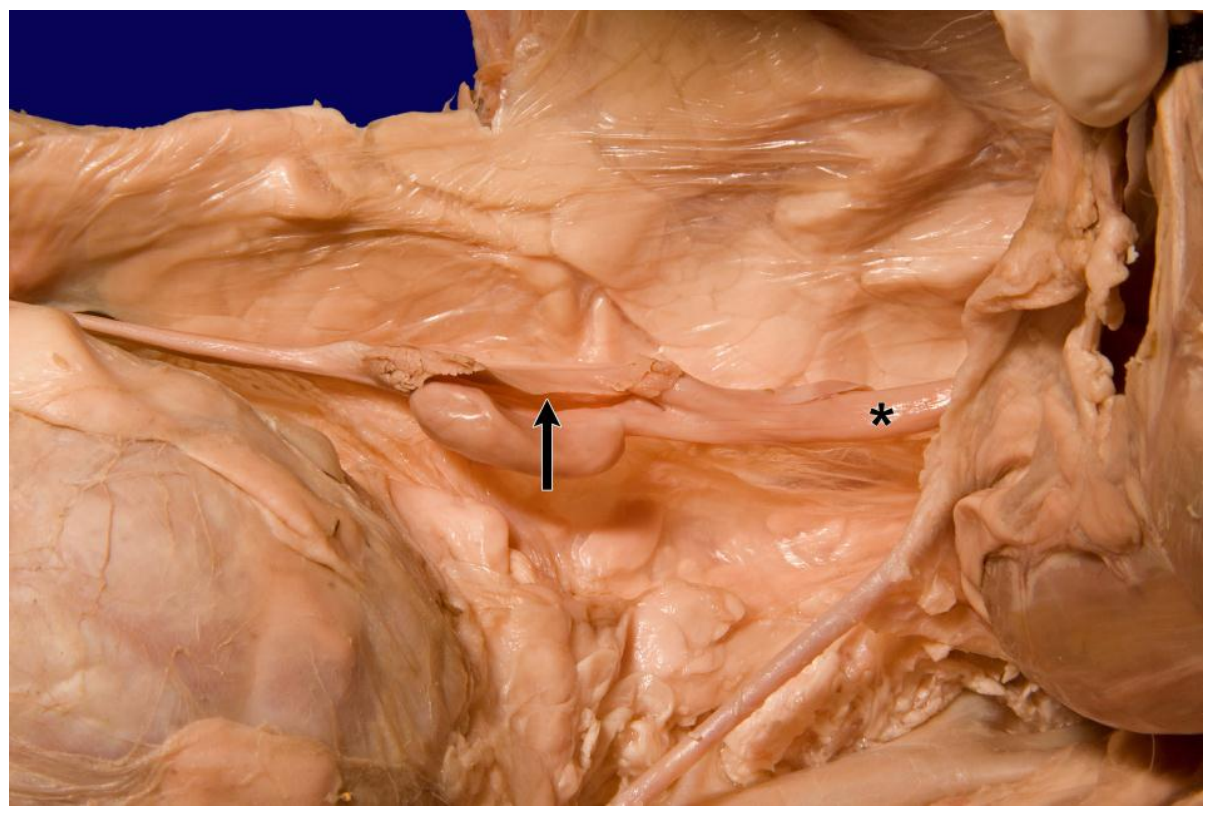

Figure 26 Ovarian bursa (arrow).

Uterine horn $(*)$. 


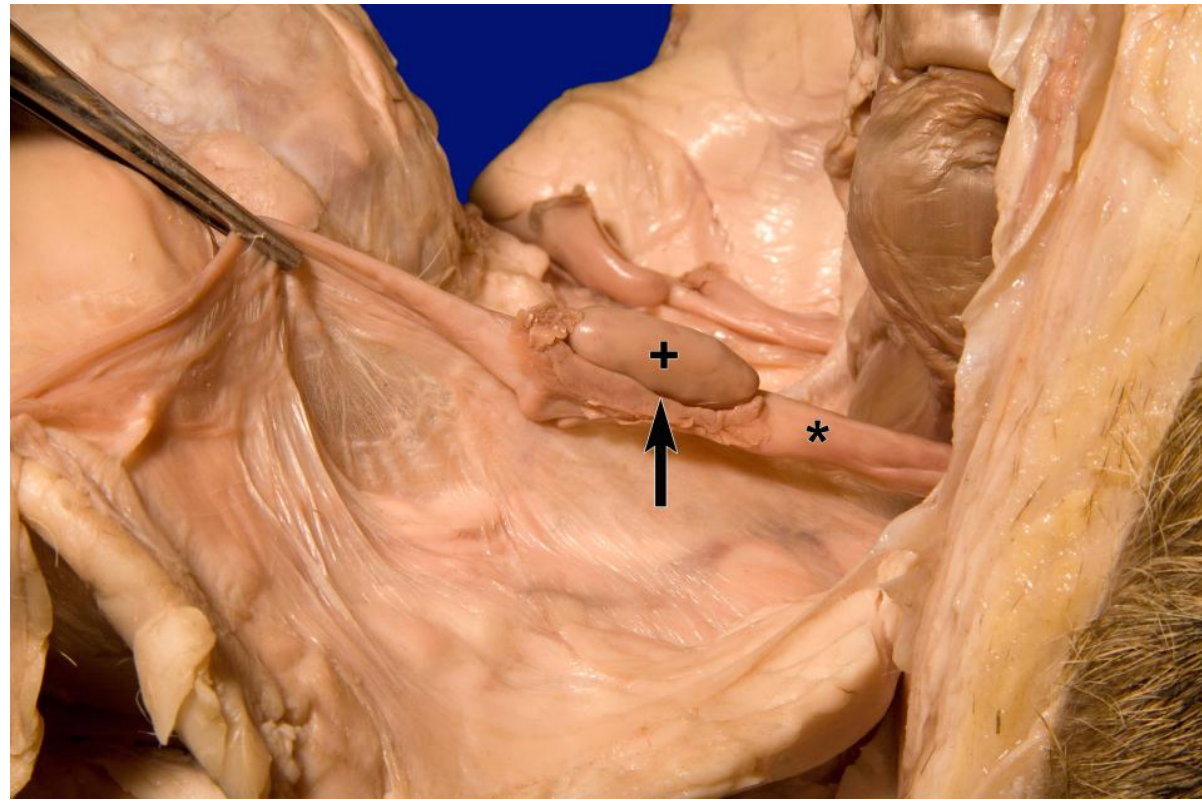

Figure 27 Ovarian bursa (arrow).

Uterine horn (*) and ovary (+).

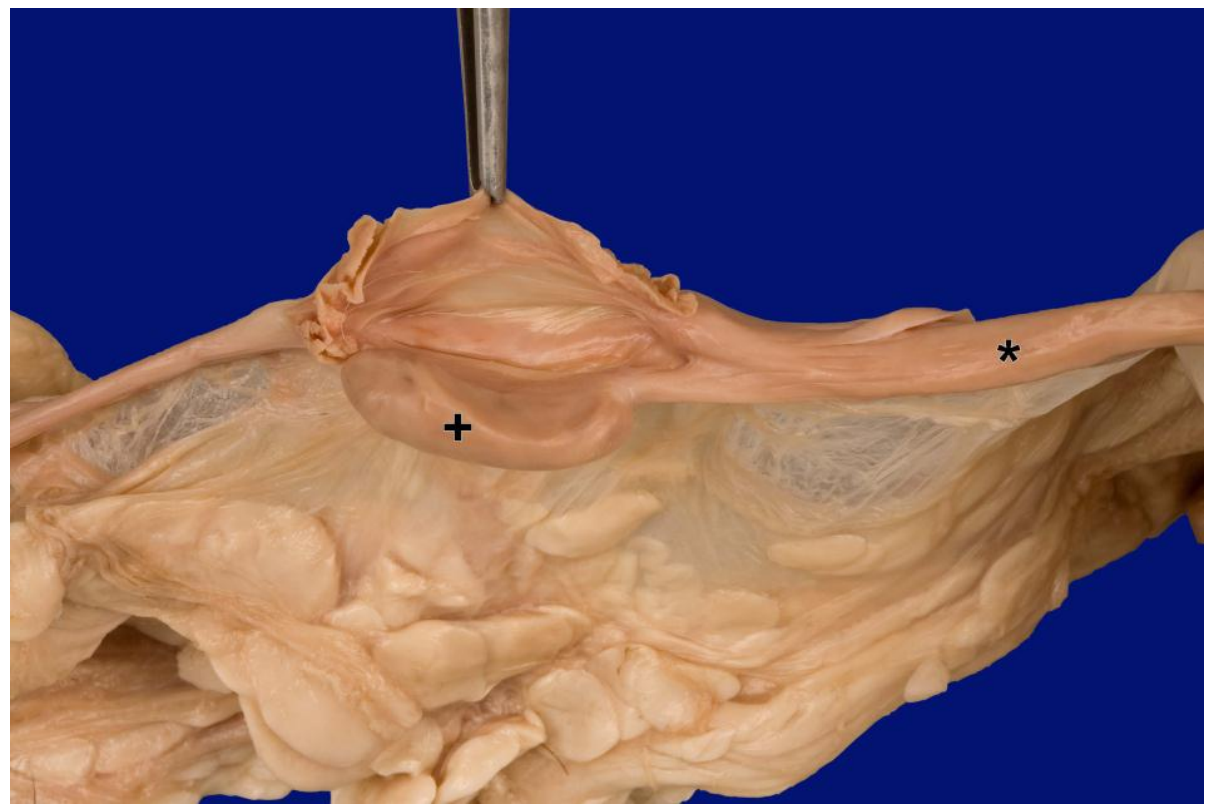

Figure 28 Ovarian bursa exposed.

Uterine horn (*) and ovary (+). 


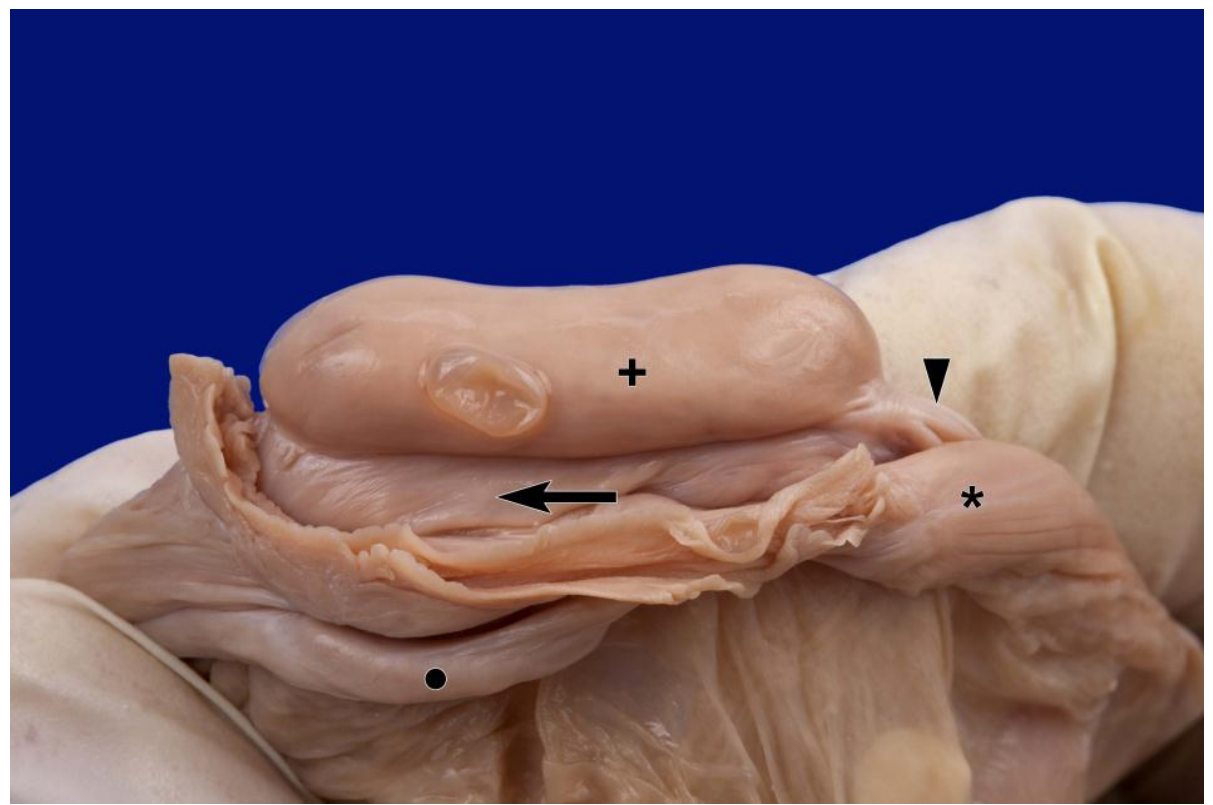

Figure 29 Ovarian bursa (arrow).

Uterine horn $(*)$, ovary $(+)$, uterine tube $(\bullet)$ and proper ligament (arrow head).

The mesosalpinx however was thick and tough and contained the convoluted uterine tube (Figures 30 and 31).

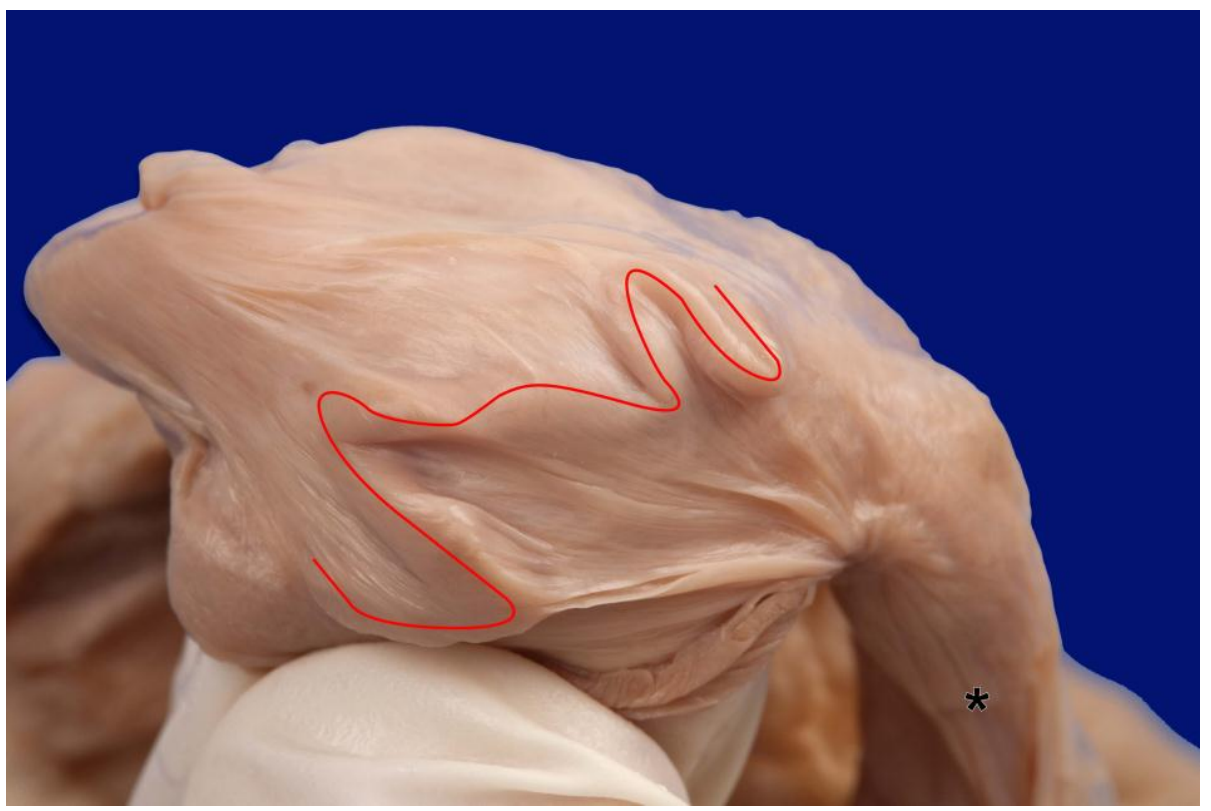

Figure $30 \quad$ Uterine tube (red curved line).

Uterine horn $(*)$. 


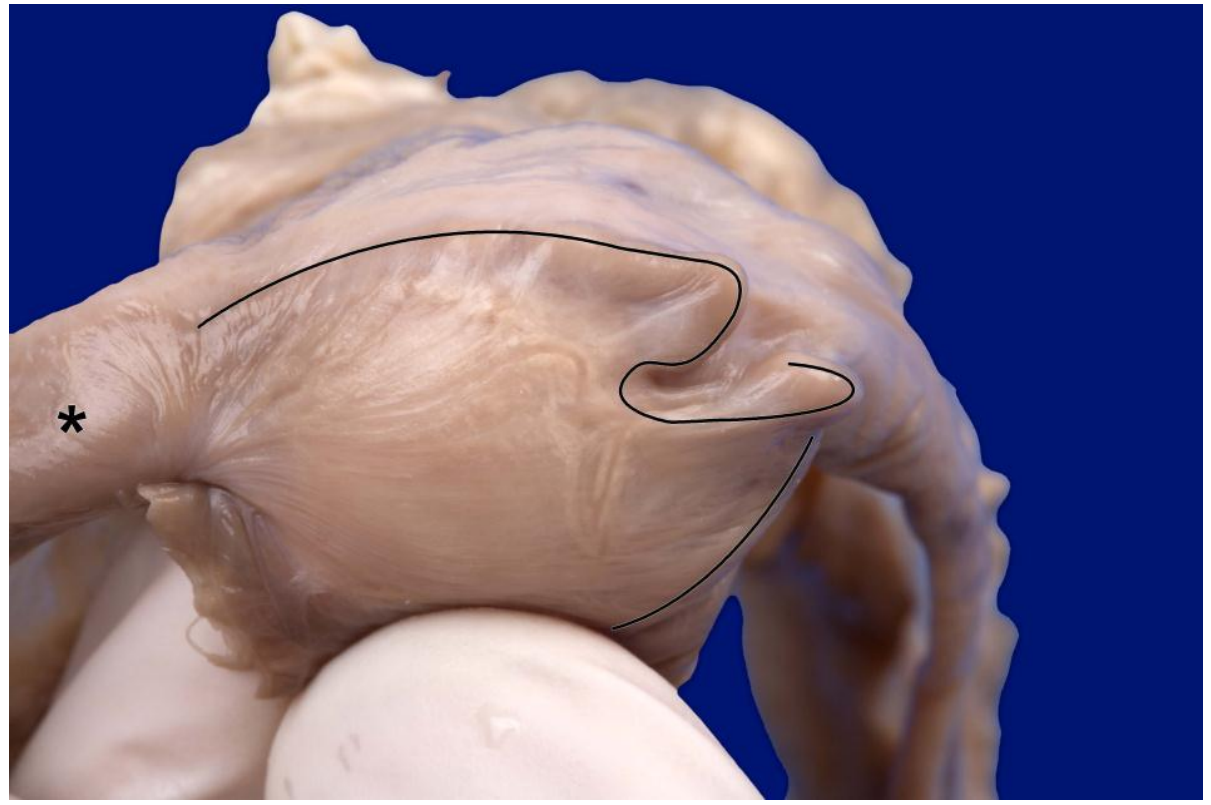

Figure 31 Uterine tube (black curved line).

Uterine horn $(*)$.

The distance from the parietal peritoneum to the mesovarial margin of the left ovary at its centre was highly variable between $1.9 \mathrm{~cm}$ and $3.6 \mathrm{~cm}$. However this distance for the right ovary was relatively constant at $2.8-3.0 \mathrm{~cm}$ (Table 4 ).

\subsection{Peritoneal excavations}

The pubovesical (Figure 32) and vesicogenital (Figure 33) pouches were situated cranially to the cranial border of the pubis in two lions with the vesicogenital pouch further cranially. The rectogenital pouch (Figure 34) and pararectal fossae (Figure 35) were located intrapelvically with the latter further caudal. The vesicogenital pouch extended to the level of the cervix and the rectogenital pouch to the caudal margin of the vagina (Figure 36). The peritoneal excavations in general were found to be highly variable amongst individuals (Table 6). 


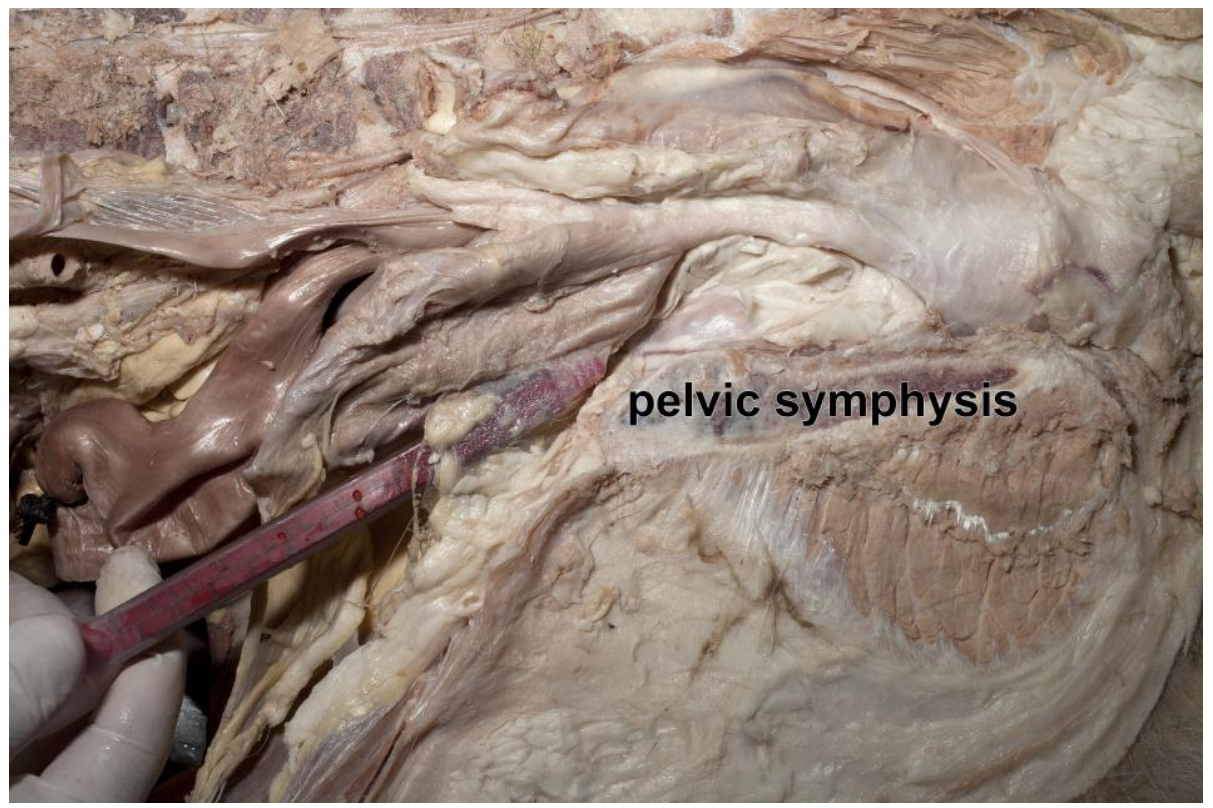

Figure 32 Pubovesical pouch. Indicated with a red probe.

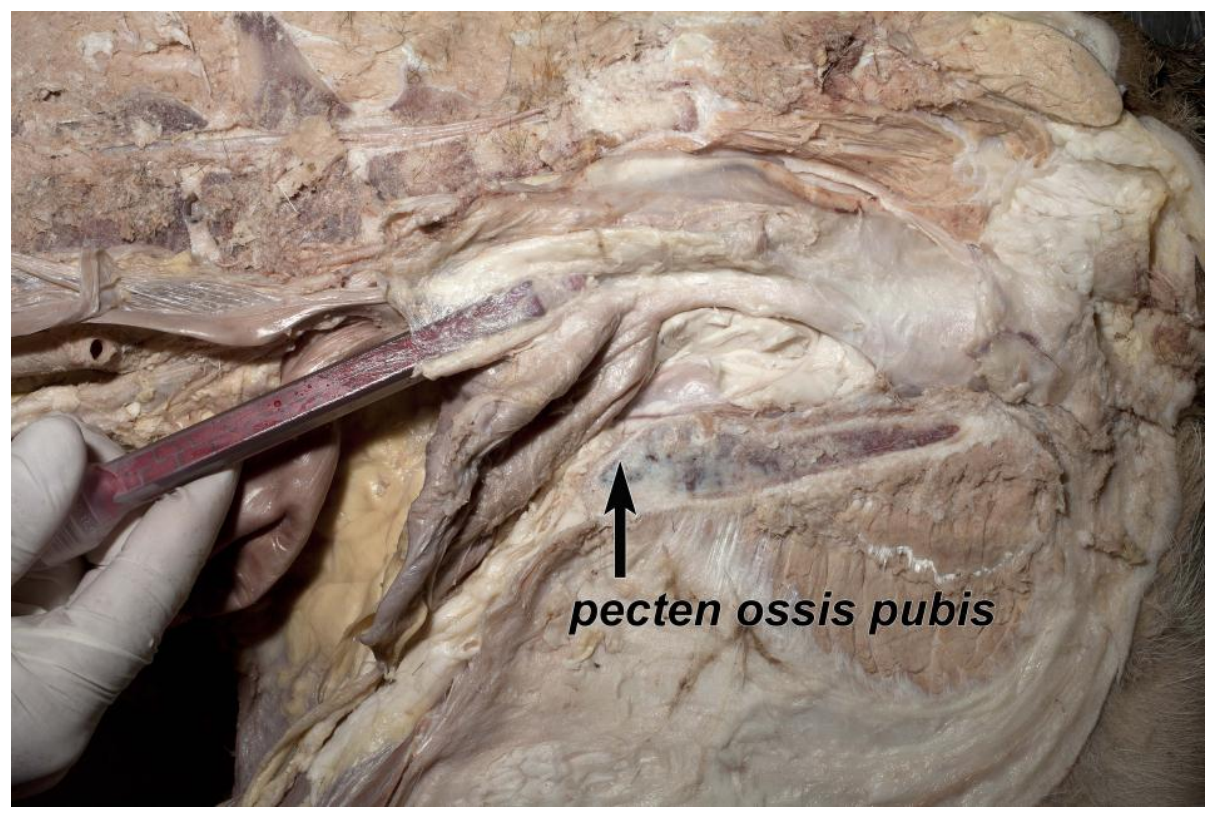

Figure 33 Vesicogenital pouch. Indicated with a red probe. 


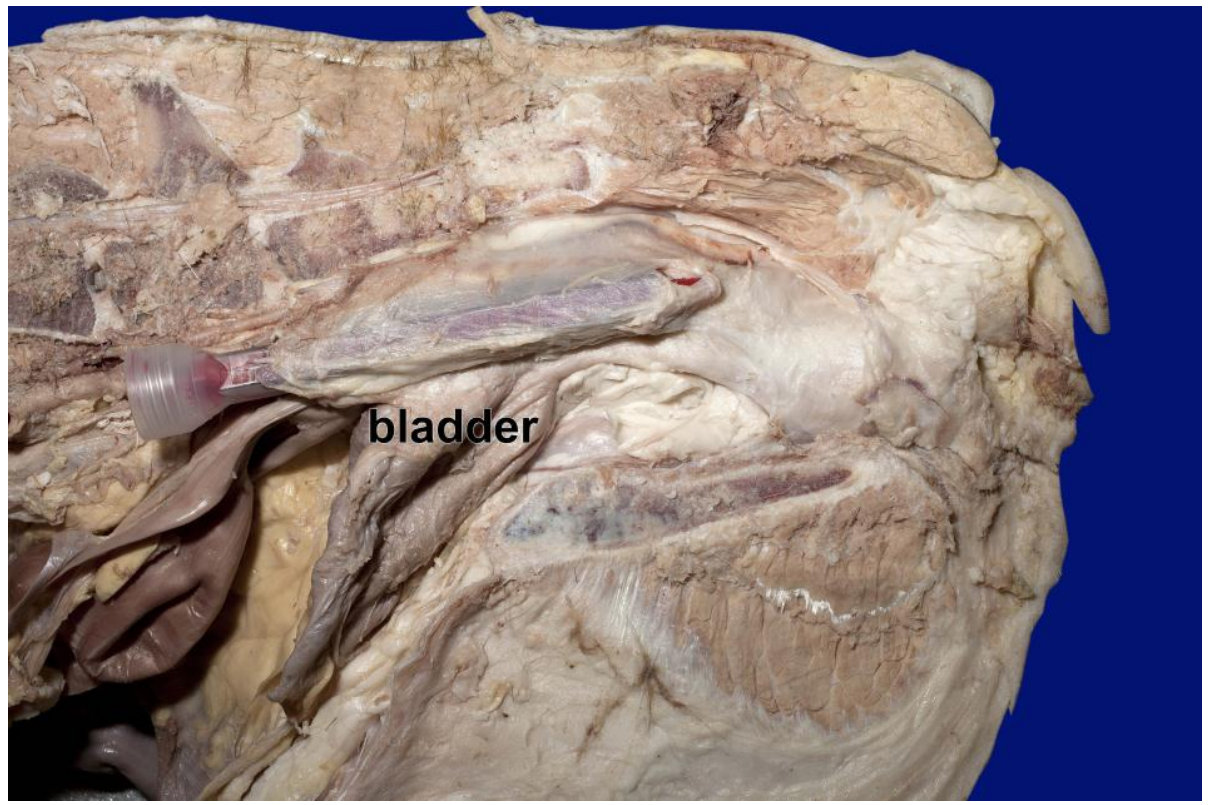

Figure 34 Rectogenital pouch. Indicated with a red probe.

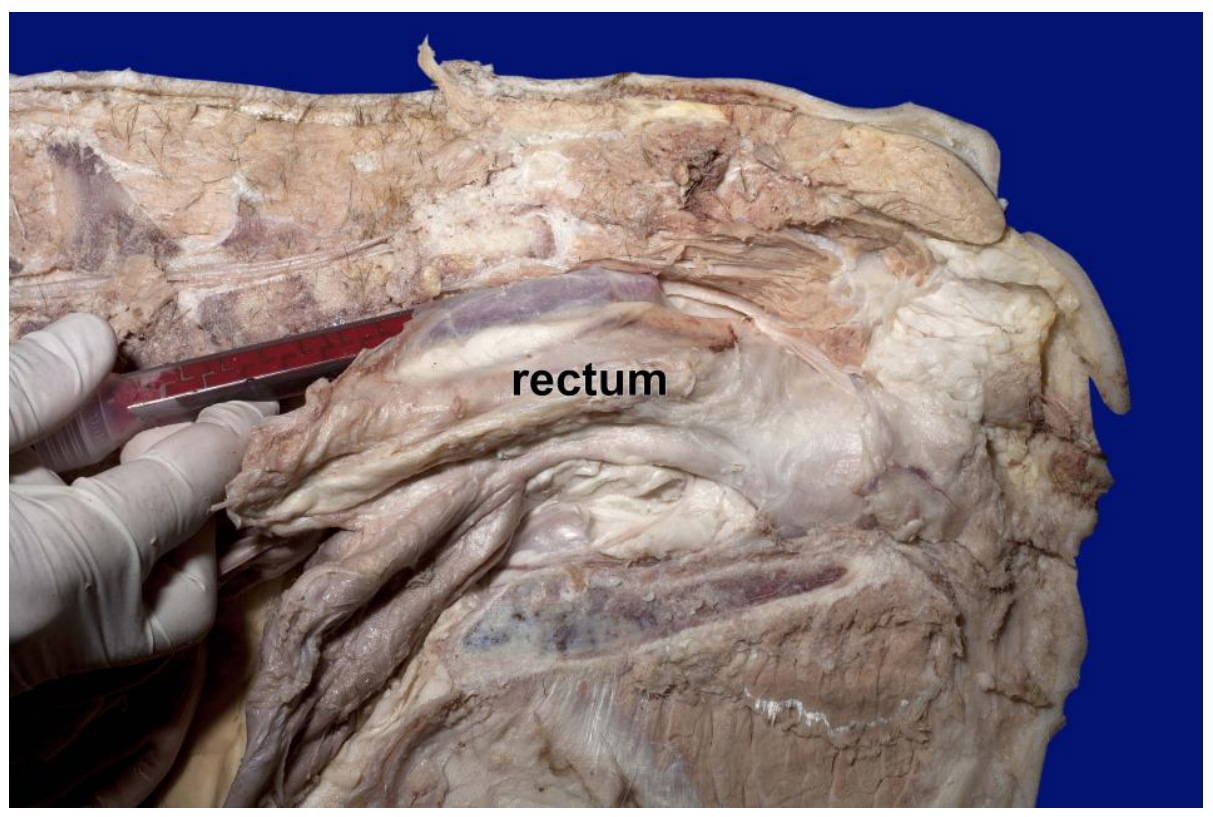

Figure 35 Pararectal fossa. Indicated with a red coloured probe. 


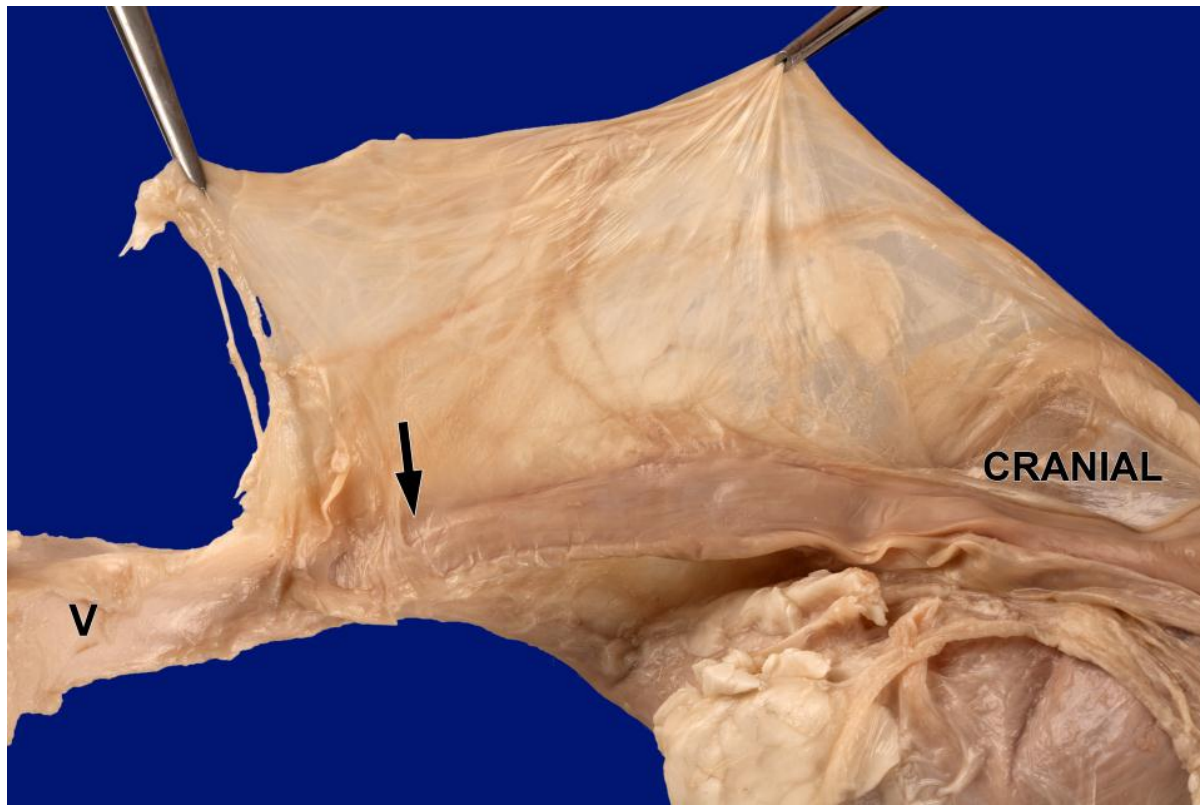

Figure 36 Peritoneal reflection on the dorsal aspect of the vagina (arrow). Vaginal vestibulum (V).

Table 6 Topographic location of lines of peritoneal reflection described in relation to the cranial border of the pubis. Negative figures indicate a location cranial to the cranial border of the pubis.

\begin{tabular}{lcccc}
\hline Lioness & $\begin{array}{c}\text { Pubovesical } \\
\text { pouch }\end{array}$ & $\begin{array}{c}\text { Vesicogenital } \\
\text { pouch }\end{array}$ & $\begin{array}{c}\text { Rectogenital } \\
\text { pouch }\end{array}$ & Pararectal fossa \\
\hline 1 & -1.8 & -3.7 & 6.1 & 10.3 \\
2 & 1.8 & 0.7 & 6.9 & 7.4 \\
3 & -0.5 & -1.5 & 7.1 & 8.6 \\
Mean & -0.17 & -1.50 & 6.70 & 8.77 \\
Standard Deviation & 1.82 & 2.20 & 0.53 & 1.46 \\
\hline
\end{tabular}

\subsection{Tubular parts}

The vaginal vestibule was 6.4-6.8 $\mathrm{cm}$ long and the vagina 8.2-10.4 cm (Table 7). The longitudinal folds of the vaginal vestibule were fewer but much more prominent (higher and wider) than those of the vagina (Figures 37-39). 


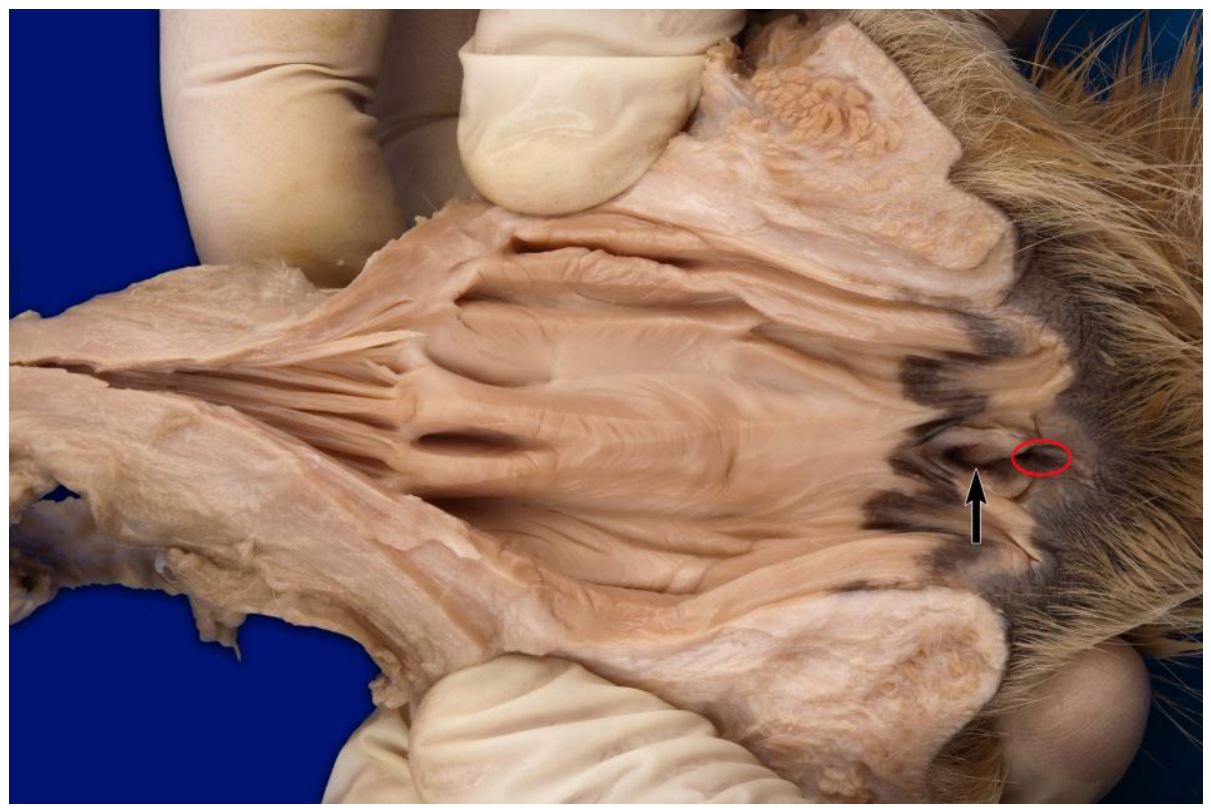

Figure 37 Opening to the clitoral fossa (oval). The clitoral fossa was incised and exposed (arrow).

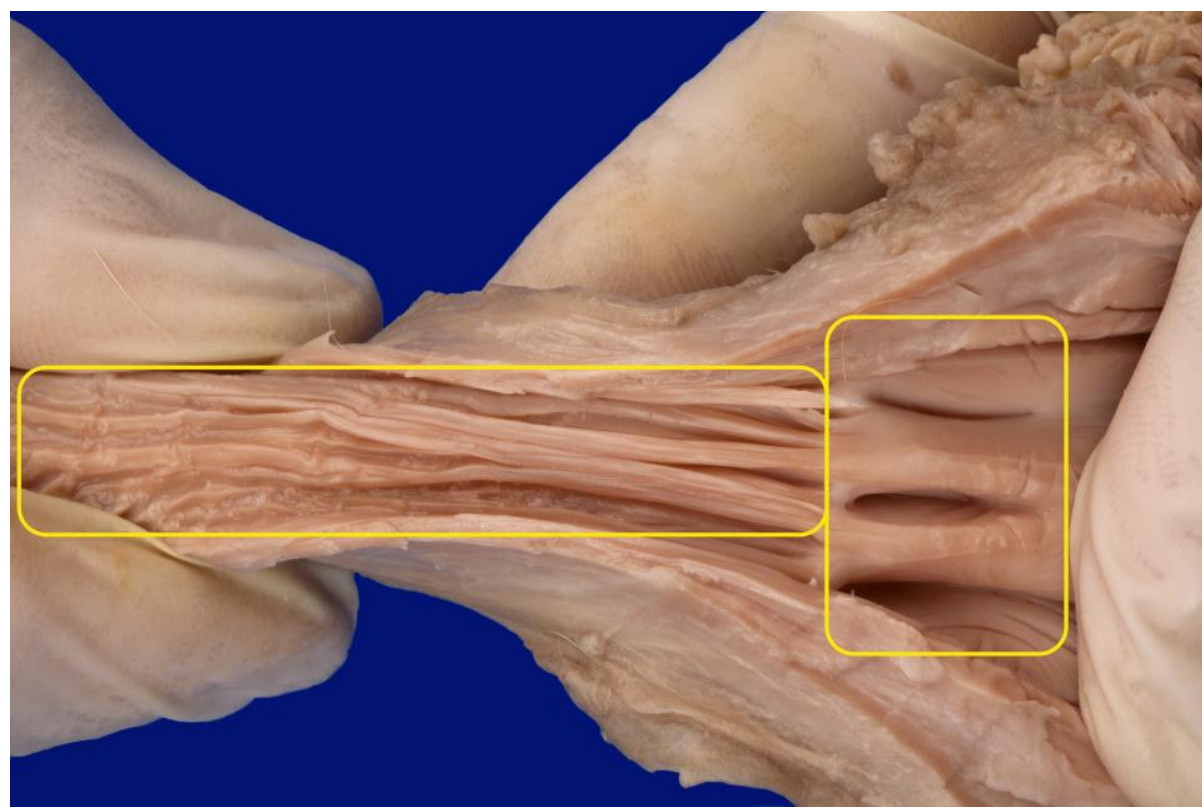

Figure 38 Vaginal vestibulum.

Containing the urethral tubercle (short wide rectangle) and exposed vagina (long narrow rectangle). 


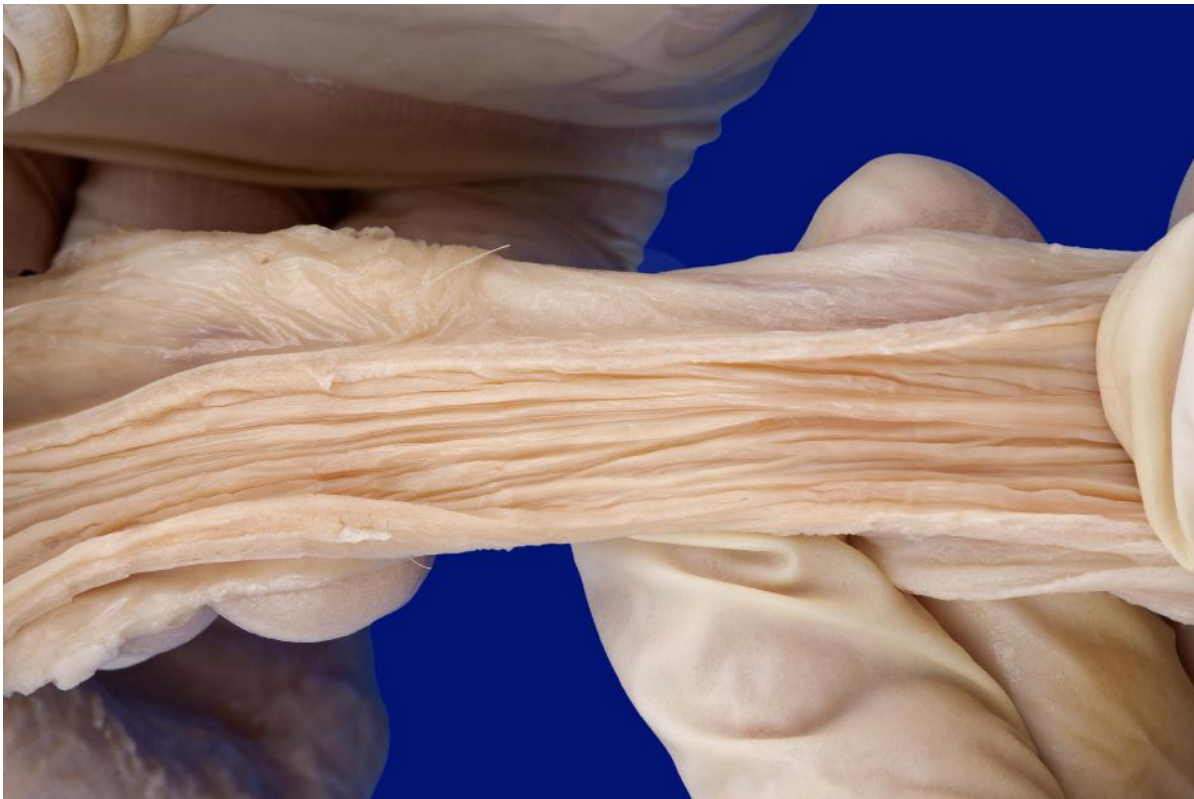

Figure $39 \quad$ Vaginal folds on the inside of an exposed vagina.

A big external urethral orifice was situated on a well developed urethral tubercle. A well developed urethral crest extended from the tubercle caudally into the vaginal vestibule ventrally (Figures 37 and 38). The clitoris and its fossa were small and poorly developed (Figure 37). The cervix was 1.4-2.1 cm long, 1.3-1.6 cm in diameter (Table 7) and was constantly located intra pelvically. It was thick walled with fine longitudinal folds and was notably short and small in relation to the rest of the reproductive organs (Figure 40).

Table $7 \quad$ Splanchnologic data of tubular parts.

\begin{tabular}{lcccccccccccc}
\hline Lioness & $\mathbf{A}$ & $\mathbf{B}$ & $\mathbf{C}$ & $\mathbf{D}$ & ${ }^{*} \mathbf{E}$ & $\mathbf{F}$ & $\mathbf{G}$ & $\mathbf{H}$ & ${ }^{*} \mathbf{I}$ & ${ }^{*} \mathbf{J}$ & ${ }^{*} \mathbf{K}$ & ${ }^{*} \mathbf{L}$ \\
\hline 1 & 6.7 & 9.5 & 16.2 & 1.5 & 1.5 & 3.2 & 21.1 & 11.7 & 2.9 & 2.3 & 0.3 & 1.2 \\
2 & 6.4 & 8.2 & 14.6 & 2.1 & 1.6 & 2.5 & 14.1 & 14.8 & $\mathbf{C}$ & 3.5 & 0.3 & 1.3 \\
3 & 6.8 & 10.4 & 17.2 & 1.4 & 1.3 & 3 & 12 & 12.2 & $\mathbf{C}$ & $\mathbf{C}$ & 0.3 & 1.2 \\
$\mathrm{Mn}$ & 6.63 & 9.37 & 16.0 & 1.67 & 1.47 & 2.90 & 15.7 & 12.9 & 2.90 & 2.90 & 0.30 & 1.23 \\
$\mathrm{SD}$ & 0.21 & 1.11 & 1.31 & 0.38 & 0.15 & 0.36 & 4.76 & 1.66 & - & 0.85 & 0.00 & 0.06 \\
\hline
\end{tabular}

$A=$ length of vaginal vestibule (measured from the cranial border of the urethral tubercle to the mucocutaneous junction of the vulva); $\mathrm{B}=$ length of vagina (measured from the cranial border of the urethral tubercle to the external orifice of the cervix); $C$ = length of vaginal vestibule + length of vagina; $D=$ length of cervix; $E=$ transverse diameter of cervix; $F$ = length of uterine body (measured from the internal orifice of the cervix to the point of convergence of the two uterine horns); $\mathrm{G}=$ length of the left uterine horn; $\mathrm{H}=$ length of the right uterine horn; $\mathrm{I}=$ length of the left uterine tube; $\mathrm{J}=$ length of the right uterine tube; $\mathrm{K}=$ diameter of the left uterine tube; $\mathrm{L}=$ diameter of the right uterine tube; * measurements done before incising and opening of tubular parts; $\mathrm{c}=$ convoluted. 


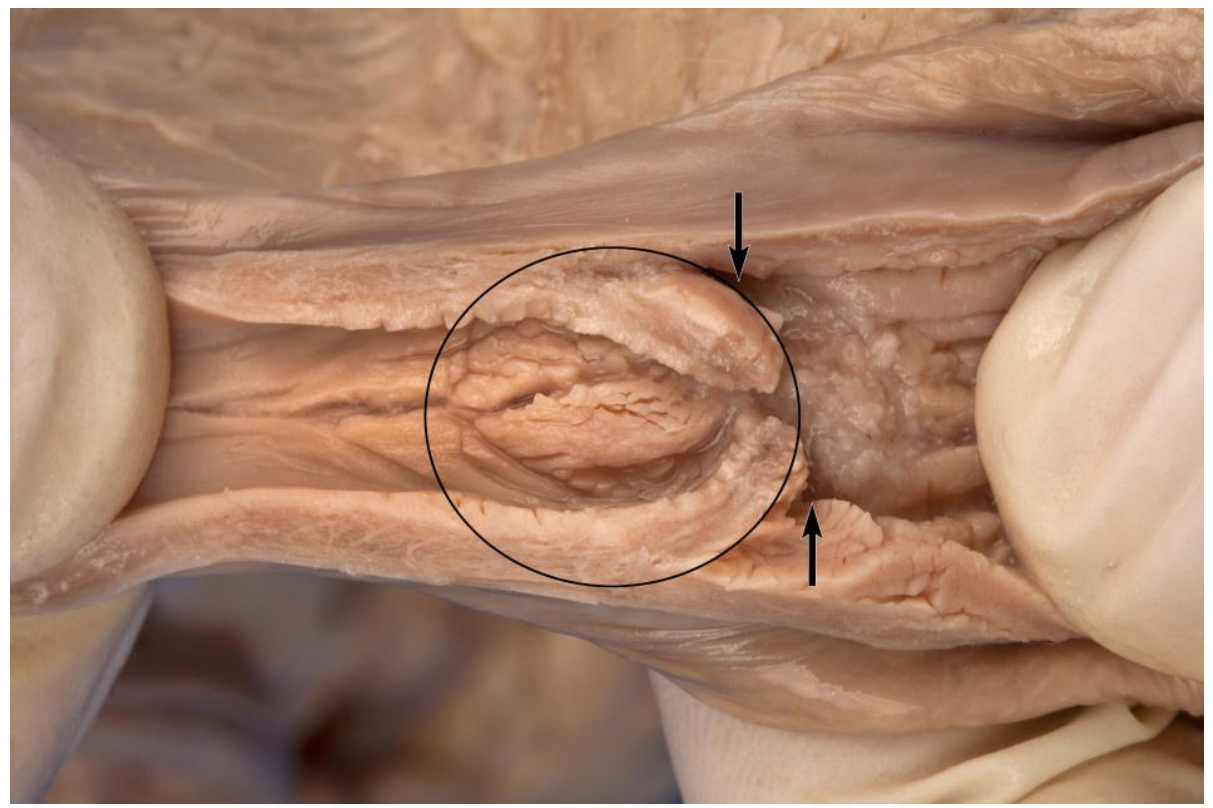

Figure 40 Cervix (circle) and vaginal fornix (arrows).

The vaginal fornix was prominent (long) in relation to the cervix. The uterine body was 2.5-3.2 $\mathrm{cm}$ in length (Table 7) and contained lesser poorly developed longitudinal folds (Figure 41) when compared to the uterine horns which had better developed longitudinal folds (Figure 42).

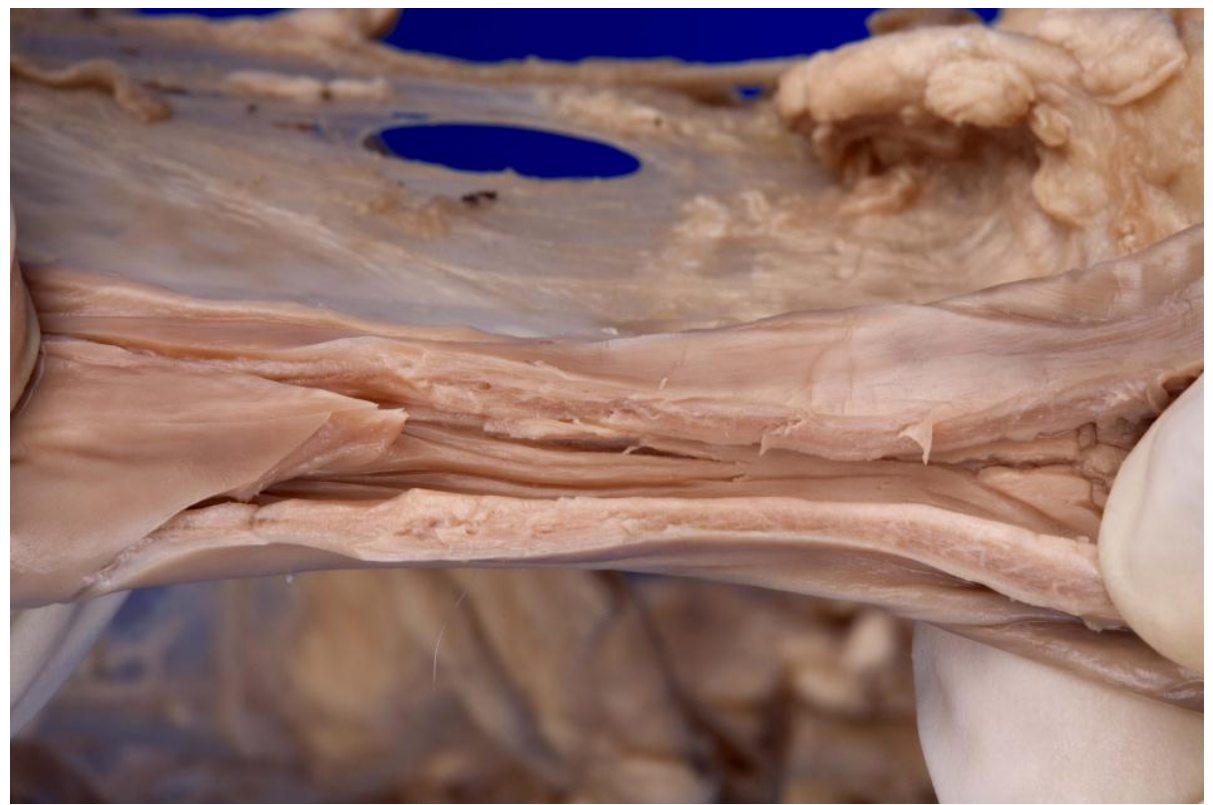

Figure $41 \quad$ Uterine body exposed. 


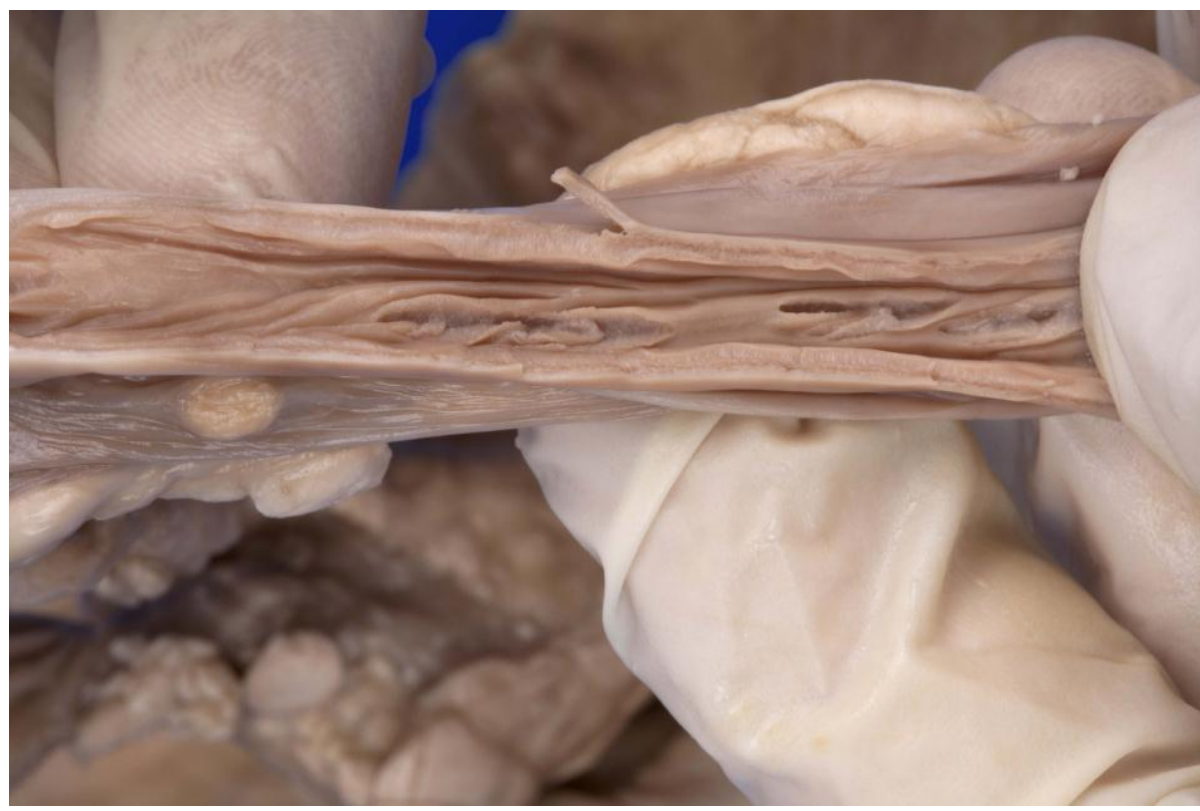

Figure 42 Uterine horn exposed.

The left uterine horn was 12-21.1 cm in length and the right uterine horn 11.7-14.8 cm (Table 7). With respect to the phrenicoabdominal artery the tip of the left uterine horn was located 13.8$17.9 \mathrm{~cm}$ caudal to it (Table 3 ) and $4.1-7.5 \mathrm{~cm}$ cranial to the ipsilateral deep circumflex iliac artery (Table 4). The tip of the right uterine horn was located $16.1-16.9 \mathrm{~cm}$ caudal to the ipsilateral phrenicoabdominal artery and $6.3-7.3 \mathrm{~cm}$ cranial to the respective deep circumflex iliac artery. The tip of the uterine horn was located dorsal to the well developed proper ligament. The uterine tube was associated with well developed fimbriae that extended along the dorsolateral aspect of the ovary for its entire length. The infundibulum started approximately in the mid ovary from where the uterine tube ran cranially then turned dorsally at the cranial pole and then caudally towards the tip of the uterine horn (Figures $\mathbf{3 0}$ and 31) where it opened directly into the tip of the uterine horn (Figures 43 and 44). The uterine tube was prominently convoluted (Figures $\mathbf{3 0}$ and $\mathbf{3 1}$ ) and was situated entirely on the lateral aspect of the ovary. 


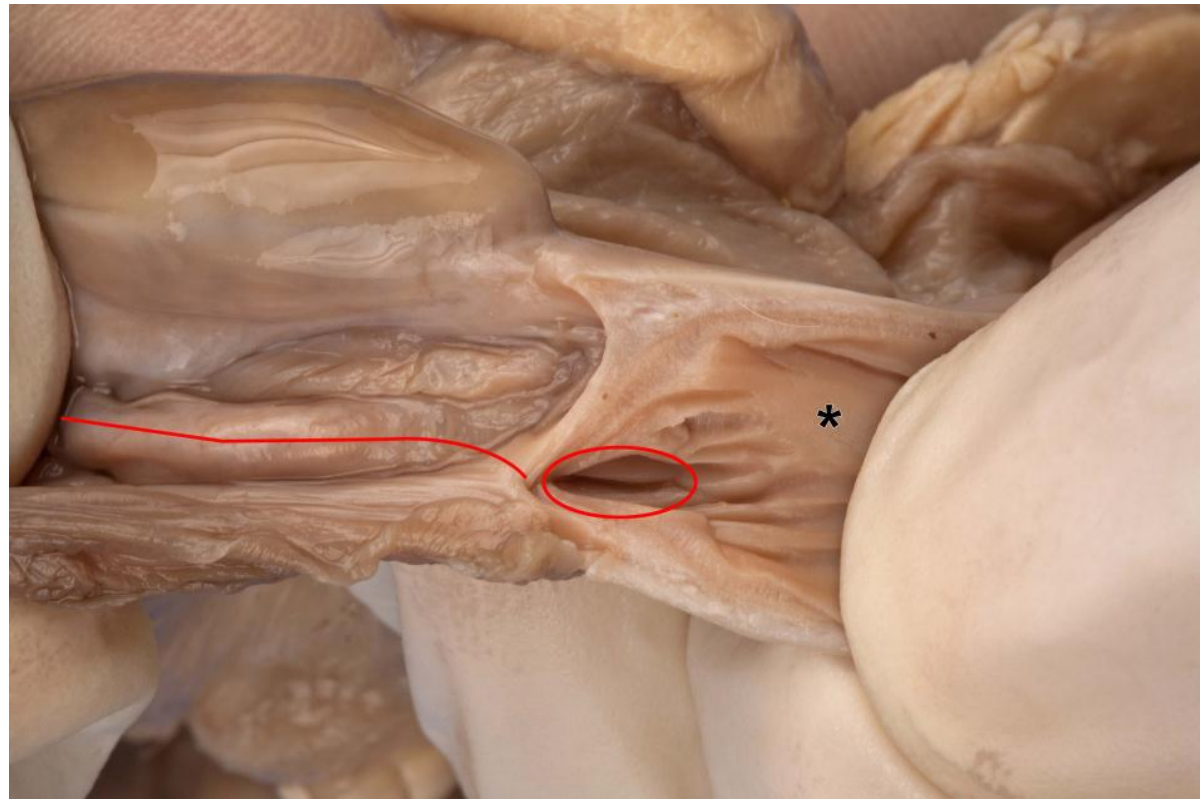

Figure 43 Opening of uterine tube (oval) and uterine tube (line). Ovary and its bursa viewed from the medial surface.

Uterine horn incised (*) to expose the opening of the uterine tube.

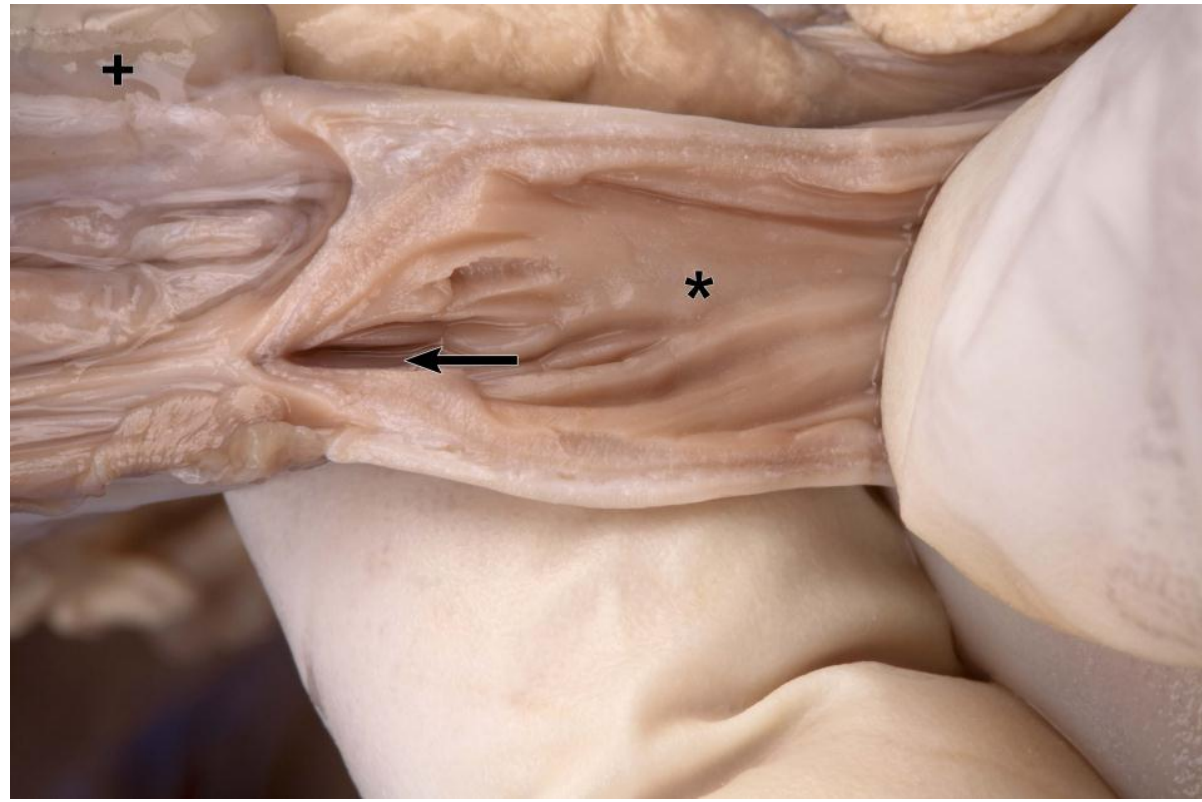

Figure 44 Opening of uterine tube (arrow).

Ovary (+) and its bursa viewed from the medial surface.

Uterine horn incised $\left(^{*}\right)$ to expose the opening of the uterine tube.

Structures found on the ovaries included various immature follicles (Figures 45 and 46) as well as one superficial cyst like structure (Figure 47) and a peri-ovarian cyst (Figure 48). 


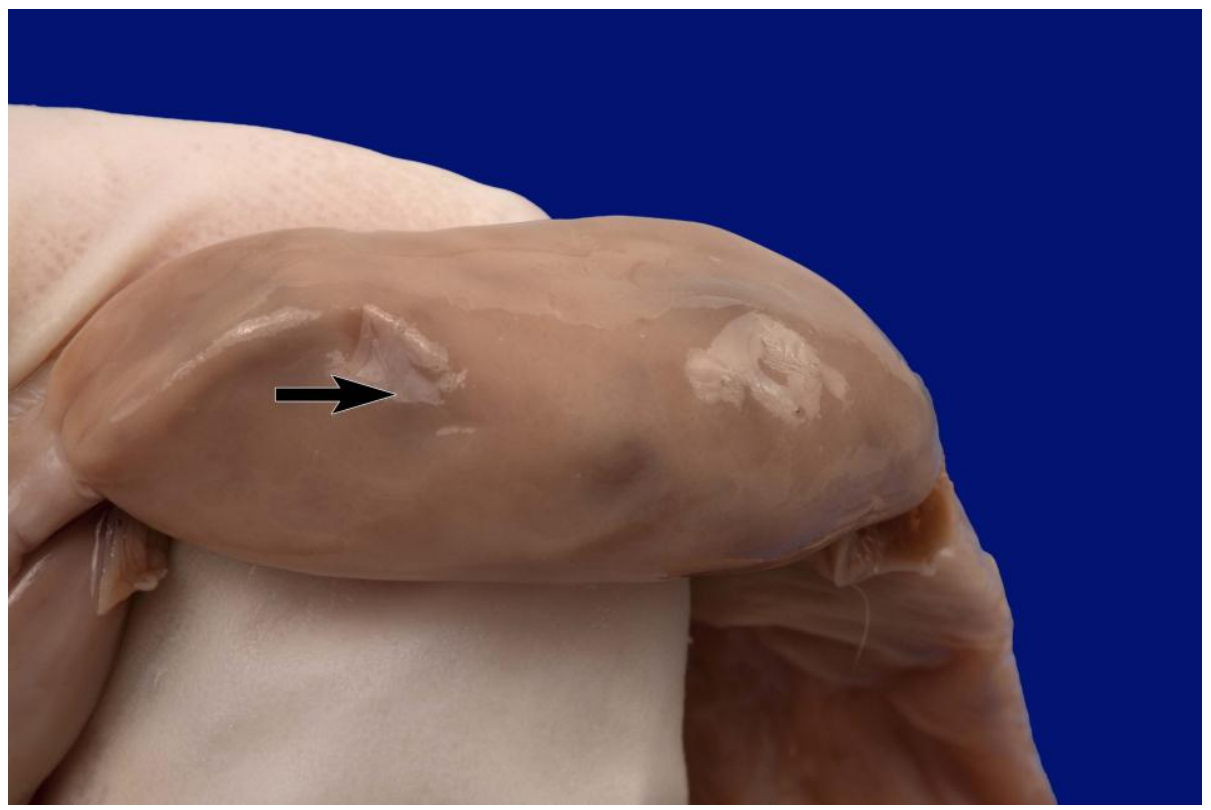

Figure 45 Immature follicle (arrow).

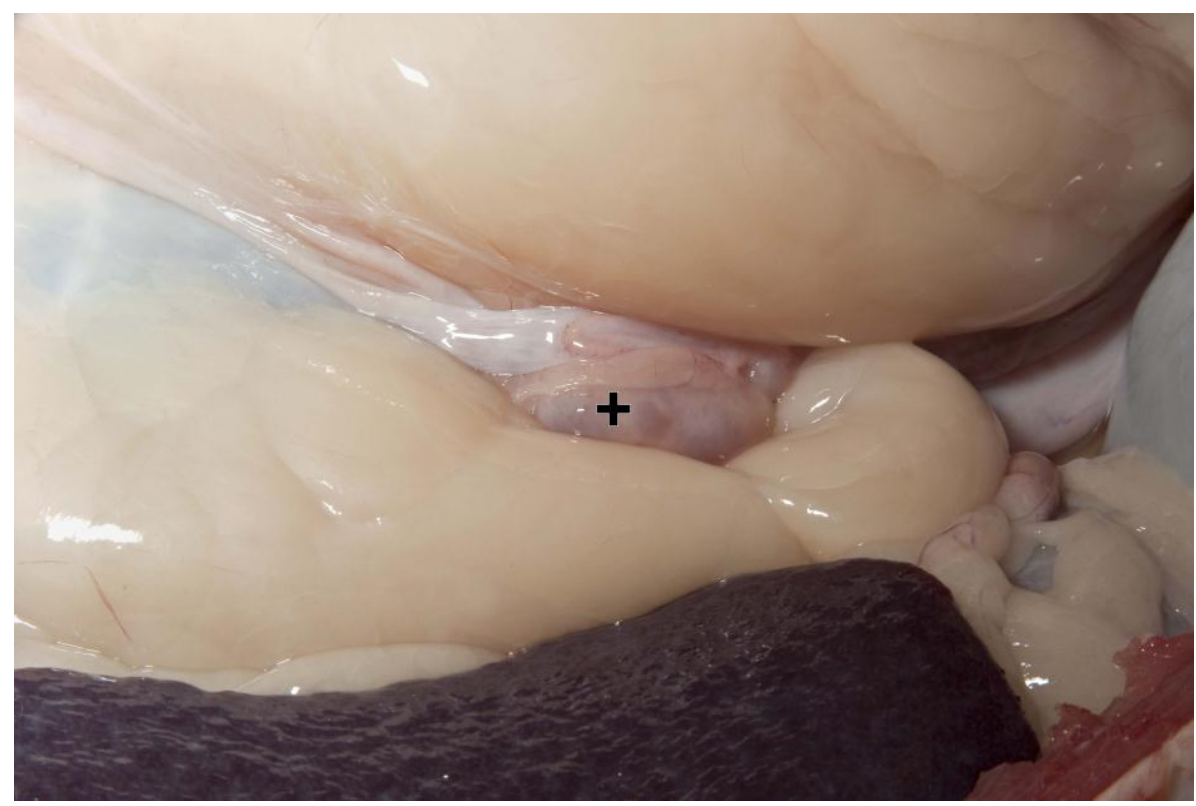

Figure 46 Immature follicles on the left ovary (+). Note the spleen at the bottom of the image. Fresh carcass. 


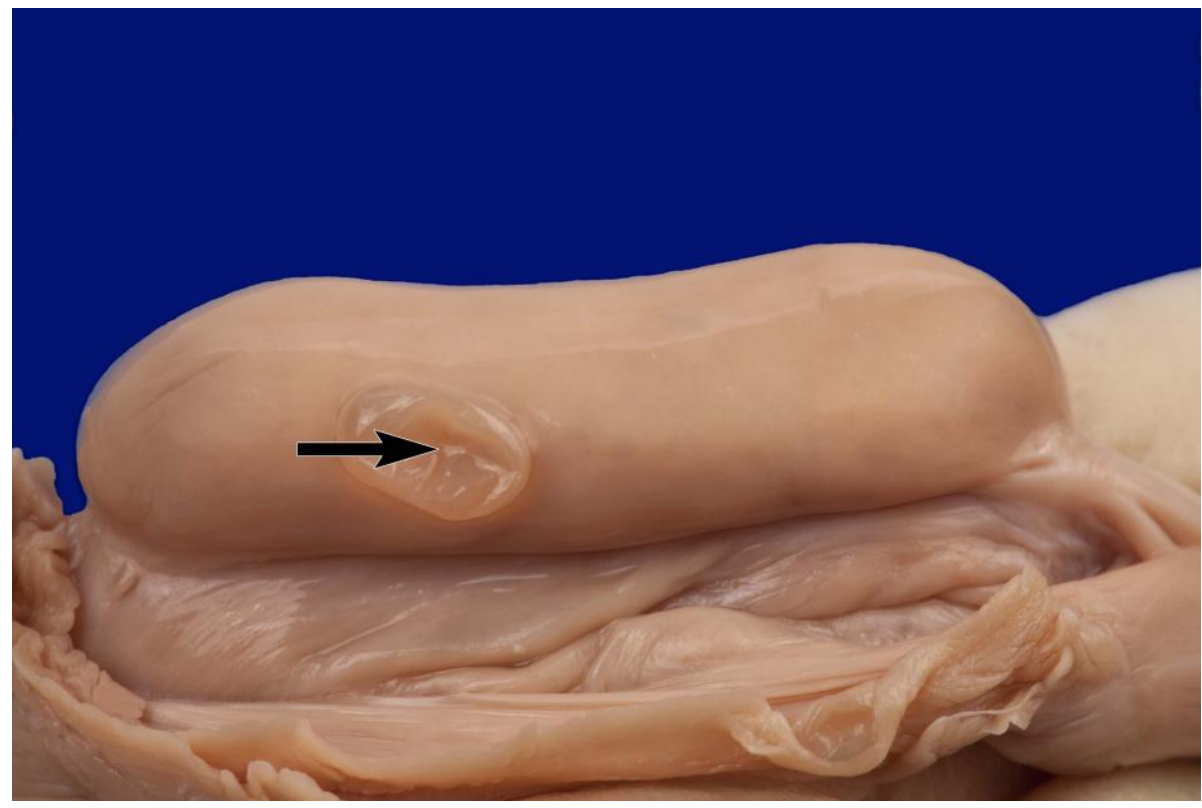

Figure 47 Superficial cyst like structure (arrow).

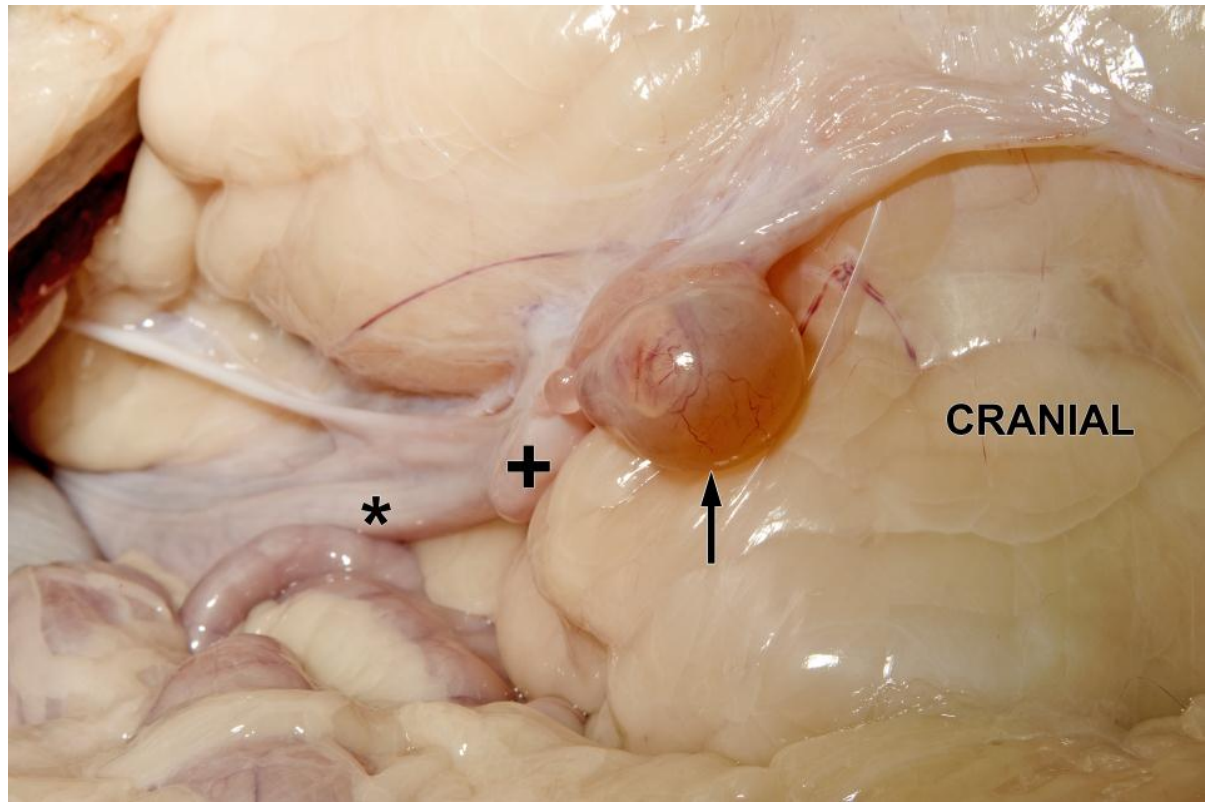

Figure 48 Peri-ovarian cyst (arrow) adjacent to the right ovary (+). Uterine horn $(*)$. Fresh carcass. 


\section{Discussion}

\subsection{Kidneys}

Each kidney was located lateral to the abdominal aorta and the caudal vena cava with the right kidney cranial to the left as in the cat ${ }^{4 ; 7}$ and the dog. ${ }^{3}$ The kidneys appeared big in relation to the rest of the cadaver and both kidneys were located far caudally in relation to the last rib. There was some variation in the location of the right kidney. The location of the kidneys with respect to the last rib has not been described in the cat. In the dog the cranial pole of the left kidney lies about $5 \mathrm{~cm}$ caudal to the upper third of the last rib and the cranial pole of the right kidney lies at the level of the thirteenth rib. ${ }^{3}$ The cranial pole of the right kidney was embedded in the renal fossa of the caudate liver lobe with the prominent interposed perirenal fat. This could be consistent to the ultrasonographic findings in the cheetah where there is a $38 \mathrm{~mm}$ space between the cranial pole of the right kidney and the renal fossa. ${ }^{29}$ No floating left kidneys were found as can be seen in the cat. ${ }^{4}$

\subsection{Ligaments}

The suspensory ligament was particularly well developed and had a unique structure and appearance. It did not originate from the middle of the last one or two ribs like in the $\mathrm{cat}^{8}$ and $\operatorname{dog}^{3}$ but in a fanlike manner with various thick separate bands from the dorsal and dorsolateral abdominal wall cranial and lateral to the kidney. In a separate study on two fresh carcasses, immediately post mortem, it was noticed that the suspensory ligament had the ability to significantly contract and relax. In the authors' opinion the proper ligament was particularly well developed compared to that of the dog and cat. The characteristics of the suspensory ligament and proper ligament might enable the lioness, who is the primary hunter, ${ }^{33}$ to suspend her ovaries and uterus closer to the body wall for hunting purposes especially during pregnancy. This could possibly prevent excessive intra-abdominal motion of the uterus and its contents as the lioness has to sustain high speeds for prolonged periods during hunting compared to other big cat predators. She also has to jump on top of large prey during the kill. A recent study determined the lioness's muscle fiber type to be type $11 \mathrm{x}^{30}$ which corresponds to these statements. The intercornual ligament was poorly developed. The broad ligament was similar to that of the cat and dog but with a much better developed cranial part of the mesovarium. The round ligament was well developed similar to that of the $\mathrm{cat}^{8}$ and $\operatorname{dog}^{3}{ }^{3}$ It extended through the 
inguinal canal but did not terminate subcutaneously in or near the vulva as in these two species. ${ }^{3 ; 8}$ The unique characteristics and origin of the suspensory ligament, the location of the tip of the uterine horn dorsal to the proper ligament, the good development of the proper and round ligaments and insertion of the round ligament on the medial femoral fascia might play a role in the behaviour of the lioness when she rolls over on her back and extend her pelvic limbs after mating. This behaviour in conjunction with the above mentioned characteristics might facilitate the ability of sperm to enter the uterine tube more effectively. In the authors' opinion the intercornual ligament was poorly developed when compared to that of the dog.

\subsection{Ovaries}

The position of the right ovary was relatively more constant and that of the left ovary more variable (Tables 3 and 4). The left ovaries were generally heavier and bigger than the right (Table 5). The ovary to body weight ratio of the dog was calculated by the authors from existing data $^{3}$ to be 0.000025 . The ovaries of the lioness were two times smaller (Table 5) in relation to bodyweight, compared to that of the dog, which could account for the average litter size of the lioness only being between 3.1 and $3.02^{33}$ cubs per litter. The ovarian bursa was poorly developed compared to that of the $\operatorname{dog}^{3}$ with most of the ovary readily visible. This would result in visualisation of the ovary and associated uterine tube during laparoscopy enabling laparoscopic salpingectomy which the senior author has already managed to perform successfully in a separate study. This is contrary to the dog where this laparoscopic procedure would be much more complicated since the ovarian bursa covers the entire ovary with the uterine tube poorly visible. In the domestic cat this procedure should also be possible. Despite the distance from the parietal peritoneum to the centre of the left ovary being highly variable and that of the right ovary being relatively constant it was evident that sufficient displacement of the ovaries from the abdominal wall and visceral organs would be achievable during laparoscopic surgery.

\subsection{Peritoneal excavations}

The peritoneal excavations were found to be highly variable. However, in general the locations of the pubovesical and vesicogenital pouches were intra-abdominal and that of the rectogenital pouch and pararectal fossae were intra-pelvic. This compared to the bitch where the pubovesical pouch is located within the first $2 \mathrm{~cm}$ after entering the pelvic cavity and all of the peritoneal excavations are situated intra-pelvic. ${ }^{6}$ Due to the intra-pelvic location of the rectogenital pouch it will be difficult in the lioness to visualise and reach this area during laparoscopic surgery but insufflation of the peritoneal cavity may assist. The vesicogenital 
pouch was situated intra-abdominally and would therefore be easier to access. Laparoscopic access to the dorsal aspect of the reproductive tract will extend further caudal than that of the ventral aspect with entire vagina accessible dorsally but only up to the cervix ventrally.

\subsection{Tubular parts}

The tubular parts contained a variety of longitudinal folds of varying degree depending on the specific area involved. The external urethral orifice, urethral tubercle and urethral crest were regarded as relatively big and well developed when compared to that of the cat $^{9}$ and dog. $^{3}$ These aspects in combination with the very prominent longitudinal folds of the vaginal vestibule could possibly hamper urethral catheterisation which was experienced during a separate study on two young anaesthetised lionesses when the senior author and co-workers failed to pass a urethral catheter.

The clitoris and clitoral fossa were small and poorly developed (Figure 7) which correlated to that of the cat. ${ }^{9}$ The clitoris however did not protrude from the clitoral fossa as in the cat. ${ }^{9}$ The left uterine horn was $21.7 \%$ longer than the right. Future studies are needed to determine if the left uterine horn bears more foetuses than its right counterpart. ${ }^{10}$ The fimbriae were situated on the lateral aspect of the ovary and extended for its entire length. In the cat the fimbriae are also situated on the ovary's lateral aspect but do not extend for the entire length. ${ }^{8}$ The uterine tube was situated entirely on the lateral aspect of the ovary unlike that of the cat ${ }^{9}$ and dog. $^{3}$ The uterine tube of the cat originates laterally from the fimbriae, runs cranially to the cranial pole of the ovary, passes to the medial side and then runs caudally to the uterine horn. ${ }^{8}$ The uterine tube did not open on a papilla as in the $\mathrm{cat}^{8}$ or $\operatorname{dog}^{5}$ but directly into the tip of the uterine horn. Convolution of the uterine tube was similar to that of the cat. ${ }^{8}$ 


\section{Conclusion}

The female reproductive organs of the African lion resemble that of the domestic cat and dog with some major differences especially to the size and development of certain structures. The clinical relevance of these differences still has to be determined.

A study on the arterial supply including a silicone technique to illustrate the arterial supply to the reproductive organs of the African lioness has been completed and will be reported elsewhere. An additional study on the histology of the ovaries and tubular parts is currently underway. During this study particular attention will be paid to determine whether the suspensory, proper and round ligaments consist of smooth muscle as in the cat $^{8}$. 


\section{References}

1. South African Predators Breeders Association. 2009. Ref. Type: Personal communication

2. DEAT. Biodiversity Act 2004 (Act No. 10 of 2004). 2008; Government Gazette No 30853.2008. Act 10 of 2004. Ref. Type: Bill/Resolution

3. Evans HE. Urogenital System. Miller's Anatomy of the Dog. 3 ed., Philadelphia: W.B. Saunders Company, 1993;494-558.

4. Nickel R, Schummer A, Seiferle E. Urogenital System. The Viscera of the Domestic Mammals. 2nd ed. Berlin, Hamburg: Verlag Paul Parey, 1979;282-393.

5. Hook SJ, Hafez SE. A comparative anatomical atudy of the mammalian uterotubal junction. J Morphol 1956;125:159-184.

6. Evans HE. The digestive apparatus and abdomen. Miller's Anatomy of the Dog. 3 ed. Philadelphia: W.B. Saunders Company, 1993;385-462

7. Crouch JE. The urogenital system-male. Text-Atlas of Cat Anatomy. Philadelphia: Lea \& Febiger, 1969;164-165.

8. Crouch JE. The urogenital system-female. Text-Atlas of Cat Anatomy. Philadelphia: Lea \& Febiger, 1969;176-177.

9. Crouch JE. The female genital organs. Text-Atlas of Cat Anatomy. Philadelphia: Lea \& Febiger, 1969;180-181.

10. Crouch JE. The gravid uterus and fetus of the cat-ventral aspect. Text-Atlas of Cat Anatomy. Philadelphia: Lea \& Febiger, 1969;184-185.

11. Park J, Ku S, Lee J, et al. Morphological study on the adrenal gland of the lion (Panthera leo). Korean J Vet Res 1997;37:471-477.

12. Abuzaid SM, Gad MRA, Wally YR. Renal venous system of the lion (Panthera leo). A gross anatomical description. Vet Med J Giza 1993;41:131-135. 
13. Abuzeid SM, El-Nahla SMM, Osman AK, et al. Some gross anatomical studies on the morphology and arterial segmentation of the spleen of the lion (Panthera leo) in Giza Zoological Garden. Assiut Vet Med J 1989;22:8-12.

14. Bhardwaj RL, Rajesh R, Sharma DN. Anatomical studies on the tongue of the lion (Felis leo) with special reference to papillae distribution. Indian J Vet Anat 2000;12:105-107.

15. Panchal KM, Bagi AS, Vyas KN, et al. A note on gross anatomy of the tongue of the lion (Felis leo). Indian J Vet Anat 1992;4:82-83.

16. Khatra GS, Singh H. Gross morphology of the liver of lion (Panthera leo). J Res Punjab Agric Univ 1987;24:311-314.

17. Kirberger RM, du Plessis WM, Turner PH. Radiologic anatomy of the normal appendicular skeleton of the lion (Panthera leo). Part 1: Thoracic limb. J Zoo Wildlife Med 2005;36:2128.

18. Kirberger RM, du Plessis WM, Turner PH. Radiologic anatomy of the normal appendicular skeleton of the lion (Panthera leo). Part 2: Pelvic limb. J Zoo Wildlife Med 2005;36:29-35.

19. Nath I, Mishra UK, Das RK, et al. Histological appraisal of sterilization in lions (Panthera leo): a case study. Indian J Vet Anat 2005;17:65-67.

20. Weissengruber GE, Forstenpointner G, Peters G, et al. Hyoid apparatus and pharynx in the lion (Panthera leo), jaguar (Panthera onca), tiger (Panthera tigris), cheetah (Acinonyx jubatus) and domestic cat (Felis silvestris f.catus). J Anat 2002;201:195-209.

21. De Waal HO, Combrinck WJ, Borstlap DG. A comprehensive procedure to measure the body dimensions of large African predators with comments on the repeatability of measurements taken from immobilized African lion (Panthera leo). $J$ Zool Lond. 2004;262:393-398.

22. Smuts GL, Anderson JL, Austin JC. Age determination of the African lion (Panthera leo). J Zool 1978;185:115-146.

23. Smuts GL, Hanks J, Whyte IJ. Reproduction and social organization of lions from the Kruger National Park. Carnivore 1978;1:17-18.

24. De Barros JBG, Paula TAR, Matta SLP, et al. Seminiferous tubules and testicular morphometry of adult African-lions (Panthera leo, Linneaus, 1758) raised in captivity. Revista Ceres 2006;53:627-634. 
25. De Barros JBG, Paula TAR, Matta SLP, et al. Sertoli cell index and spermatic reserves in adult captive African lions (Panthera leo, Linnaeus, 1758). Anim Repro Science 2007;102:350-356.

26. Cohrs P, Schneider KM. Cryptorchism in the lion and genital hypoplasia with cryptorchism in the red deer. Zool Garten 1936;8:201-209.

27. Miya PS, Soler TB, Correa SHR, et al. Spermogram of African lions (Panthera leo Linnaeus, 1758) housed at Fundacao Parque Zoologico de Sao Paulo. Braz J Vet Res Anim Sci 2007;44:65-70.

28. Munson L, Brown JL, Bush M, et al. Genetic diversity affects testicular morphology in freeranging lions (Panthera leo) of the Serengeti plains and Ngorongoro crater. J Repro Fert 1996;108:11-15.

29. Carstens A, Kirberger RM, Spotswood T, et al. Ultrasonography of the liver, spleen, and urinary tract of the Cheetah (Acinonyx jubatus). Vet Radiol Ultrasound 2006;47:376-383.

30. Kohn TA, Burroughs R, Hartman MJ, et al. Fiber type and metabolic characteristics of lion (Panthera leo), caracal (Caracal caracal) and human skeletal muscle. Comp Biochem and Phys Part A June 2011;159,2:125-133.

31. Kirberger RM, Schulman ML, Hartman MJ. Ultrasonographic and laparoscopic evaluation of the reproductive tract of the captive female African lion (Panthera leo). Theriogenology $2011 ; 76: 810-818$.

32. International Anatomical Nomenclature Committee. Organa genitalia feminina interna. Nomina Anatomicala. 6 ed. Edinburgh London Melbourne New York: Churchill Livingstone, 1989;A48.

33. Skinner JD, Chimimba TC. Lion Panthera leo (Linnaeus, 1758). Mammals of the Southern African Subregion. 3 ed. Cambridge: Cambridge University Press, 2005;390-396. 


\section{Annexures}

\section{A Topographic location of kidneys}

\begin{tabular}{|c|c|c|c|c|c|c|}
\hline \multirow[t]{2}{*}{ Lioness } & \multicolumn{2}{|c|}{$\begin{array}{l}\text { Tuberculum costa of rib } \\
13 \text { to centre of kidney }\end{array}$} & \multicolumn{2}{|c|}{$\begin{array}{l}\text { Caudal costal arch (rib } \\
\text { 13) to centre of kidney }\end{array}$} & \multicolumn{2}{|c|}{$\begin{array}{c}\text { Centre of kidney to crista } \\
\text { iliaca }\end{array}$} \\
\hline & Left & Right & Left & Right & Left & Right \\
\hline 1 & 16.8 & 12.5 & 7.5 & 3.3 & 12.0 & 12.6 \\
\hline 2 & 16.4 & 13.2 & 7.6 & 3.6 & 11.2 & 14.1 \\
\hline 3 & 15.4 & 10.0 & 7.4 & 3.1 & 12.2 & 16.2 \\
\hline 4 & 18.1 & $19.8 \#$ & 10.6 & 7.7 \# & 15.6 & 14.7 \\
\hline 5 & 18.9 & 9.1 & 9.4 & 1.6 & 9.3 & 14.6 \\
\hline Mean & & & & & & \\
\hline SD & & & & & & \\
\hline
\end{tabular}

Measurements in centimetres

Dr. M.J. Hartman, Lecturer Section of Small Animal Surgery, CACS

Room 4-52, Tel. 012529 8005/8087 Cell. 0726712151 marthinus.hartman@up.ac.za 


\section{B Topographic location of ovaries situated caudal in relation to the caudal pole of the kidneys.}

\begin{tabular}{|c|c|c|c|c|c|c|}
\hline \multirow[t]{2}{*}{ Lioness } & \multicolumn{2}{|c|}{$\begin{array}{l}\text { Distance between } \\
\text { caudal pole of kidney } \\
\text { and cranial pole of } \\
\text { ovary }\end{array}$} & \multicolumn{2}{|c|}{$\begin{array}{l}\text { Medio-lateral topographic } \\
\text { location of ovary }\end{array}$} & \multicolumn{2}{|c|}{$\begin{array}{c}\text { Distance from centre of } \\
\text { ovary to crista iliaca }\end{array}$} \\
\hline & Left & Right & Left & Right & Left & Right \\
\hline 1 & 0 & 3.8 & $\begin{array}{l}\text { immediately } \\
\text { caudo-lateral } \\
\text { to caudal } \\
\text { pole }\end{array}$ & $\begin{array}{l}\text { caudally in } \\
\text { the saggital } \\
\text { midline of the } \\
\text { kidney }\end{array}$ & 6.8 & 7.1 \\
\hline 2 & 0 & 3.9 & $\begin{array}{l}\text { immediately } \\
\text { caudo-lateral } \\
\text { to caudal } \\
\text { pole }\end{array}$ & $\begin{array}{l}\text { caudally in } \\
\text { the saggital } \\
\text { midline of the } \\
\text { kidney }\end{array}$ & 7.3 & 7.1 \\
\hline 3 & 0 & 3.9 & $\begin{array}{l}\text { immediately } \\
\text { caudo-lateral } \\
\text { to caudal } \\
\text { pole }\end{array}$ & $\begin{array}{l}\text { caudally in } \\
\text { the saggital } \\
\text { midline of the } \\
\text { kidney }\end{array}$ & 6.1 & 7.2 \\
\hline 4 & 0 & 2.8 & $\begin{array}{l}\text { immediately } \\
\text { caudo-lateral } \\
\text { to caudal } \\
\text { pole }\end{array}$ & $\begin{array}{l}\text { caudally in } \\
\text { the saggital } \\
\text { midline of the } \\
\text { kidney }\end{array}$ & 13.6 & 4.7 \\
\hline 5 & 0 & 2.0 & $\begin{array}{l}\text { immediately } \\
\text { caudo-lateral } \\
\text { to caudal } \\
\text { pole }\end{array}$ & $\begin{array}{l}\text { caudally in } \\
\text { the saggital } \\
\text { midline of the } \\
\text { kidney }\end{array}$ & 10.3 & 5.5 \\
\hline Mean & & & & & & \\
\hline
\end{tabular}




\section{C Topographic location of anatomical landmarks of female reproductive organs situated caudal in relation to the origin of the ipsilateral phernico-abdominal artery.}

\begin{tabular}{|c|c|c|c|c|c|c|}
\hline Lioness & LO & RO & TLUH & TRUH & $\begin{array}{l}\mathrm{OL} \\
\mathrm{AO}\end{array}$ & $\begin{array}{l}\text { OR } \\
\text { AO }\end{array}$ \\
\hline 1 & 12.1 & 14.5 & 13.8 & 16.1 & $\begin{array}{l}8.5 \\
10.0\end{array}$ & 11.4 \\
\hline 2 & 16.4 & 15.2 & 17.8 & 16.9 & 11.8 & 12.3 \\
\hline 3 & 17.1 & 14.5 & 17.9 & 16.3 & 10.0 & 9.8 \\
\hline 4 & & & & & & \\
\hline 5 & & & & & & \\
\hline Mean & & & & & & \\
\hline SD & & & & & & \\
\hline
\end{tabular}

$L O=$ cranial pole of left ovary; $R O=$ cranial pole of right ovary; $T L U H=$ tip of left uterine horn; $\mathrm{TRUH}=$ tip of right uterine horn; OLAO = origin of left arterie ovarica; OAO = origin of right arterie ovarica;

*PP to $L O=$ distance from parietal peritoneum to left ovary; ${ }^{*} \mathrm{PP}$ to $\mathrm{RO}=$ distance from parietal peritoneum to right ovary

* maximum distance was measured from the reflexion of the medial aspect of the mesovarium onto the parietal peritoneum up to the margo mesovaricus at the centre of the ovarium Measurements were taken in centimetres from the centre of all arteries.

Significant soft tissue dissection was required to expose the phrenico-abdominal artery and it is doubtful whether this artery would be visible during laparoscopy.

Dr. M.J. Hartman, Lecturer Section of Small Animal Surgery, CACS

Room 4-52, Tel. 012529 8005/8087 Cell. 0726712151 marthinus.hartman@up.ac.za 


\section{D Topographic location of anatomical landmarks of female reproductive organs situated cranial in relation to the origin of the ipsilateral deep circumflex iliac artery.}

\begin{tabular}{|c|c|c|c|c|c|c|c|c|}
\hline $\begin{array}{l}\text { Lion } \\
\text { ess }\end{array}$ & LO & RO & TLUH & TRUH & $\begin{array}{l}\text { OL } \\
\text { AO }\end{array}$ & $\begin{array}{l}\text { OR } \\
A O\end{array}$ & $\begin{array}{c}\text { PP to } \\
\text { LO }\end{array}$ & $\begin{array}{l}\text { PP to } \\
\text { Ro }\end{array}$ \\
\hline 1 & 5.9 & 8.1 & 4.1 & 6.8 & $\begin{array}{l}6.8 \\
5.6\end{array}$ & 3.9 & 3.6 & 2.9 \\
\hline 2 & 8.2 & 8.0 & 5.6 & 6.2 & 4.2 & 3.2 & 1.9 & 2.8 \\
\hline 3 & 8.7 & 7.8 & 7.5 & 7.3 & 3.9 & 2.7 & 2.8 & 3.0 \\
\hline 4 & & & & & & & & \\
\hline 5 & & & & & & & & \\
\hline Mean & & & & & & & & \\
\hline SD & & & & & & & & \\
\hline
\end{tabular}

$\mathrm{LO}=$ cranial pole of left ovary;

$\mathrm{RO}=$ cranial pole of right ovary;

TLUH = tip of left uterine horn;

$\mathrm{TRUH}=$ tip of right uterine horn;

OLAO = origin of left arterie ovarica;

$\mathrm{OAO}=$ origin of right arterie ovarica

$\mathrm{PP}$ to $\mathrm{LO}=$ distance from parietal peritoneum to centre of left ovary;

$\mathrm{PP}$ to $\mathrm{RO}=$ distance from parietal peritoneum to centre of right ovary

Measurements were taken in centimetres and from the centre of all arteries.

The deep circumflex artery was constantly visible and assessable during measurements. This artery should be constantly visible during laparoscopy. The cervix was constantly located intra pelvic.

Dr. M.J. Hartman, Lecturer Section of Small Animal Surgery, CACS

Room 4-52, Tel. 012529 8005/8087 Cell. 0726712151 marthinus.hartman@up.ac.za 
8.E Topographic location of the lines of peritoneal reflection in relation to the pecten ossis pubis recorded in centimetres.

\begin{tabular}{|c|c|c|c|c|}
\hline Lioness & $\begin{array}{c}\text { Excavatio } \\
\text { pubovesicalis }\end{array}$ & $\begin{array}{c}\text { Excavatio } \\
\text { vesicogenitalis }\end{array}$ & $\begin{array}{c}\text { Excavation } \\
\text { rectogenitalis }\end{array}$ & $\begin{array}{c}\text { Fossa } \\
\text { pararectalis }\end{array}$ \\
\hline 1 & 1.8 cranial & 3.7 cranial & 6.1 caudal & 10.3 caudal \\
\hline 2 & 1.8 caudal & 0.7 caudal & 6.9 caudal & 7.4 caudal \\
\hline 3 & 0.5 cranial & 1.5 cranial & 7.1 caudal & 8.6 caudal \\
\hline 4 & & & & \\
\hline 5 & & & & \\
\hline Mean & & & & \\
\hline SD & & & & \\
\hline
\end{tabular}

Dr. M.J. Hartman, Lecturer Section of Small Animal Surgery, CACS

Room 4-52, Tel. 012529 8005/8087 Cell. 0726712151 marthinus.hartman@up.ac.za 


\section{F Splanchnologic data of the ovaries}

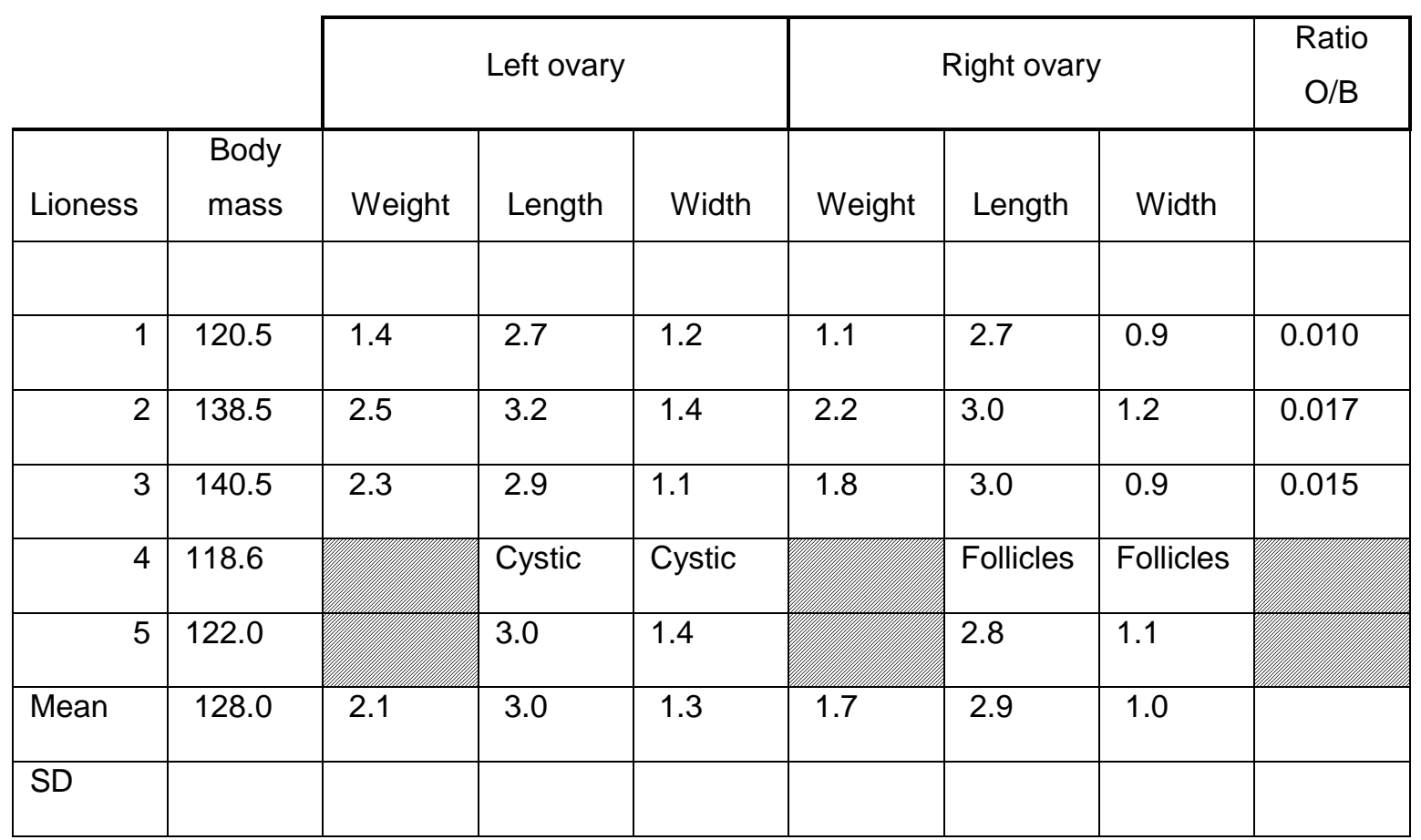

Body mass measured in kilograms

Weight measured in grams

Length and Width measured in centimetres

Ratio $\mathrm{O} / \mathrm{B}=$ Ratio of mean ovarian weight over bodyweight

Weight of ovaries of lionesses 4 and 5 will be affected by silicone injection

Dr. M.J. Hartman, Lecturer Section of Small Animal Surgery, CACS

Room 4-52, Tel. 012529 8005/8087 Cell. 0726712151 marthinus.hartman@up.ac.za 


\section{G Splanchnologic data of the tubular parts $(\mathrm{cm})$}

\begin{tabular}{|c|c|c|c|c|c|}
\hline Lioness & 1 & 2 & 3 & Mean & SD \\
\hline $\mathrm{LVe}$ & 6.7 & 6.4 & 6.8 & 6.6 & \\
\hline L Va & 9.5 & 8.2 & 10.4 & 9.4 & \\
\hline$L V e+L V a$ & 16.2 & 14.6 & 17.2 & 16.0 & \\
\hline $\mathrm{LCe}$ & 1.5 & 2.1 & 1.4 & 1.7 & \\
\hline${ }^{\star \star} \mathrm{DCe}$ & 1.5 & 1.6 & 1.3 & 1.5 & \\
\hline L Co & 3.2 & 2.5 & 3.0 & 2.9 & \\
\hline L Cu Left & 21.1 & 14.1 & 12.0 & 15.7 & \\
\hline L Cu Right & 11.7 & 14.8 & 12.2 & 12.9 & \\
\hline${ }^{*}$ L Sa Left & 2.9 & $\begin{array}{l}\text { Very } \\
\text { convoluted }\end{array}$ & Convoluted & & \\
\hline **L Sa Right & 2.3 & 3.5 & Convoluted & & \\
\hline${ }^{\star \star} \mathrm{D}$ Sa Left & 0.3 & 0.3 & 0.3 & 0.3 & \\
\hline${ }^{* \star}$ D Sa Right & 0.3 & 0.27 & 0.27 & 0.28 & \\
\hline $\begin{array}{l}\text { Portio } \\
\text { vaginalis }\end{array}$ & 1.2 & 1.3 & 1.2 & 1.2 & \\
\hline $\begin{array}{l}\text { Total weight } \\
\text { (grams) }\end{array}$ & & & & & \\
\hline
\end{tabular}

$\mathrm{L} V \mathrm{e}=$ length of vestibulum;

$L V a=$ length of vagina (measured from the ostium uteri externum of the cervix);

$\mathrm{L} C \mathrm{Ce}=$ length of cervix;

$\mathrm{D} C \mathrm{C}=$ transverse diameter of cervix;

$\mathrm{L} C o=$ length of corpus uteri (measured from the ostium uteri internum of the cervix);

$\mathrm{L} \mathrm{Cu}=$ length of cornu uteri

$\mathrm{LSa}=$ length of salpinx;

$\mathrm{D} \mathrm{Sa}=$ diameter of salpinx

** measurements done before incising and opening of tubular parts

Dr. M.J. Hartman, Lecturer Section of Small Animal Surgery, CACS

Room 4-52, Tel. 012529 8005/8087 Cell. 0726712151 marthinus.hartman@up.ac.za 
(C) University of Pretoria 